ESTUDIO

\title{
CAMBIOS DEMOGRÁFICOS Y SUS IMPACTOS EN CHILE ${ }^{1}$
}

\author{
Rodrigo A. Cerda
}

\begin{abstract}
En este trabajo se discuten las implicancias de los cambios demográficos ocurridos en Chile durante las últimas décadas. Se indica que la transición demográfica continuará en el futuro próximo, y que se producirá un envejecimiento paulatino y marcado de la población. Se esbozan distintos impactos a futuro en áreas tales como el crecimiento del ingreso per cápita y el mercado laboral, la acumulación de capital humano y su relación con la desigualdad social. Para tener una idea de la magnitud de estos impactos, en especial en el crecimiento económico y la desigualdad social, se utilizan modelos de simulación. Asimismo se enfatiza la importancia de desarrollar políticas públicas para los adultos mayores, que sería el grupo con mayor crecimiento en el futuro próximo.
\end{abstract}

Rodrigo A. Cerda. Ph.D. en Economía, Universidad de Chicago. Actualmente es profesor del Departamento de Economía de la Pontificia Universidad Católica de Chile y se encuentra afiliado al Economic History Cliometrics Laboratory (EH-Clio Lab) de la Pontificia Universidad Católica de Chile. Email: rcerda@faceapuc.cl. Correspondencia: Casilla 76, Correo 17, Santiago, Chile. Teléfono: (562) 354 7101. Fax: (562) 5532377.

1 Ésta es una versión extendida y revisada de "Cambios Demográficos: Desafíos y Oportunidades de un Nuevo Escenario", publicado en Temas de la Agenda Pública de la Pontificia Universidad Católica de Chile (2007). Esta investigación utilizó información - entre otras bases de datos- de la Encuesta de Protección Social, en sus versiones 2002 y 2004. El autor agradece a la Subsecretaría de Previsión Social de Chile haberle permitido disponer de su base de datos. Todos los resultados del estudio son de responsabilidad del autor y en nada comprometen a dicha subsecretaría.

Estudios Públicos, 110 (otoño 2008). 


\section{Introducción}

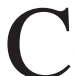

hile ha experimentado considerables cambios económicos y sociales en los últimos treinta años, que han implicado un cambio en el bienestar de las personas. Por un lado, si analizamos cifras económicas, el producto per cápita se dobló en el período 1970-2000, mientras que la tasa de inversión pasó de $22 \%$ a $27 \%$ y los salarios reales aumentaron cerca de $46 \%$ en ese mismo período. Por otro lado, si analizamos variables que pueden ser más indicativas del cambio en el bienestar de las personas, tales como la expansión en el tamaño del parque automovilístico o el acceso a la telefonía fija y celular, también se observan importantes cambios: el parque automovilístico aumentó 60\% mientras que la telefonía fija lo hizo en 213\% y la celular en más de 50 veces.

Sin embargo, uno de los cambios más significativos y no incluidos en las cifras anteriores es la variación en la demografía. Una de las características de esta transición demográfica han sido los cambios en expectativas de vida y tasas de mortalidad. De hecho, Chile tuvo mejoramientos importantes en sus principales indicadores de mortalidad desde principios del siglo pasado. La tasa de mortalidad general cayó desde 30 por 1.000 habitantes en 1924 hasta cerca de 5 por 1.000 habitantes en 1999, mientras que las tasas de mortalidad infantil (menores de un año fallecidos por cada 1.000 nacidos vivos) y mortalidad neonatal (menores de un mes fallecidos por cada 1.000 nacidos vivos) cayeron desde 254 y 136 en 1915 hasta 10 y 5 por mil en el año 1999, respectivamente.

Una segunda característica de esta transformación demográfica es la variación en las tasas de natalidad durante el siglo 20. Como se observa en el Gráfico No 1, la tasa de natalidad por cada 1.000 habitantes en Chile era cercana a 40 por 1.000 hasta 1930. Más aún, si bien existió una pequeña caída en esta tasa de natalidad hasta 1965, aún se mantenía en la cercanía de 35 por 1.000 habitantes en esa fecha. Sin embargo, desde ese momento se produjo una continua disminución que se acentuó desde comienzos de los años noventa para situarse a comienzos del siglo 21 en aproximadamente 17 por 1.000 habitantes, lo que representa menos de la mitad de las tasas de natalidad observadas a mitad del siglo 20.

Un dato adicional es que la tasa global de fecundidad por mujer en Chile ha ido cayendo hasta situarse desde casi 5 hijos por mujer en 1950 hasta cerca de 2,3 en el 2005, de acuerdo a Celade (2002), y se acerca rápidamente a 2,1, cifra que se alcanzaría en la cercanía del 2020. De acuerdo a otras fuentes, como la oficina del Censo en Estados Unidos, esta cifra se habría alcanzado en el 2003. Alcanzar esta cifra global de fecundidad de 2,1 
GRÁFICO N ${ }^{\circ}$ 1: TASA DE NATALIDAD, NACIDOS VIVOS POR CADA 1.000 HABITANTES, CHILE 1900-1999

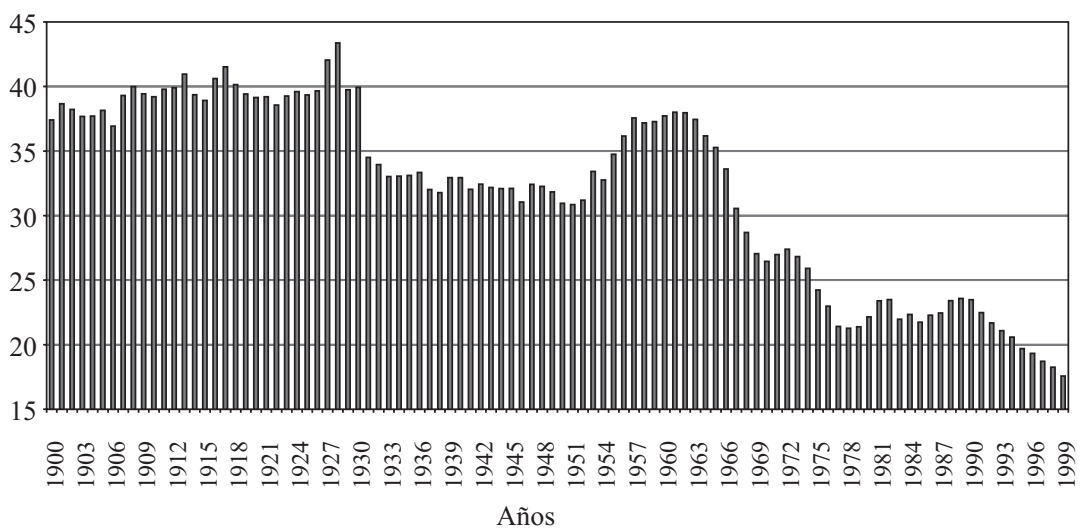

Fuente: Díaz, Lüders y Wagner (2008).

(cifra conocida como tasa de reemplazo) implica que finalmente los hijos nacidos por cada mujer no alcanzarían para renovar la población una vez que fallezcan la madre y el padre de esos hijos.

Estas variaciones demográficas no son un fenómeno aislado. De hecho, Greenwood y Seshadri (2002) indican que en 1800 en Estados Unidos las mujeres tenían en promedio cerca de 7 niños durante su vida fértil. Esta cifra disminuye a un promedio cercano a dos hijos por mujer en 1940. Las cifras en el caso de Suecia también muestran variaciones significativas, pasando la tasa de natalidad de cerca de 30 por mil habitantes en 1860 a 15 por cada mil habitantes en 1940. Un caso más cercano es el de Perú: en 1975 cada mujer tenía casi 5 hijos, mientras que en el 2000 esa cifra pasó a 3,1 hijos.

Como discutiremos posteriormente, estos cambios demográficos están directamente relacionados con la estructura de la población por grupos de edades y con el tamaño de la población futura del país: al disminuir la tasa de fecundidad por mujer y al aumentar la expectativa de vida, el grupo de adultos y adultos mayores se hace relativamente más importante y la población tiende a estabilizarse o eventualmente a decrecer.

¿Tiene alguna implicancia este tipo de cambios demográficos? En general, estas transiciones demográficas van de la mano de múltiples desafíos sociales, económicos y políticos. Por ejemplo, por un lado se hace más escasa la oferta de trabajo, sobre todo en empleos menos calificados, y los países generalmente reaccionan por medio de una activa política de inmigra- 
ción, lo que genera espacio de activas negociaciones entre países. Además, el envejecimiento poblacional junto a menores tasas de natalidad produce un aumento de la relación de dependencia debido a la disminución relativa de la población en edad de trabajar. Éste es un punto no menor, en la medida en que la población de adultos mayores recibe significativos subsidios y transferencias en especies del sector público (como por ejemplo en salud). Estas transferencias pueden ser menos factibles de financiar al disminuir relativamente la población activa, que es la que finalmente se lleva la mayor carga impositiva. Por lo tanto, se produce un nuevo polo de tensión interna al tener que financiar estos gastos con mayores cargas impositivas. Además pueden existir impactos sociales no despreciables. Por ejemplo, la formación de los hijos es una de las principales funciones realizadas por las familias. Cambios en decisiones de tasas de fecundidad por mujer pueden influir sobre el valor de la institución que conocemos como “familia”. Por lo tanto, el tema de fecundidad parece ser un tema central en la discusión del cambio en las estructuras familiares ${ }^{2}$.

En este trabajo se busca dar una mirada a las causas y posibles consecuencias de estos cambios demográficos en el caso de Chile. Inicialmente se subrayan los cambios demográficos más significativos de los últimos 30 años para luego detenerse en las fuentes y sus implicancias en términos de crecimiento, impactos fiscales, acumulación de capital humano, desigualdad y situación de los adultos mayores. Además se indican posibles impactos en los sectores educación y salud.

\section{Los cambios demográficos}

\subsection{Los cambios demográficos de Chile en el último siglo}

La tasa de natalidad ha cambiado significativamente en Chile en el último siglo: hasta 1930 ésta era cercana a 40 por 1.000 habitantes, y se mantuvo en la cercanía de 35 por 1.000 habitantes hasta 1965. Desde ese momento se produjo una continua disminución que se acentuó desde comienzos de los años noventa para situarse a comienzos del siglo XXI en aproximadamente 17 por 1.000 habitantes, lo que representa menos de la mitad de las tasas observadas a comienzos del siglo 20. Esta variación se relaciona con la caída de la tasa global de fecundidad por mujer en Chile:

${ }^{2}$ Como se sabe, la conformación de las familias en Chile ha cambiado bruscamente en los últimos años. De acuerdo a la encuesta del Centro de Estudios Públicos (CEP), la fracción de personas casadas ha disminuido desde el 60\% en 1994 a cerca del $48 \%$ en el 2004. 
desde casi 5,4 hijos por mujer en el quinquenio 1950-1955, a 1,9 en 2004 (Celade 2002, INE, 2004).

En segundo lugar, los patrones de mortalidad han cambiado bruscamente. La mortalidad general se ha reducido de 8,7 muertos por mil habitantes a 5,5, entre 1970 y 1999, en tanto la mortalidad infantil ha pasado de 82,2 muertos menores de un año por mil niños nacidos vivos a sólo 10 muertos por mil nacidos vivos en el mismo período. En relación con esto, cabe decir que la esperanza de vida se incrementó de 54,5 años a 75,2 en el período 1950-2000.

Este escenario lleva a un cambio importante en la pirámide de población: la población se compone cada vez más de individuos de mayor edad. Por ejemplo, en 1975 los menores de 15 años representaban cerca del 37\% de la población y los mayores de 60 eran sólo el 7,9\%. Para 2050 se esperan cambios drásticos: el grupo de jóvenes sería sólo el 18\%, mientras que los adultos de 15 a 59 años representarían el 57\%, y el grupo de mayores de 60 pasaría a ser el 25\% de la población.

\subsection{Chile y el resto del mundo}

¿Es Chile en términos de demografía un caso muy distinto del de otros países a través del mundo? La verdad es que Chile no parece ser un caso anómalo. Si se toma a los países de la OECD como puntos de comparación —países que también han experimentado transiciones demográficas significativas durante el siglo XX - se observa que el comportamiento de la tasa de fecundidad o de crecimiento poblacional en el caso de Chile no es significativamente distinto. De hecho, como se observa en el Gráfico $\mathrm{N}^{\circ} 2$, las tasas de fecundidad en Chile por mujer en edad fértil están prácticamente en el promedio si se considera una muestra amplia de países tomados de la OECD. Además, como se observa en el Gráfico $N^{\circ} 3$, la tasa de crecimiento poblacional, por cada 100 habitantes, es aún alta considerando esa misma muestra de países. De esta forma, el escenario demográfico que ha vivido Chile en el último siglo forma parte de cambios que han afectado a múltiples países, partiendo con los países desarrollados.

Los Gráficos Nos 2 y 3 ponían énfasis en los cambios en las tasas de fecundidad y crecimiento poblacional; sin embargo, una variable adicional a considerar es el envejecimiento del país. El Gráfico $\mathrm{N}^{\circ} 4$ compara esta dimensión para el caso de Chile versus el resto del contexto internacional. Como puede observarse, a comienzos del siglo 21, Chile es un país en el que aún la población de adultos mayores no es tan importante como en los otros 
GRÁFICO N 2: $\quad$ TASA DE FECUNDIDAD POR MUJER DE 15 A 49 AÑOS DE EDAD, AÑO 2004 O ÚLTIMO DATO DISPONIBLE

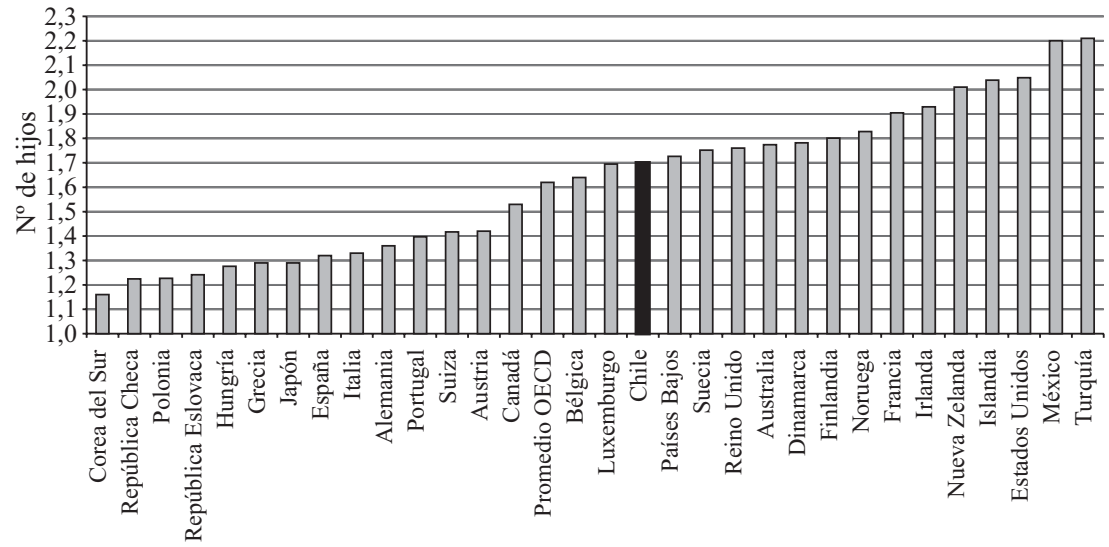

Fuente: OECD: “OECD Factbook 2007: Economic Environment and Social Statistics”.

GRÁFICO No 3: TASA DE CRECIMIENTO DE POBLACIÓN, CRECIMIENTO PROMEDIO 19922005, O ÚLTIMO DATO DISPONIBLE

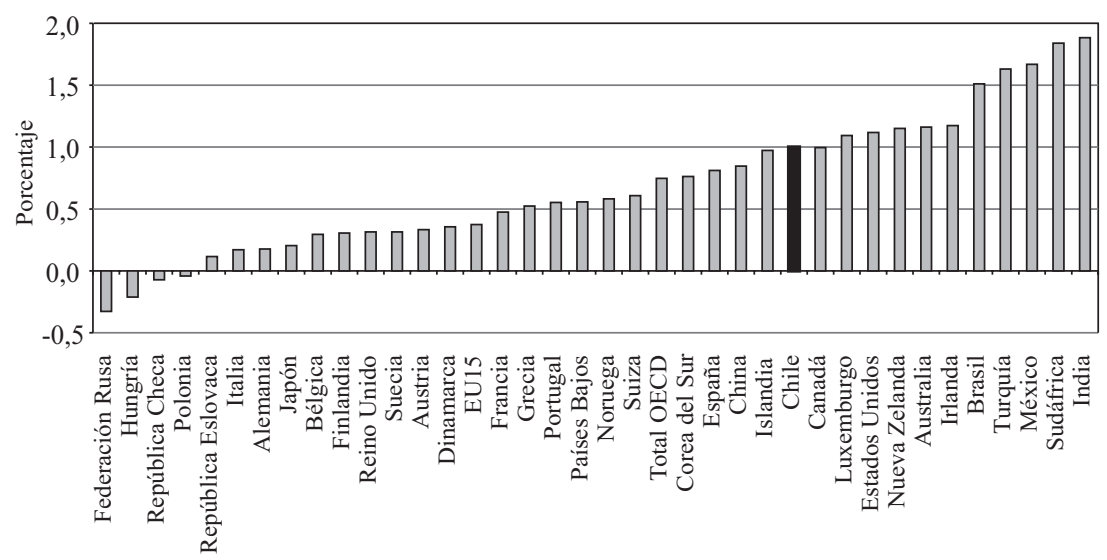

Fuente: OECD: “OECD Factbook 2007: Economic Environment and Social Statistics”. 
GRÁFICO No ${ }^{4}$ : POBLACIÓN DE 60 AÑOS Y MÁS, COMO FRACCIÓN DE LA FUERZA DE TRABAJO
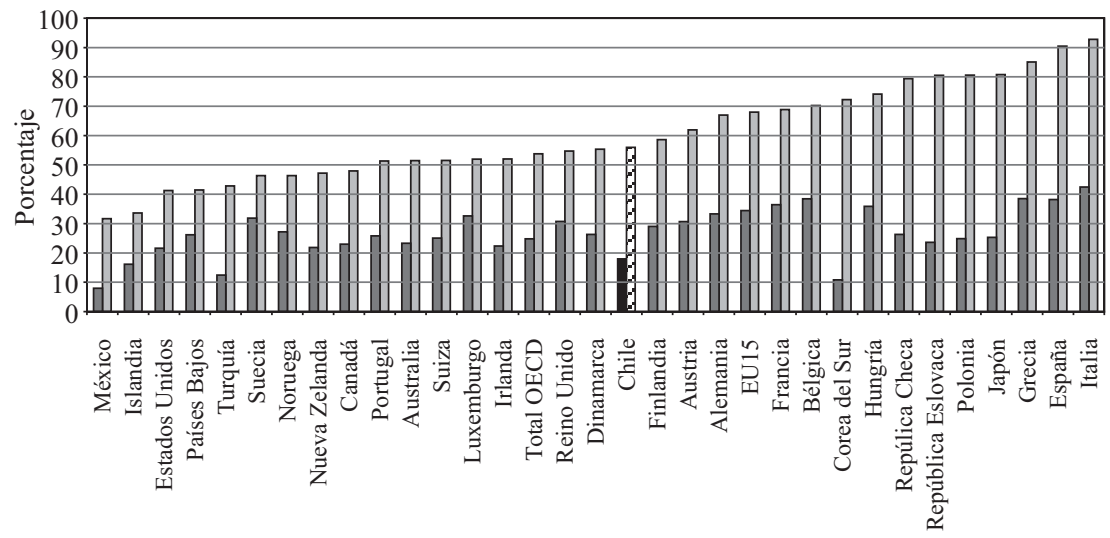

$\square$ año $2000 \quad \square$ año 2050

Fuente: OECD: “OECD Factbook 2007: Economic Environment and Social Statistics”.

países con los que lo comparábamos anteriormente. Sin perjuicio de aquello, las proyecciones para 2050 muestran una explosión de esta variable en el caso chileno, alcanzando niveles muy similares a los de países más desarrollados.

De esta forma, Chile es un país que no muestra en la actualidad grandes diferencias en términos de sus variables demográficas con otros países que han experimentado transiciones demográficas durante el siglo XX. Más aún, puede esperarse incluso alguna evolución adicional en su demografía, sobre todo respecto al envejecimiento de su población, debido a que Chile está transitando, y aún parece no haber completado, su transición demográfica. De hecho, tal como se discute a continuación, existen ciertas fases, bastante estudiadas a nivel internacional, de transición demográfica y Chile parece estar entrando en la última de ellas.

\subsection{Las fases de la transición demográfica}

Los procesos de transición demográfica han sido estudiados extensamente por la literatura especializada. En general, estos procesos se pueden caracterizar en distintas fases. La primera de ellas es una fase de crecimiento poblacional alto y estable que se destaca por altas tasas de fecundidad y 
altas tasas de mortalidad. Esta etapa tradicionalmente se relaciona con países europeos entre 1800 y 1850, que fue la de pre-industrialización, en que no existía ningún tipo de planificación familiar; muchos niños fallecían al nacer y a los que sobrevivían se les hacía trabajar en la tierra. Al mismo tiempo existían plagas o hambrunas, junto a una muy pobre higiene, lo que producía una alta tasa de mortalidad general.

La segunda fase de transición demográfica es una etapa de alto y acelerado crecimiento poblacional. Esta etapa tiene similares características a las de la fase uno en lo que respecta a tasas de natalidad, pero varía por la disminución considerable de las tasas de mortalidad debido a la mejoría en medicamentos y vacunas (medicina en general), así como en servicios sanitarios. Por lo tanto, ésta es una etapa de altas tasas de natalidad pero acompañadas con disminuciones sustanciales en las tasas de mortalidad. Esto es lo que típicamente ocurría en los países europeos entre 1850 y 1910.

Estas dos primeras fases, tal como se ha indicado, parecen corresponder a lo que ocurría en Europa en el siglo 19, y son muy similares a lo que ha ocurrido recientemente en países africanos que han sufrido epidemias que han causado altas tasas de mortalidad. Como discutiremos un poco más adelante en el caso de Chile, estas etapas tienden a retardarse en los países en desarrollo.

La tercera fase está caracterizada por tasas de mortalidad similares a las de la fase dos, pero con una disminución significativa en las tasas de natalidad. De esta forma, la población continúa con tasas de crecimiento positivas, pero cada vez menores. Los cambios en tasas de natalidad en esta etapa ocurren por múltiples factores. Entre ellos destacan: (i) cambios en las decisiones de fecundidad de las mujeres; (ii) la aparición de programas de planificación familiar, que incluyen anticonceptivos, esterilización u otros programas de gobierno; (iii) otro tipo de mecanismos como, por ejemplo, la legalización del aborto o la disminución en la tasa de mortalidad infantil, que, a su vez, disminuye la presión por tener hijos, o (iv) el proceso de industrialización, que requiere menos insumo laboral.

Finalmente, la cuarta fase de transición demográfica está típicamente caracterizada por una baja (cercana a cero), pero estable, tasa de crecimiento poblacional que va de la mano de bajas tasas de natalidad y bajas tasas de mortalidad. Esta última fase es en la que eventualmente deberían converger los países.

¿Qué ocurre en el caso de Chile? Tal como se puede observar en el Gráfico N 5, hasta 1915 aproximadamente, Chile pasaba por la primera fase descrita: tenía una alta tasa de mortalidad junto a una alta tasa de natalidad, con crecimiento estable y significativo de la población (aproximadamente de 


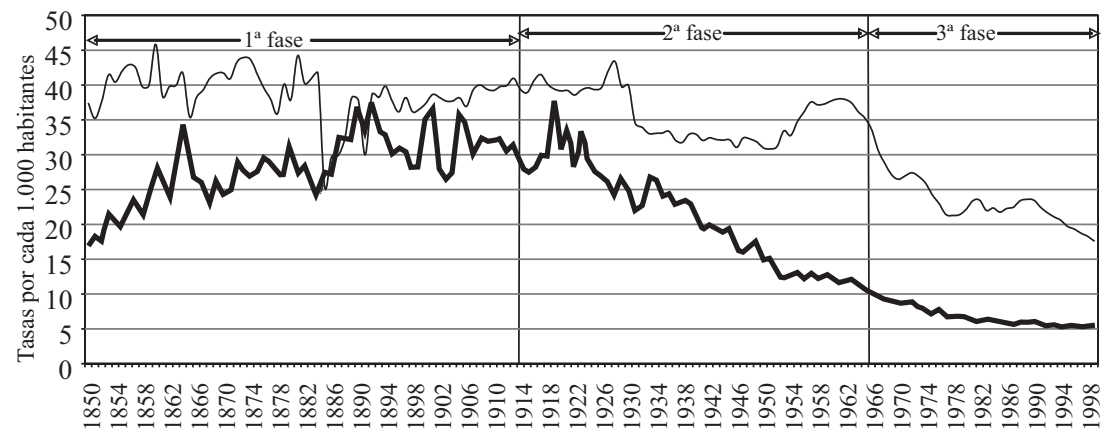

— Tasa de natalidad — Tasa de mortalidad

Fuente: Díaz, Lüders y Wagner (2008).

$1,5 \%$ al año). Desde ese momento, y hasta comienzos de los 60 , pasa a tener un aumento en su tasa de crecimiento poblacional, llegando casi a 2,5\% a comienzo de los 60. Como se observa en el gráfico, este período se caracteriza por la significativa disminución de tasas de mortalidad general desde casi $3 \%$ hasta $1,5 \%$, mientras que la tasa de natalidad se mantenía en la cercanía del 3,5\%. Esta fase es similar a la fase dos de transición demográfica esbozada con anterioridad, y está determinada por los mejoramientos sanitarios así como de los tratamientos médicos ocurridos en esas fechas. Desde mediados de la década de los 60, el país entra en la tercera fase de transición demográfica, con una disminución sustancial en las tasas de natalidad y reducciones adicionales en tasas de mortalidad, que se deben a las menores tasas de mortalidad infantil como consecuencia de las mejorías en los tratamientos hospitalarios y patrones de nutrición para los recién nacidos impulsadas por el gobierno de Chile.

Tal como se aprecia al final del gráfico, Chile estaría entrando en la cuarta y última fase de transición demográfica, es decir, en una fase de bajo, pero estable, crecimiento poblacional, con bajas tasas de fecundidad y bajas tasas de mortalidad. Esta última fase, por tener bajas tasas de mortalidad, está caracterizada por alta expectativa de vida y, por lo tanto, por un consecuente envejecimiento paulatino de la población.

El caso de Chile, si bien hemos indicado que es similar a lo que ocurre en el resto de países que han pasado por procesos de transición demográfica, presenta un par de diferencias con relación al resto de los países con los que lo hemos comparado. La transición demográfica tiene (i) 
un comienzo posterior al del resto de los países de la OECD, y además (ii) es bastante más rápida que en esos mismos países. Si tomamos como ejemplo Estados Unidos, en 1800 la mayoría de las mujeres tenía en promedio siete hijos mientras que en 1940 cada mujer tenía en promedio dos hijos. Un patrón similar se observaba en Europa (Lee, 2003). En Chile los grandes cambios en variables demográficas se observan sólo a partir 1960 y la transición en tasas de mortalidad y fecundidad parece completarse a comienzos del siglo XXI, es decir en una etapa de sólo 50 años.

\section{4. ¿Hacia dónde vamos?}

Tal como se ha discutido, Chile ha tenido cambios demográficos significativos y bastante rápidos en los últimos años. Los efectos de estos cambios están por aparecer. En primer lugar, las disminuciones en tasas de natalidad producen crecimientos cada vez menores en la población del país, que finalmente tienden a converger en la cercanía de 20 millones de personas en 2040, ver Gráfico № 6. Ésta es una consecuencia no menor, en la medida en que el crecimiento de la fuerza de trabajo está directamente relacionado con el crecimiento poblacional. Éste es, por lo tanto, un potencial cuello de botella para el crecimiento futuro por el lado de la oferta de trabajo.

Una segunda implicancia de la transición demográfica del caso de Chile se relaciona con los cambios en la pirámide poblacional. La Tabla No 1 muestra varios índices demográficos y su evolución desde 1970 hasta 2050,

\section{GRÁFICO N ${ }^{\circ}$ 6: $\quad$ POBLACIÓN, NÚMERO DE PERSONAS. EVOLUCIÓN PROYECTADA A} PARTIR DE LA OBSERVADA

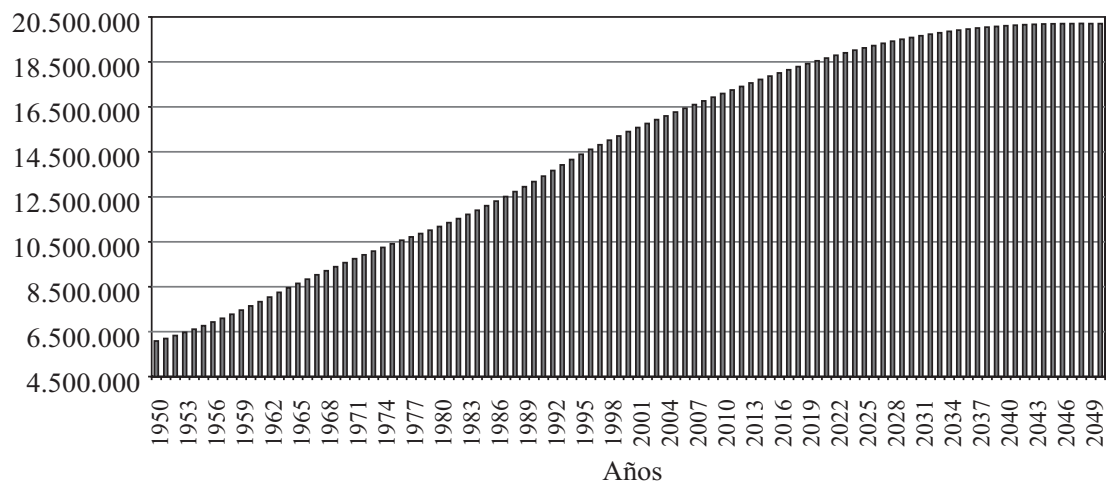

Fuente: Celade (2002). 


\begin{tabular}{|c|c|c|c|c|c|c|c|c|c|}
\hline & & & & & & & & & \\
\hline & 1970 & 1980 & 1990 & 2000 & 2010 & 2020 & 2030 & 2040 & 2050 \\
\hline Población (en \%): & & & & & & & & & \\
\hline 0-14 años & 39,7 & 33,0 & 29,9 & 27,8 & 22,3 & 20,2 & 18,7 & 17,3 & 16,6 \\
\hline 15-64 años & 55,3 & 61,4 & 64,0 & 65,0 & 68,7 & 67,9 & 64,8 & 62,9 & 61,8 \\
\hline 65 y más & 5,0 & 5,5 & 6,1 & 7,2 & 9,0 & 11,9 & 16,5 & 19,8 & 21,6 \\
\hline $\begin{array}{l}\text { Relación de dependencia } \\
\text { (por cien) }\end{array}$ & 81,0 & 62,8 & 56,2 & 53,8 & 45,6 & 47,3 & 54,4 & 58,9 & 61,8 \\
\hline $\begin{array}{l}\text { Edad mediana de la } \\
\text { población }\end{array}$ & 20,2 & 22,6 & 25,7 & 28,7 & 32,0 & 35,1 & 38,7 & 41,5 & 42,9 \\
\hline $\begin{array}{l}\text { Relación } 3^{\mathrm{a}} \text { edad/jóvenes } \\
\text { (por cien) }\end{array}$ & 12,7 & 16,8 & 20,3 & 25,8 & 40,4 & 58,7 & 88,4 & 114,3 & 130,1 \\
\hline $\begin{array}{l}\text { Relación niños/mujeres } \\
\text { (por cien) }\end{array}$ & 58,2 & 40,5 & 41,1 & 32,4 & 27,4 & 27,3 & 26,1 & 25,7 & 26,4 \\
\hline $\begin{array}{l}\% \text { de mujeres en edad } \\
\text { fértil }\end{array}$ & 45,8 & 51,4 & 53,3 & 52,7 & 52,8 & 48,6 & 46,1 & 43,1 & 40,6 \\
\hline
\end{tabular}

Relación de dependencia (población de 0-14 más población de 65 y más / población de 15-64 años) × 100 .

Relación viejos/jóvenes (población de 65 y más / población de 0-14) × 100 .

Relación niños/mujeres (población de 0-4 / población femenina de 15-49) × 100

Porcentaje de mujeres en edad fértil (población femenina de 15-49 / población femenina total) $\times 100$.

Fuente: Celade (2002).

donde los datos desde 2010 muestran proyecciones. La fuente de esta tabla es INE-Celade (ver Celade 2002) y en ella se analizan los cambios en la pirámide poblacional. Nótese que la fracción de adultos en tercera edad se ha mantenido relativamente constante, en la cercanía del 5 a 7\%, desde 1970 hasta 2000. Sin embargo, el proceso de envejecimiento de nuestra población se traduce en un aumento considerable de la importancia de este grupo de personas, que llega al 9\% en 2010 y a más del 20\% en 2050. Es decir, el proceso de envejecimiento de nuestra población está por venir, y va a llegar bastante rápido. Además resulta también notable el hecho de que mientras el grupo de los adultos mayores aumenta, el grupo de menores de 15 años disminuye drásticamente desde casi el 40\% en 1970 hasta un 28\% en 2000 y 17\% en 2050.

Estos cambios en la pirámide alteran la importancia relativa de la población de 15 a 64 años de edad. Esta población incluye a aquellas personas en edad de trabajar y por lo tanto es bastante importante para la evolución de las perspectivas económicas futuras. Resulta interesante observar 
que desde los años 80 y hasta el 2000 este grupo representaba cerca de 65\% de la población, pero a partir del 2000 y hasta el 2020 este grupo aumenta su importancia al ser casi el 70\% de la población. Del 2020 en adelante el proceso se revierte y este grupo baja su participación llegando a la cercanía del 60\% en el 2050. ¿A qué se debe el aumento inicial en la importancia de este grupo? Esto ocurre debido a la disminución en tasas de natalidad de la década de los 90, que hace disminuir al grupo de jóvenes y aumenta la importancia relativa del grupo en edad para trabajar. Esto es lo que usualmente se conoce como "bono demográfico" (ver Bloom y Canning, 2001 y 2004; Bloom, Canning y Malaney, 2000; Bloom y Williamson, 1998). Este efecto se conoce como bono demográfico porque permite durante algunos años aumentar la proporción de la población que se encuentre en edad de trabajar, lo que afecta positivamente la oferta de trabajo y potencialmente el crecimiento económico, subsanando en parte el cuello de botella por el lado de la oferta de trabajo.

Otra particularidad interesante es la disminución en la relación de dependencia (fracción de jóvenes o personas de tercera edad en la población) desde 1970 hasta 2010 y su posterior reversión hasta el 2050, cuando alcance nuevamente los niveles de 1980. La evolución de esta variable va de la mano de los cambios en la pirámide poblacional antes expuestos y si bien pareciera que nuestra población vuelve a tener las características de 1980, lo que realmente ocurre es un importante cambio en su composición. Tal como lo muestra la relación tercera edad a jóvenes en 1980, sólo había 16 personas de tercera edad por cada 100 jóvenes. Esa cifra pasa a ser del orden de 130 personas de tercera edad por cada 100 jóvenes en el 2050.

En síntesis, debemos esperar tasas de crecimiento poblacionales cada vez menores y una eventual convergencia de la población en la cercanía de 20 millones de personas. Además, la composición de la población cambia drásticamente, y si bien se mantiene una alta tasa de dependencia, ésta pasa a ser cada vez más intensiva en la tercera edad. Éste es un desafío para las políticas públicas del país que enfrentarán demandas muy distintas a las actuales.

A continuación analizaremos las causas de la transición demográfica y sus implicancias para Chile.

\section{3. ¿A qué se deben estos cambios demográficos?}

Las razones de estos cambios en las variables demográficas pueden ser múltiples y existe una amplia literatura al respecto (ver entre otros Becker, 1981; Becker y Lewis, 1973; Cerda, 2005; Cigno y Rosatti, 1996; 
Holtz et al., 1997; Schultz, 1997; Willis, 1973). Dentro de estos factores destacan los siguientes. En primer lugar, han existido cambios sociales que pueden haber incidido en las decisiones demográficas de las personas, como por ejemplo la caída en la tasa de nupcialidad. En segundo lugar, han ocurrido cambios socioeconómicos importantes en los últimos treinta años que pueden afectar decisiones de fecundidad: particularmente, el aumento significativo en el nivel educacional de las mujeres chilenas y su relación con el número de hijos promedio por familia. En tercer lugar, puede existir otro tipo de factores que también alteren decisiones de fecundidad, entre los que destaca el uso de métodos anticonceptivos.

A continuación se describe y analiza cada una de estas posibles fuentes de disminución en tasas de natalidad. Este análisis es sólo descriptivo. Posteriormente, se procede a realizar análisis econométrico para determinar la importancia de estos factores. Sin embargo, antes de discutir acerca de los fundamentos de las disminuciones en tasas de natalidad, seguiremos un enfoque netamente contable para entender las fuentes de cambios en natalidad. Siguiendo a Larrañaga (2006), primero se analiza la creación de familias debido a que las decisiones de fecundidad se pueden tomar tanto al interior como al exterior de las familias. De esta forma una posible hipótesis es que hoy en día existe una “menor creación” de familias, lo que inmediatamente puede llevar a suponer que las mujeres frente a un escenario familiar más precario deciden tener menos hijos. En segundo lugar, se analiza cómo han cambiado las decisiones de fecundidad al interior de las familias.

\subsection{Enfoque contable: La tasa de nupcialidad y la creación de familias}

Ha existido una significativa disminución en la tasa de nupcialidad entre los chilenos: el número de matrimonios ha disminuido desde algo más de 7 matrimonios por cada 1.000 habitantes a principios de los 70 a cerca de 3,6 en el año 2003. Estos datos podrían indicar que parte de la caída en la tasa de fecundidad obedece a la disminución en las tasas de nupcialidad. De hecho la observación de la evolución comparada de las tasas de natalidad y tasas de fecundidad son muy sugerentes en ese sentido (ver Gráfico $\mathrm{N}^{\mathrm{o}} 7$ ).

Sin embargo, no debe perderse de vista que aunque la nupcialidad ha disminuido, al mismo tiempo han aumentado las uniones consensuales. De hecho, de acuerdo a datos del censo, las mujeres casadas en el grupo de edad 35 a 45 años en 1960 representaban cerca del 70\%, mientras que en el año 2002 esta cifra llegaba sólo al 62\%. En ese mismo período, las uniones 
GRÁFICO N ${ }^{\circ} 7: \quad$ EVOLUCIÓN TASAS DE NATALIDAD Y TASAS DE NUPCIALIDAD, CHILE:1971-2003

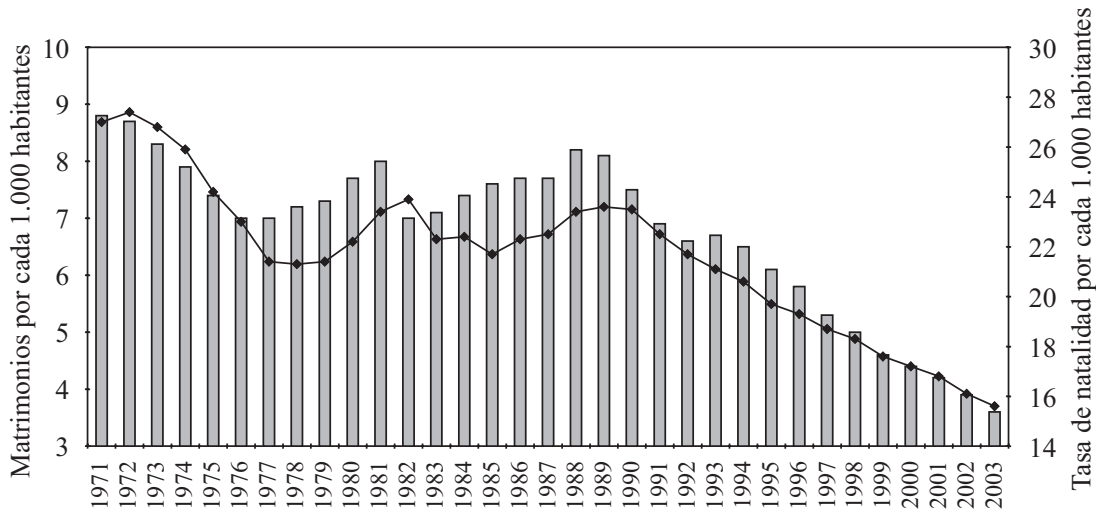

$\square$ Tasa de nupcialidad por 1.000 hab. $\rightarrow$ Natalidad por 1.000 hab.

Fuente: Díaz, Lüders y Wagner (2008).

consensuales en este mismo grupo de mujeres pasó de cerca del 4\% a casi el $11 \%$, por lo que gran parte de la disminución en uniones civiles formales se debe al aumento de uniones consensuales. Por otro lado, en el mismo grupo etario, las mujeres que se definen en otras categorías (solteras/nunca casadas, anuladas, separadas, viudas) mantienen una importancia bastante estable, cercana al $9 \%$.

Toda esta evidencia indica que efectivamente existen ciertos cambios. El concepto tradicional de familia a partir de la formación de un matrimonio, aunque aún es mayoritario, parece que se está reemplazando parcialmente por el de unión consensual, por lo que la disminución de matrimonios parece que se explica totalmente por el aumento de uniones consensuales. La creación de hogares con uniones de adultos (tanto uniones formales del tipo matrimonio como uniones consensuales) parece mantenerse relativamente constante.

\subsection{Enfoque contable: Número de hijos por familia}

De acuerdo con datos del censo, la principal caída en el número de hijos por mujer se da en mujeres en matrimonio y/o unión consensual. En 1960 en el grupo de mujeres casadas de 35 a 45 años, en promedio el número 
de hijos era 4,5 y cerca del 55\% tenía 4 o más hijos. En el caso de mujeres en uniones consensuales, en promedio el número de hijos era 4,1 y además más del 50\% de estas mujeres tenía 4 o más hijos. Estas mismas cifras en el 2002 eran sólo de 2,6 y 2,7 hijos respectivamente y sólo 19\% de las mujeres casadas tenía 4 o más hijos — cifra que en las mujeres con uniones consensuales era de $2,7 \%$. Por otro lado, mujeres en el mismo grupo de edad pero que se declaran solteras, separadas o anuladas han mantenido bastante constante su número de hijos en un promedio de 1,6.

De esta forma, los cambios en las decisiones sobre número de hijos ocurre al interior de las familias y lo que debe tratar de explicarse es por qué las mujeres en matrimonio y/o en convivencia tienen menos hijos en promedio desde fines del siglo XX y en el siglo XXI. Esto es lo que pasamos a analizar a continuación.

\subsection{Posibles determinantes}

\section{3.a. Aumento significativo en los niveles educacionales ${ }^{3}$}

Ha habido dos cambios importantes que posiblemente puedan explicar la diferencia entre el número de hijos por mujer en una familia estable (sea matrimonio o unión consensual) y en mujeres fuera del matrimonio o de unión consensual. En primer lugar, ha existido un aumento muy significativo en los niveles educacionales de las chilenas ( $\mathrm{y}$ chilenos en general) debido a políticas educacionales impulsadas desde el Estado y al alto retorno privado que se obtiene de educarse. En 1960 cerca del 90\% de las mujeres casadas o en uniones consensuales cuya edad fluctuaba entre 35 y 45 años había completado solamente su educación primaria. En 2002, en este mismo grupo de mujeres esta cifra había caído a cerca del 35\% en el caso de las mujeres casadas y a $50 \%$ en el caso de mujeres en uniones consensuales. Además se observa que cerca del $50 \%$ adicional ha completado su educación media. Si se compara este grupo con las mujeres de la misma edad pero declaradas como solteras, separadas o anuladas, las cifras muestran que en 1960 cerca del 75\% alcanzaba sólo la educación primaria o menos, cifra que desciende a 34\% en 2002. Además, en este último año, cerca del 18\% de las mujeres sin matrimonio o unión consensual tiene niveles de educación post-secundaria, mientras que esta cifra es sólo cercana al $9 \%$ en mujeres en unión consensual y 15\% en mujeres en matrimonio. Por lo

\footnotetext{
${ }^{3}$ En estas secciones las cifras corresponden a cálculos propios a partir de extractos de los censos.
} 
tanto, es importante notar que (1) en general, las mujeres fuera de matrimonio y/o unión consensual presentan niveles educacionales algo superiores a los de mujeres casadas o en uniones consensuales, pero además (2) hay un aumento considerable en los niveles educacionales de todas las mujeres, en particular de las mujeres casadas o en unión consensual.

\section{3.b. Creciente participación de las mujeres en el mercado laboral}

En segundo lugar, desde 1960 ha cambiado la participación de las mujeres en el mercado laboral. De hecho, cerca del 90\% de las mujeres casadas (85\% en uniones consensuales) en el mismo grupo de edad se declaraban como dueñas de casa en 1960 y sólo un 11\% (15\%) trabajaba en ese año. Estas cifras son radicalmente distintas en 2002: sólo un 61\% se declara como dueña de casa (56\% en los casos de unión consensual) y casi 35\% participa en el mercado laboral (40\% en los casos de unión consensual). Estas cifras contrastan claramente con las de mujeres fuera del matrimonio y/o unión consensual: en 1960 sólo un 43\% se declaraba dueña de casa y casi el 54\% participaba en el mercado laboral. En 2002 estas cifras eran 23\% y 70\% respectivamente. Por lo tanto, mujeres fuera del matrimonio y/o unión consensual muestran tasas de participación laboral más altas y tanto mujeres casadas como fuera de matrimonio y/o unión consensual han aumentado significativamente su participación laboral, siendo el cambio mucho más drástico en el caso de las mujeres casadas y/o en unión consensual.

Es esperable que los aumentos en educación así como los aumentos en participación laboral estén relacionados: mujeres más educadas pueden obtener una mejor retribución económica del mercado laboral, lo que las incentiva a salir a trabajar y eso lleva a disminuir el número de hijos deseados por mujer y a retardar el momento de tener hijos. Cierta evidencia en ese sentido puede encontrarse en los datos del censo: en 1960 mujeres de nivel educacional primario o menor tenían en promedio 4 hijos, mientras que mujeres con educación secundaria tenían en promedio 2,5 hijos y mujeres con educación superior tenían en promedio 1,9 hijos. Las cifras para el 2002 son 2,8, 2,3 y 1,9 hijos respectivamente. ¿A qué se debe esta relación? Posiblemente a que mujeres más educadas salen más a trabajar y tienen menos tiempo para dedicarles a sus hijos, por lo que pueden desear disminuir el número de hijos que ellas deseen criar. Esta relación también lleva a que las mujeres tengan hijos de forma más tardía: de hecho, Larrañaga (2006) muestra que la edad promedio de las mujeres casadas al tener su primer hijo era 24 años en 1990 y aumentaba paulatinamente hasta los 27 años de edad en el 2003. 


\subsection{El gasto en los hijos}

Pueden existir otros factores que también estén detrás de la caída observada en las tasas de fecundidad. Uno de estos factores puede ser el “costo” de tener hijos. Este concepto de “costo” de los hijos está relacionado con el hecho de que los padres tienen cierto presupuesto determinado por sus ingresos que debe ser utilizado en distintos gastos como, por ejemplo, arriendo, supermercado, colegios, etc. Por lo tanto, cierta parte del presupuesto debe ser asignada a los hijos (sea por gasto en educación, salud, ropa) y este gasto aumenta con el número de hijos. Obviamente no resulta ilógico suponer que los padres consideren este problema presupuestario al determinar el número de hijos que ellos eventualmente desean criar. Este factor puede tener un impacto considerable en la evolución de las tasas de fecundidad. De hecho, si se piensa en los bienes relacionados con gastos en educación y salud de los hijos, así como en vestuario infantil y ropa de guagua, se observa que los precios de estos bienes han crecido bastante más que el IPC, especialmente el gasto en educación, que ha crecido más que el doble del IPC en el período 1986-2003.

Los datos del Gráfico No 8 muestran la evolución de los precios de bienes y servicios del sector educación, de alimentos lácteos y huevos y de ropa de menores de un año, obtenidos del desglose del índice de precios al consumidor y medidos como fracción del IPC. La forma de leer este gráfico es la siguiente. Si estos precios, medidos como fracción del IPC, se mantuvieran relativamente constantes a través del tiempo, entonces no habría aumento del costo de los bienes y servicios usados intensivamente en la crianza de los hijos más allá de lo que han aumentado los precios del resto de los bienes de la economía incluidos en el IPC. Si, por otro lado, estos precios aumentaran (disminuyeran) como fracción del IPC, entonces los costos de estos bienes crecerían más rápido (lento) que los de otros bienes y servicios de la economía y se estaría haciendo relativamente más caro (barato) comprar bienes y servicios para criar a nuestros hijos. Lo interesante del Gráfico $N^{\circ} 8$ es que si bien los precios de los alimentos se mantienen relativamente constantes y los de vestuario de bebé tienden incluso a disminuir al final del período, los costos educacionales crecen muy rápido en este período y más que doblan el aumento de los precios de otros bienes. Es decir, los costos educacionales hoy son muy superiores a los costos de hace 20 años, medidos en pesos reales, lo que puede incidir en la decisión de fecundidad.

Obviamente, se podría argumentar que la mayoría de los hijos de los chilenos acuden a colegios gratuitos, por lo que esto no debería ser rele- 


\section{GRÁFICO No 8: $\quad$ COSTO DE GASTOS EN HIJOS, COMO FRACCIÓN DEL IPC}

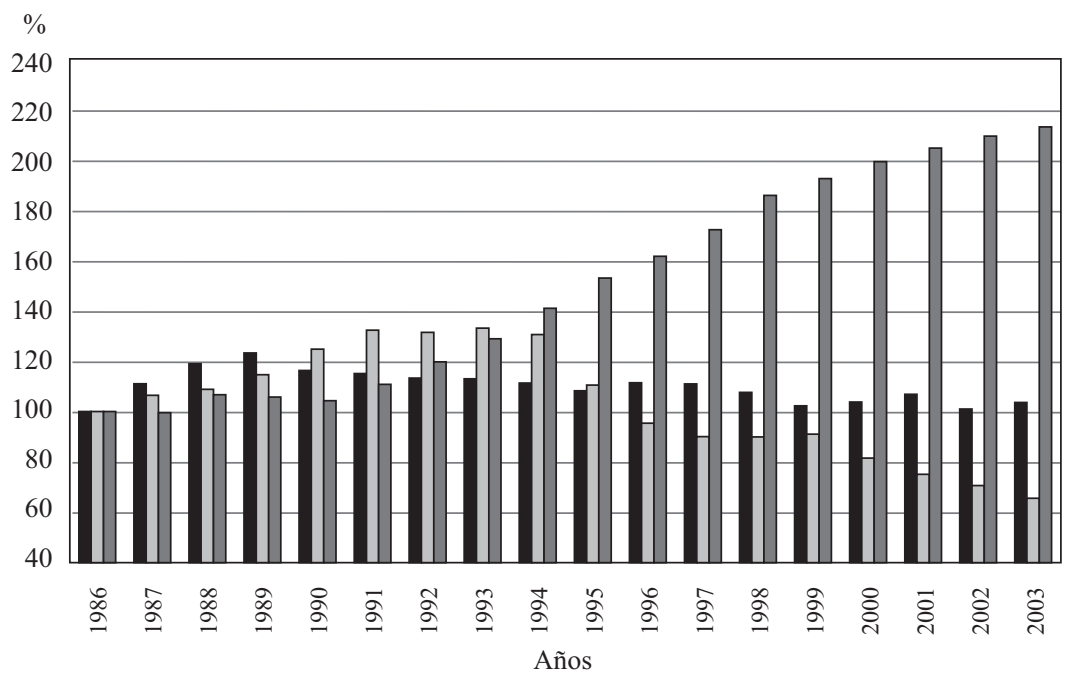

Productos lácteos y huevos $\square$ Vestuario de guagua $\square$ Educación

Fuente: Instituto Nacional de Estadísticas (INE): “Indicadores Mensuales - Índices de Precios”, Boletín Informativo, varios números.

vante. Sin embargo, este tipo de argumento no se aplica a los útiles escolares o a las matrículas universitarias, los que como hemos indicado han tenido aumentos de precios bastante más altos que el resto de los bienes y servicios de nuestra economía en los últimos 20 años. Además los padres al momento de decidir el número de hijos posiblemente observen los precios educacionales del mercado como expectativas de los precios que deberán enfrentar ellos con posterioridad.

Todo este análisis de costos educacionales y de otro tipo de gastos en nuestros hijos como determinante de disminución en la tasa de fecundidad es relevante en la medida en que estos costos sean importantes para las familias chilenas. Para tener alguna idea de la importancia de los gastos en los hijos en el presupuesto familiar considérense los datos de la Tabla $\mathrm{N}^{\circ} 2$, que muestra los diferentes gastos anuales en que se incurre para la educación de los hijos. La fuente de datos es la Encuesta de Protección Social (EPS) 2002, encargada por la Subsecretaría de Previsión Social y elaborada por el Centro de Microdatos de la Universidad de Chile; se calcula en base a hogares con al menos un menor de edad. Como se observa en la tabla, efectivamente una fracción importante de los hogares no incurre en gastos de colegiatura, sin embargo el gasto en colegiaturas para el resto de los hogares es considerable. 


\begin{tabular}{|c|c|c|c|c|c|}
\hline & Colegiaturas & Matrículas & Útiles & Movilización & Total \\
\hline \multicolumn{5}{|c|}{$\%$ hogares que no } & - \\
\hline Gasto promed & 230.068 & 38.137 & 69.147 & 53.194 & 467.267 \\
\hline $1^{\mathrm{er}}$ quintil & 0 & $0-2.000$ & $0-15.000$ & 0 & $0-50.000$ \\
\hline $2^{\circ}$ quintil & $0-5.000$ & $2.000-8.000$ & $15.000-29.000$ & 0 & $50.000-110.000$ \\
\hline $3^{\text {er }}$ quintil & $5.000-42.000$ & $8.000-18.000$ & $29.000-48.000$ & $0-15.000$ & $110.000-230.000$ \\
\hline $4^{\circ}$ quintil & $42.000-200.000$ & $18.000-49.500$ & $48.000-99.300$ & $15.000-99.000$ & $230.000-545.000$ \\
\hline $5^{\circ}$ quintil 2 & $200.000-3.600 .000$ & $49.500-525.000$ & $99.300-700.000$ & $99.000-600.000$ & $545.000-5.410 .000$ \\
\hline
\end{tabular}

Fuente: Cálculos propios a partir de EPS 2002.

Algo similar ocurre con las matrículas escolares. Pero más allá de estas consideraciones, nótese que el gasto promedio anual en que incurren estos hogares en la educación de sus hijos es aproximadamente 467.000 del año 2002, lo que es una cifra bastante significativa si se considera que el ingreso autónomo promedio mensual de un hogar en noviembre de 2003 fue aproximadamente de 528.000, de acuerdo a la encuesta Casen 2003 (Mideplán, 2004).

De esta forma, el costo de los hijos parece ser un elemento importante en la decisión de tener hijos en la medida en que el gasto en que incurren los hogares en la educación de sus hijos es bastante significativo. El aumento en los precios de los bienes y servicios que se utilizan en el proceso de criar hijos, desde ese punto de vista, parece que también explica a lo menos parte de la disminución en las tasas de fecundidad.

\subsection{Otros factores que podrían explicar la caída en las tasas de fecundidad}

Hay otros factores relevantes que también podrían explicar la significativa disminución en las tasas de fecundidad. Estos argumentos provienen desde el ámbito de la política pública de salud.

En primer lugar, ha habido una significativa disminución en las tasas de mortalidad infantil. Éste es un argumento a considerar porque en países con alta mortalidad infantil (es decir mortalidad de menores de un año de vida) las madres que deseen un determinado número de hijos pueden decidir tener un número mayor al estimar que algunos de sus hijos pueden fallecer prematuramente. De esta forma, mayores tasas de mortalidad infantil se relacionan con mayores tasas de fecundidad.

Este punto debe considerarse al analizar el caso chileno (y latinoamericano en general) debido a que se han dado cambios significativos en la mortalidad infantil durante el siglo 20. La mortalidad infantil era cercana a 300 por 1.000 niños nacidos vivos entre 1920 y 1924 en Chile, cifra que 
disminuyó a 125 por 1.000 en 1960 y que disminuyó aun más drásticamente a partir de los 70, llegando a 8,3 por cada 1.000 nacidos vivos en el año 2003. A priori, este factor podría ser importante para explicar la disminución de tasas de fecundidad en la década de los 60, pero no debería ser un factor demasiado influyente desde mediados de los 80 , porque las tasas de mortalidad infantil eran ya bastante bajas en esos años.

Por otro lado, otro factor relevante podría ser el uso masivo de anticonceptivos desde los 60. Este factor también puede ser altamente relevante en la explicación del fenómeno, a lo menos en el momento de su aparición inicial. Más aún, de acuerdo a Cepal (2007), el uso de métodos anticonceptivos habría explicado cerca del 50\% de la reducción en las tasas de fecundidad en América Latina y el Caribe en los años noventa. Para el caso de Chile en particular no existen aún estimaciones convincentes al respecto.

Finalmente, pueden haber ocurrido cambios culturales que también hayan desencadenado estas variaciones en las tasas de natalidad. Entre otros cambios culturales se puede destacar el cambio en los hábitos de consumo de los chilenos en general, y de las parejas en particular, que pudieron inducir a posponer el momento de tener su primer hijo con la finalidad de disfrutar de esas posibilidades antes de dedicarse a criar a sus hijos.

\subsection{Análisis empírico}

¿Cuáles de todos estos factores deben ser los más relevantes en la disminución de la tasa de fecundidad? Para responder esta pregunta, en Cerda (2006) se desarrolla un análisis estadístico con datos de la Encuesta de Protección Social del año 2002, que se presenta en esta subsección y la siguiente. La descripción de datos se encuentra en el Apéndice 1. Se utilizan estos datos porque corresponden a una encuesta de personas realizada a nivel de hogares en la que, entre otras cosas, se detallan los hijos deseados y/o planeados por mujer y se conoce además la fecha de nacimiento de cada hijo. Además se puede distinguir entre nacimientos adentro o fuera de matrimonio y/o convivencia. Se analizará en los ejercicios econométricos siguientes tanto la decisión del número de hijos planeados por mujer como el intervalo entre nacimientos. Esta última dimensión permite analizar las razones del retraso en la edad de las mujeres para tener hijos.

\section{6.a. Número de hijos planeados: Metodología y resultados}

Los datos de fecundidad por mujer son del tipo datos de conteo, es decir son datos de tipo discreto, con múltiples ceros y valores pequeños. Estos tipos de datos son generalmente estudiados por medio de modelos de 
regresión del tipo Poisson (ver Greene, 1993). En nuestro caso seguiremos esa misma estrategia. Sea $n_{i}$ el número de hijos planeados por la mujer $i$ en nuestra muestra. Supondremos que esta variable surge de una distribución del tipo Poisson con parámetro $\gamma_{i}$. Es decir,

$$
P\left(N_{i}=n_{i}\right)=\frac{e^{-\lambda i} \gamma_{i}^{n_{i}}}{n_{i} !} \quad n_{i}=0,1,2, \ldots
$$

Donde $N_{i}$ es la variable aleatoria y $n_{i}$ es la realización para la madre $i$. Además se supone que el parámetro $\gamma_{i}$ está relacionado con nuestras variables de interés a través de la siguiente especificación:

$$
\ln \gamma_{i}=x_{i}^{\prime} \beta
$$

Donde $x_{i}$ incluye las variables de interés que hemos discutido con anterioridad. Específicamente en nuestras estimaciones incluiremos educación, fracción del tiempo trabajado por cada mujer durante su edad fértil, tasa de mortalidad infantil enfrentada por las madres, el costo de los bienes y servicios necesarios para criar a los hijos y una variable ficticia igual a uno si la mujer ha estado casada o conviviendo. Además se incorporan variables adicionales de ingreso (ingreso laboral, ingreso no laboral y subsidios del Estado) para medir si las decisiones de natalidad consideran esta variable por sí sola.

La Tabla $\mathrm{N}^{\circ} 3$ reporta los resultados de las estimaciones. Esta tabla muestra estimaciones para la fecundidad total por mujer, fecundidad por mujer dentro del matrimonio o en convivencia y fecundidad por mujer fuera del matrimonio o en convivencia. En cada uno de estos casos se presentan estimaciones excluyendo e incluyendo las variables de costos educativos. La razón por la que se presentan ambas estimaciones es que al incluir la variable de precios relativos sólo podemos hacer estimaciones a partir de 1983, debido al rango de esos datos. Por lo tanto, estas últimas estimaciones corresponden a una muestra algo más corta. La Tabla $\mathrm{N}^{\circ} 3$ corresponde a estimaciones con el conjunto de mujeres en nuestra muestra.

La Tabla $\mathrm{N}^{\circ} 3$ muestra los siguientes resultados —inicialmente nos referiremos a fecundidad total, sin discriminar entre los impactos dentro o fuera del matrimonio o convivencia. Posteriormente se analizarán esos casos. En primer lugar, si una mujer no se casa y no convive, su fecundidad tiende a disminuir entre 0,6 y 1,1 hijos en promedio. Este resultado indica la 


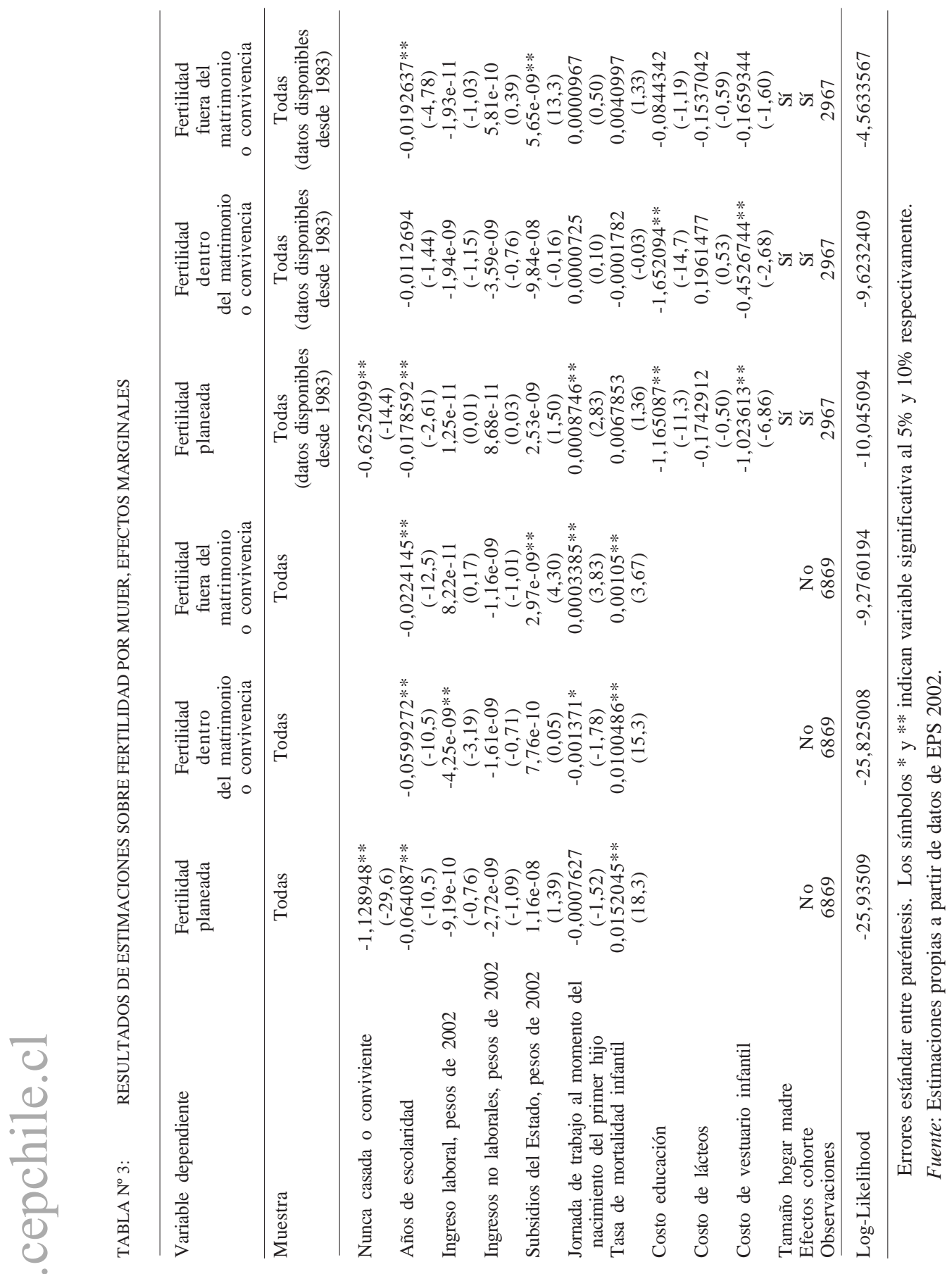


importancia de una relación marital estable (sea matrimonio o convivencia) en la decisión de fecundidad de las mujeres. En segundo lugar, cada año de educación adicional en la mujer disminuye el número de hijos en cerca de 0,06 cuando se considera la muestra completa. Este efecto disminuye hasta ser un impacto negativo de 0,017 por año de educación adicional en las mujeres si se considera el período más corto. Estos efectos indican que si los años de educación aumentan en seis en promedio, en el caso de las mujeres (tal como ocurrió entre 1960 y finales del siglo 20) el número de hijos por mujer debiera disminuir por este factor entre 0,4 y 0,15 hijos en promedio.

En tercer lugar, los efectos de ingresos — sean provenientes del trabajo de las mujeres o de otras fuentes, como subsidios del Estado- no son significativos. El impacto de la jornada de trabajo, en general, tampoco es significativo. En cuarto lugar, la variable tasa de mortalidad es altamente relevante en el período largo. De hecho, disminuciones de tasas de mortalidad infantil desde niveles de 73 por mil nacidos vivos en 1971 hasta 8 por mil en 2001, están relacionadas con una disminución de casi un hijo por mujer en promedio. En quinto lugar, los cambios en los precios relativos de insumos son muy relevantes. Por un lado, el costo de la ecuación tiene un coeficiente asociado de -1,6 mientras que el coeficiente de vestuario infantil es también relevante, siendo aproximadamente igual a -1. Nótese que el precio relativo de la educación casi se ha doblado en los últimos 20 años, lo que de acuerdo con nuestras estimaciones sería consistente con una disminución de cerca de 1,6 hijos por mujer en promedio en este período. El efecto de vestuario infantil va en el sentido contrario. Este índice ha disminuido en aproximadamente $30 \%$ si se comparan los últimos 20 años, lo que aumentaría la demanda por hijos en cerca de 0,3 hijos por mujer en promedio.

Vale la pena diferenciar los resultados para mujeres dentro del matrimonio y/o convivencia versus mujeres fuera del matrimonio y/o convivencia. Dentro del matrimonio y/o convivencia los efectos precios relativos son los determinantes fundamentales en las decisiones de fecundidad. Esto contrasta con lo que ocurre con la fecundidad fuera del matrimonio. En este caso, los principales determinantes son las fuentes de ingreso de la madre, como por ejemplo los años de escolaridad de la madre ${ }^{4}$, y fuentes de ingresos no dependientes del mercado del trabajo, como los subsidios estatales. En este caso, más que un componente de precios, las madres se preocupan de tener ingresos mínimos que les permitan mantener a sus hijos.

${ }^{4}$ Que finalmente se relacionan con los componentes permanentes de los potenciales salarios de las madres en el mercado del trabajo. 
La Tabla $\mathrm{N}^{\circ} 4$ presenta resultados de estimaciones similares a las de la Tabla $\mathrm{N}^{\circ} 3$ pero con la diferencia de que se reconoce la posible simultaneidad en la decisión de fecundidad versus otro tipo de decisiones, como la de contraer matrimonio o la convivencia estable, escolaridad, ingreso laboral, subsidio del Estado y jornada de trabajo. La razón es que, por ejemplo, la decisión de contraer matrimonio o de convivir, si bien suele depender de determinantes como el amor en la pareja, perspectivas futuras como pareja, etc., también puede depender de variaciones exógenas de fecundidad; esto quiere decir que pueden existir casos en que las mujeres decidan contraer matrimonio y/o convivencia estable ante un sorpresivo embarazo. Similarmente ante shocks de fecundidad, las mujeres pueden decidir poner término a su etapa educativa modificando sus años de escolaridad e ingresos laborales. Alternativamente, el cuidado de los hijos puede influir sobre las decisiones de trabajar y de cuántas horas trabajar. Por último, los subsidios del Estado también tienen un componente de subsidios familiares a hogares de escasos ingresos con menores de edad, por lo que éstos también pueden ser endógenos a la fecundidad. En estos casos no sólo existirá causalidad desde las variables anteriormente citadas hacia la fecundidad, sino que también al revés, lo que puede invalidar las estimaciones. Por esa razón, se decide ocupar variables instrumentales. Dentro de los instrumentos se consideraron las características del padre y de la madre (o mujer) que toma las decisiones de su fecundidad. Los instrumentos incluyen información del padre y la madre relacionada con años de estudios de cada uno de ellos, si saben leer y escribir, si cada uno de ellos se casó y si cada uno de ellos trabajaba.

Los resultados, al corregir por posible simultaneidad, confirman los resultados anteriores. La tasa de mortalidad infantil es importante para explicar las caídas en la tasa de natalidad antes de 1983. Con posterioridad a esta fecha, esa variable pierde importancia. Sin embargo, las variables relacionadas con los precios de criar a los hijos son altamente significativas con magnitudes similares a las estimaciones anteriores. Además, estos precios ahora aparecen relevantes en las decisiones de fecundidad fuera del matrimonio, aunque los impactos son bastante menores que los que se observan dentro del matrimonio y/o convivencia. Además, reafirmando la conclusión anterior, las fuentes de ingresos son muy relevantes en explicar la fecundidad fuera del matrimonio: mujeres sin pareja estable pasan a aumentar su demanda por hijos al tener mayores fuentes de ingresos. 


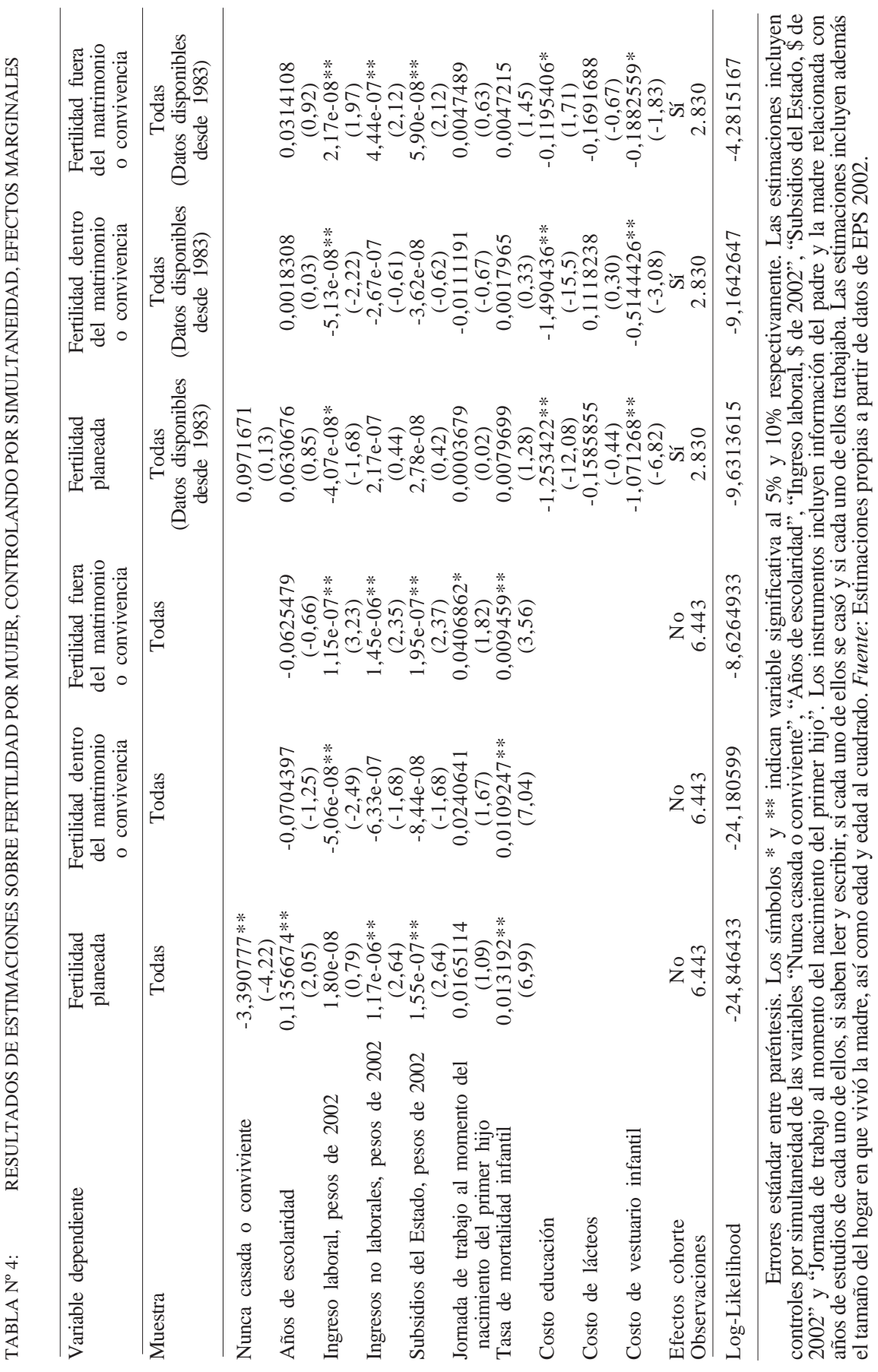




\section{6.b. Intervalos entre nacimientos}

En las estimaciones anteriores nos hemos centrado en los determinantes del número de hijos por mujer a lo largo de su ciclo de vida. Una estrategia empírica alternativa es analizar el intervalo entre nacimientos. Esto es lo que se conoce como un análisis de duración, en este caso de la duración del tiempo que transcurre entre los nacimientos de los hijos.

Siguiendo la contribución de Newman y McCulloch (1984), se procederá a estimar modelos Cox proporcionales que buscan explicar el momento de los nacimientos durante el ciclo de vida fértil de las mujeres. Es decir, en el análisis se buscará explicar la tasa a la que ocurren los nacimientos, una vez que hayan pasado $t>0$ períodos —esto es lo que se conoce como hazard rate en la literatura empírica de modelos de duración. Aplicaciones adicionales de esta técnica para el caso de fecundidad se pueden encontrar en Adsera (2004 y 2005).

Realizar este tipo de análisis es interesante porque el análisis de modelos del tipo Poisson nos indicaba sólo los impactos de las variables socioeconómicas e institucionales sobre el número de hijos por mujer. Sin embargo no debemos perder de vista que la evidencia encontrada no nos entrega información sobre las razones por las que las mujeres eventualmente retrasan sus decisiones de fecundidad. Al hacer el análisis de duración en esta sección podremos tratar de explicar las razones que retrasan o adelantan las decisiones de tener hijos.

La idea es modelar la probabilidad de ocurrencia del evento en un período $t$ determinado. Formalmente, para mujeres que se indexan por $i$ donde $i=1,2$, .,I, la probabilidad de ocurrencia del nacimiento en el período $t$ es:

$$
f_{i t}=\lambda_{i t} \prod_{k=1}^{t-1}\left(1-\lambda_{i k}\right)
$$

Donde $\lambda_{i t}$ es la tasa a la que ocurren los nacimientos en el caso de la mujer $i$. Siguiendo el modelo Cox proporcional, se asume que esta tasa de transición tiene la siguiente forma:

$$
\lambda_{i t}=\lambda_{0}(t) \exp \left(X_{i t}^{\prime} \beta\right)
$$

Donde $\lambda_{0}(t)$ es la función de transición base (es decir cuántas mujeres tendrían su primer hijo en ausencia de otras variables explicativas) y las variables $X_{i t}$ representan el conjunto de variables explicativas que se utilizaron en los modelos del tipo Poisson estimados con anterioridad. 
Se estimarán estas funciones de transición para los cuatro primeros nacimientos por mujer ocupando modelos Cox-proporcionales. Antes de presentar los resultados de las estimaciones, resulta interesante graficar las funciones de sobrevivencia para distintos nacimientos. Estas funciones se pueden observar en los Gráficos Nos 9 a 12. El Gráfico No 9 corresponde a la transición al primer hijo (nacimiento). Se muestran curvas para mujeres en matrimonio y/o convivencia versus mujeres sin matrimonio y/o convivencia. En este caso, cada curva indica la fracción de mujeres que después de una cierta cantidad de tiempo se mantienen sin tener su primer hijo. El momento inicial son los 14 años de edad para cada mujer, por lo que, por ejemplo, en el gráfico la edad 20 representa mujeres de 34 años. Como puede observarse en ese gráfico, la curva correspondiente a mujeres sin matrimonio y/o convivencia se mantiene por encima de la curva de mujeres en matrimonio y/o convivencia durante todo el horizonte de tiempo. Esto indica que para cada edad, las mujeres sin matrimonio y/o convivencia son menos proclives a transitar hacia el nacimiento del primer hijo.

Más aún, nótese que la curva de las mujeres sin matrimonio y/o convivencia converge en $25 \%$, lo que indica que cerca del $25 \%$ de esas mujeres no tendrá jamás un primer hijo, mientras que la curva de mujeres en matrimonio y/o convivencia converge en cifras cercanas al 3\%.

El Gráfico $N^{\circ} 10$ muestra un ejercicio similar, pero para el caso del tránsito al segundo hijo. En este caso lo que se mide es cuánto se demoran las mujeres en tener un segundo hijo, si con anterioridad tuvieron un primer hijo. Las diferencias entre mujeres en convivencia y/o matrimonio versus mujeres sin convivencia y/o matrimonio son mucho más acentuadas que en el caso anterior. De hecho, las mujeres en ausencia de relación formal convergen cerca de un 70\%, indicando que de las mujeres sin matrimonio y/o convivencia que tuvieron un hijo, cerca del 70\% no tendrá un segundo hijo. Los Gráficos Nos 11 y 12 muestran este mismo análisis para el caso del tercer y cuarto hijo. Si bien las diferencias entre grupos de mujeres se mantienen, éstas dejan de ser tan acentuadas. Por lo tanto, parece haber diferencias entre grupos siendo las mujeres en relación formal más proclives a no retrasar sus decisiones de natalidad. Esta conclusión se observa sobre todo en el caso del segundo hijo.

No debe perderse de vista, sin embargo, que los gráficos anteriores representan simples correlaciones. Para obtener resultados más confiables se procede a realizar el análisis de duración. Los resultados de las estimaciones pueden verse en las Tablas $\mathrm{N}^{\text {os }} 5$ a 7, en las que se presentan dos tipos de estimaciones: (a) sin utilizar y (b) utilizando instrumentos para las potenciales variables endógenas — tal como en el caso de los modelos de tipo 
GRÁFICO No 9: $\quad$ TRANSICIÓN AL PRIMER HIJO

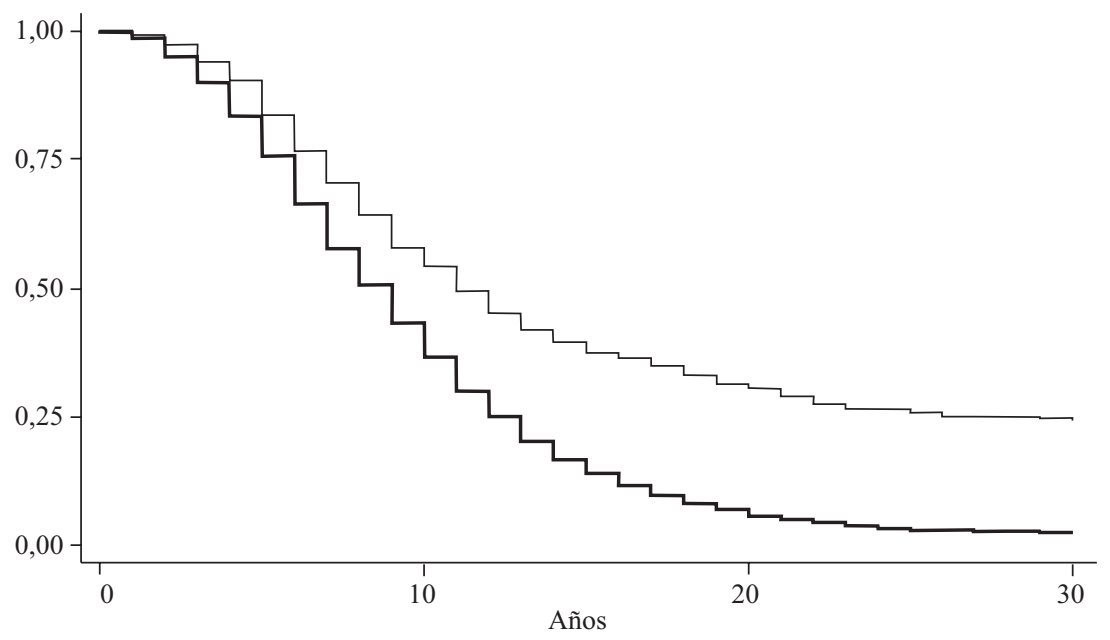

- Con matrimonio o convivencia - Sin matrimonio o convivencia

Fuente: Cálculos propios a partir de EPS 2002.

GRÁFICO No 10: TRANSICIÓN AL SEGUNDO HIJO

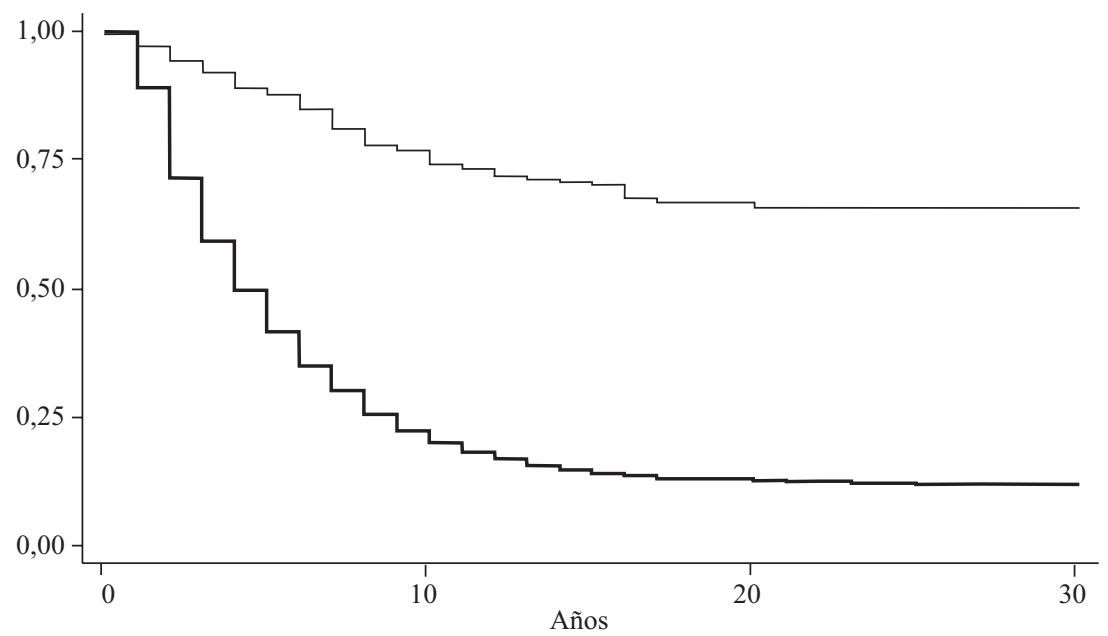

Con matrimonio o convivencia - Sin matrimonio o convivencia

Fuente: Cálculos propios a partir de EPS 2002.: 
GRÁFICO N 11: TRANSICIÓN AL TERCER HIJO

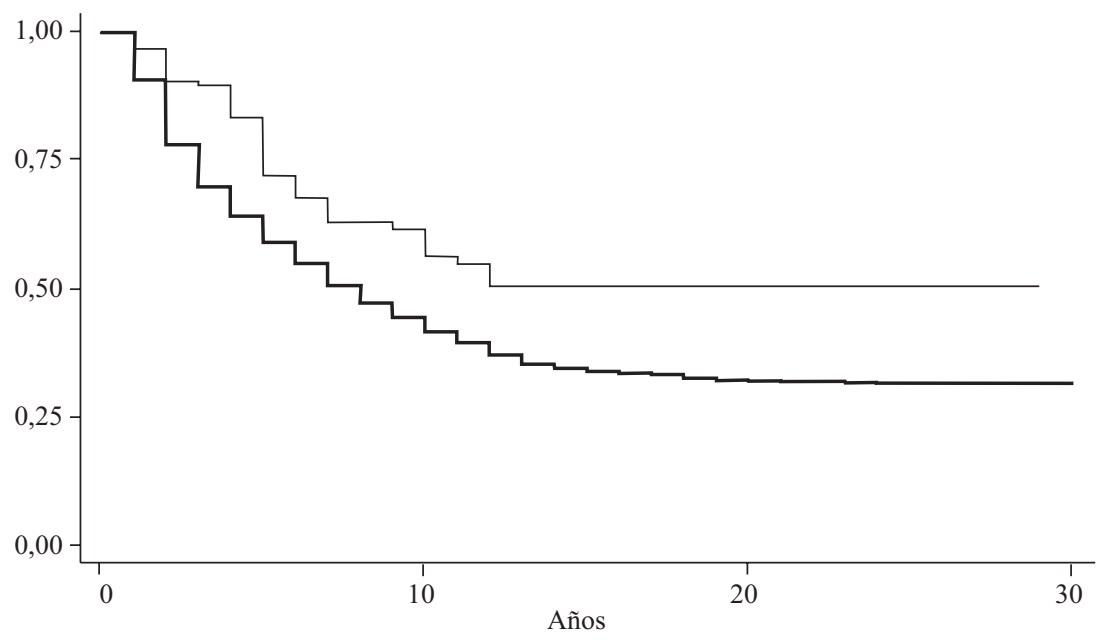

- Con matrimonio o convivencia - Sin matrimonio o convivencia

Fuente: Cálculos propios a partir de EPS 2002.

GRÁFICO No 12: $\quad$ TRANSICIÓN AL CUARTO HIJO

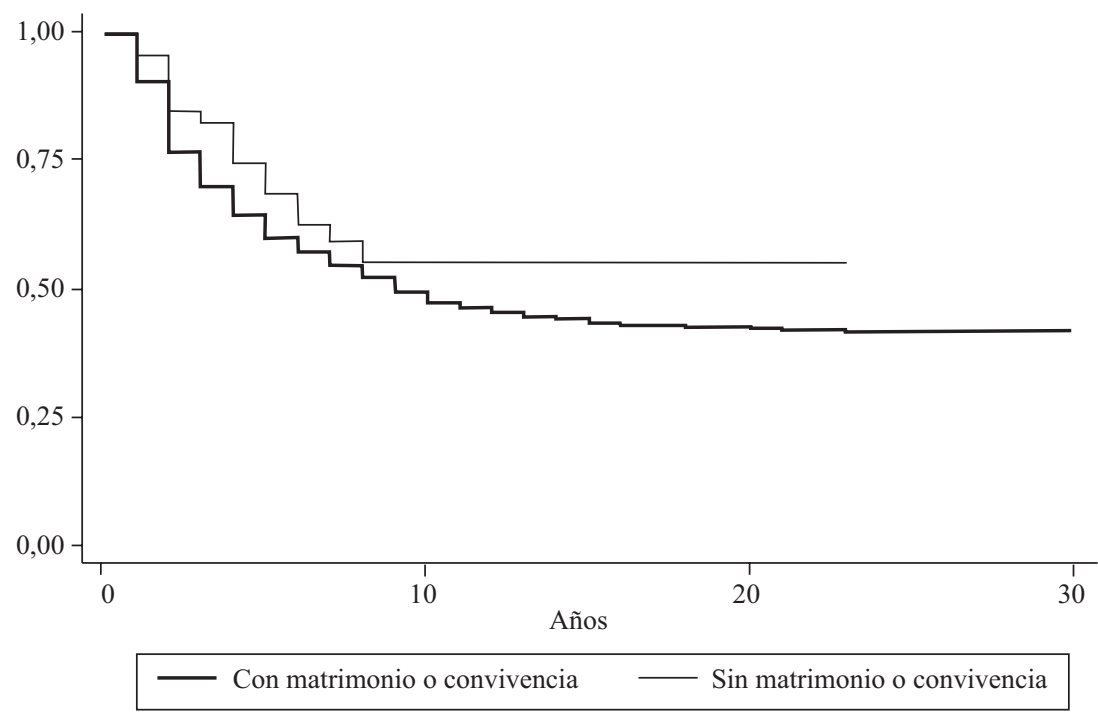

Fuente: Cálculos propios a partir de EPS 2002. 


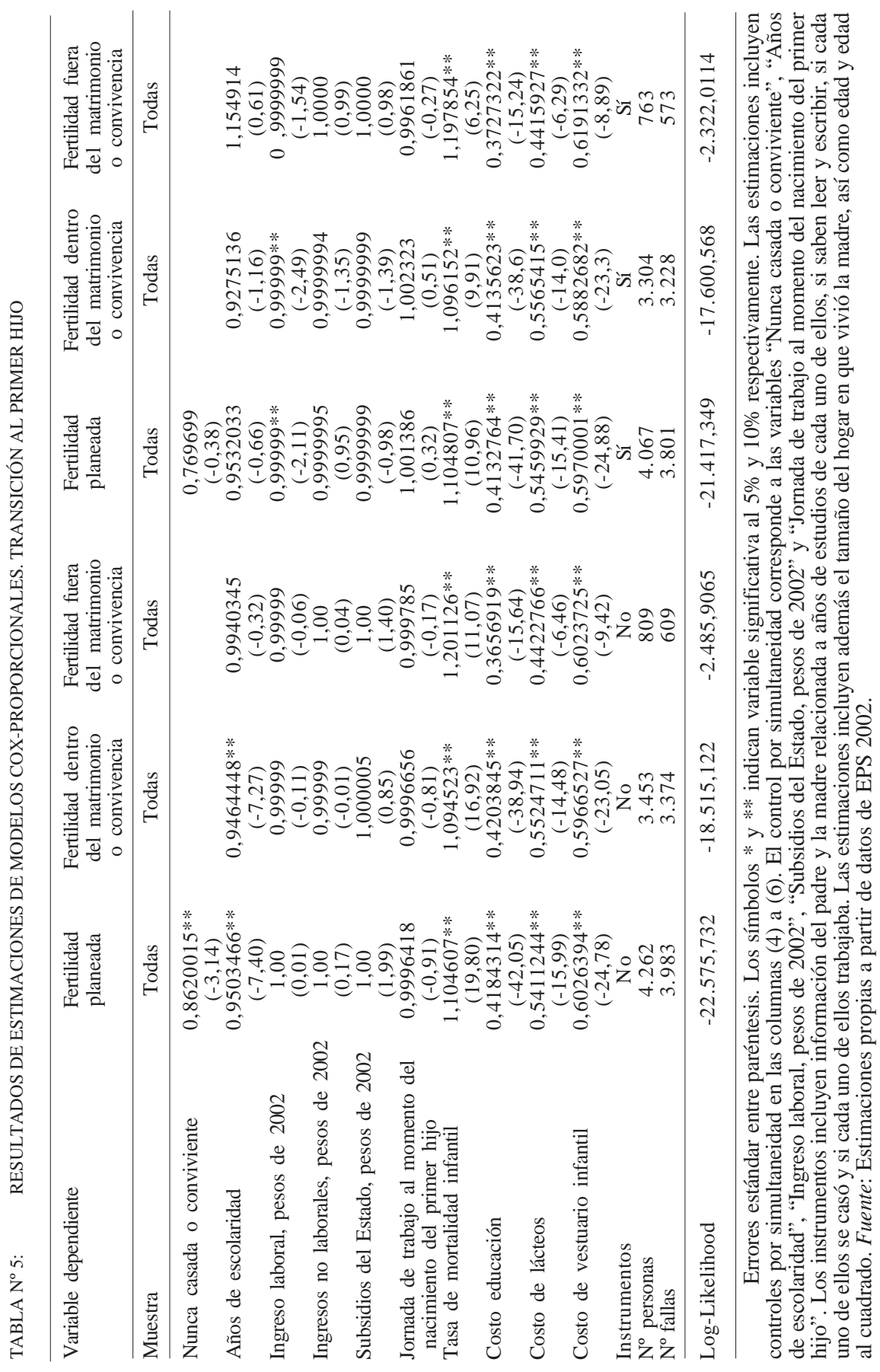




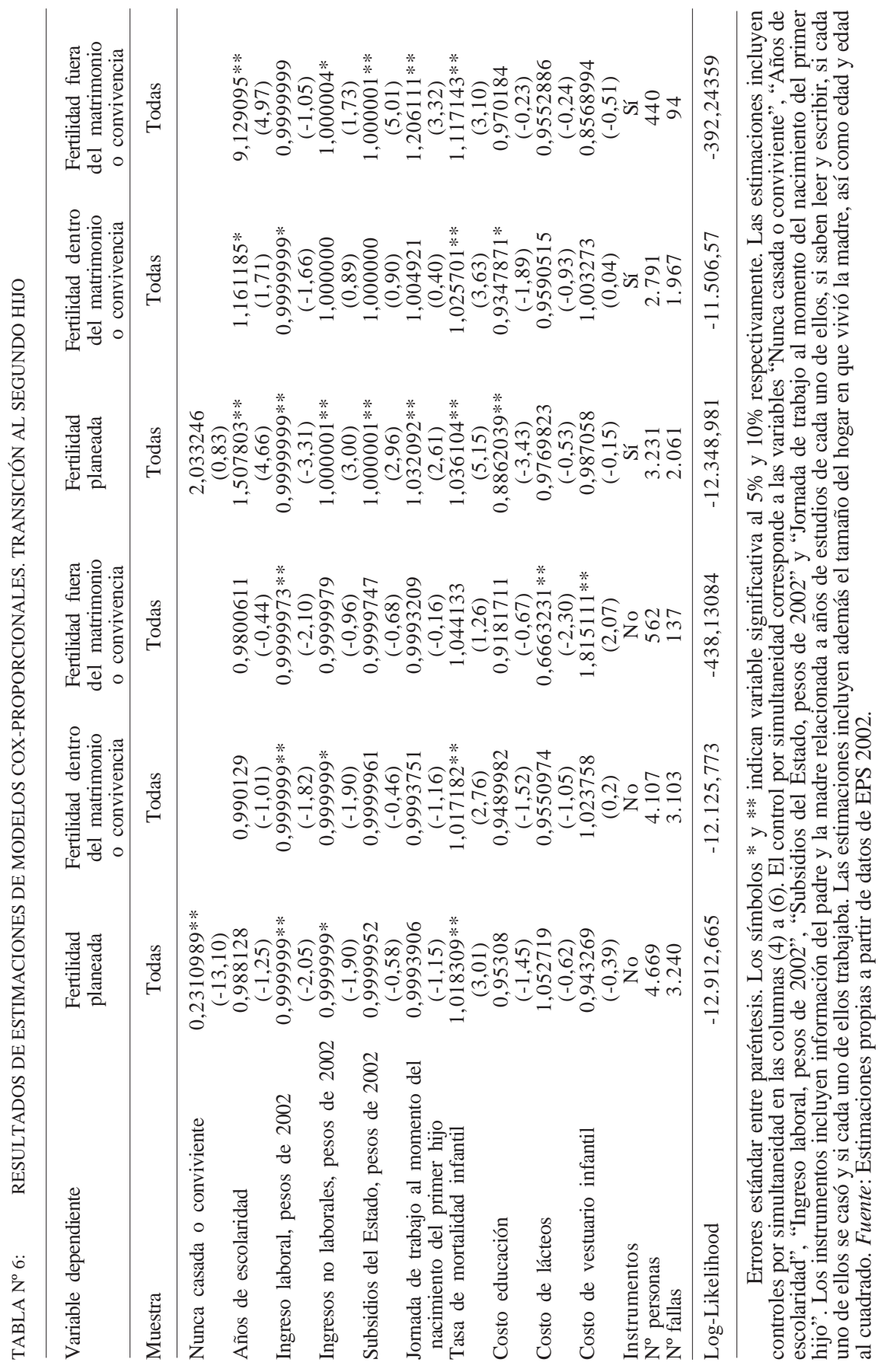




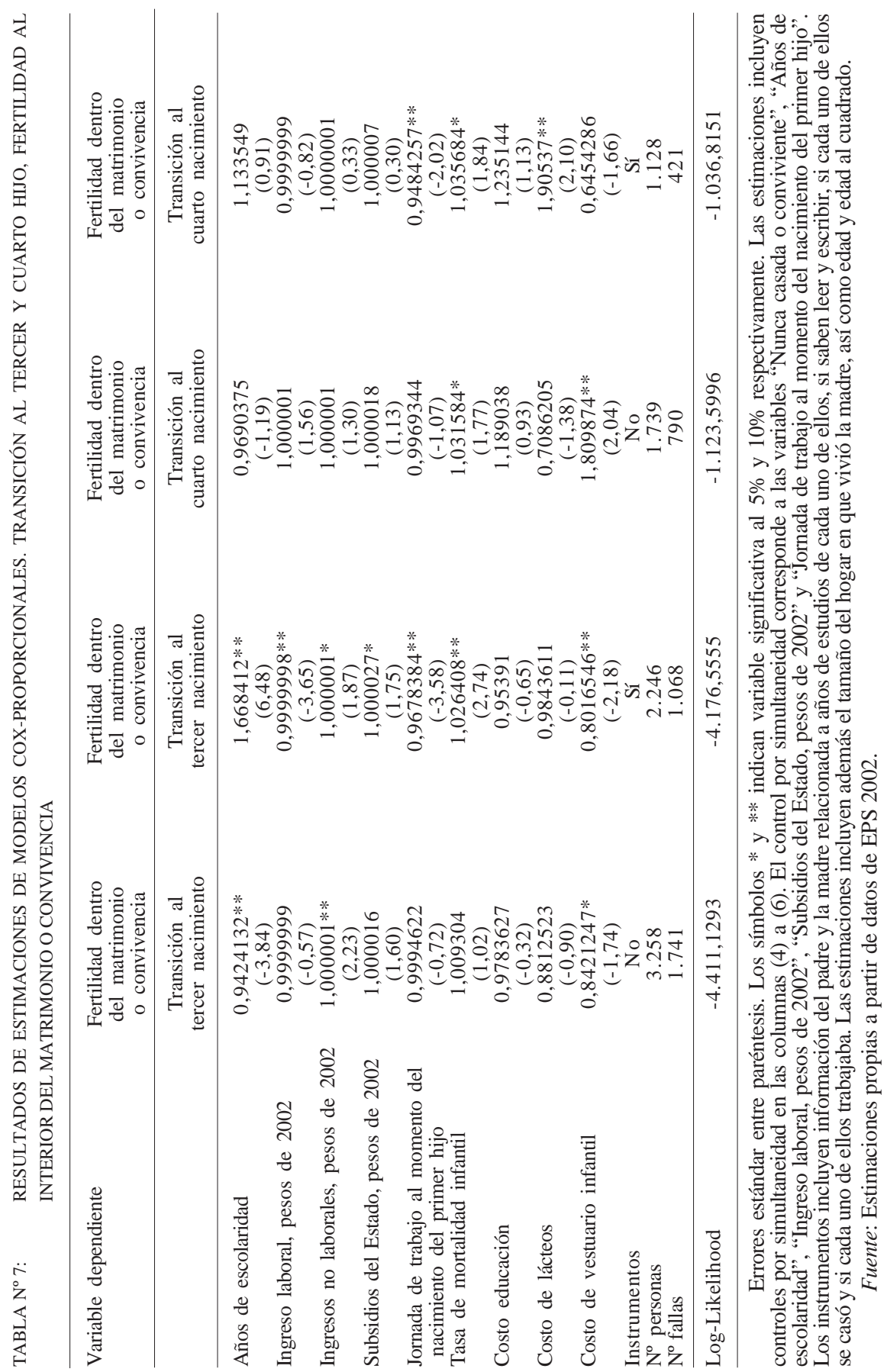


Poisson. Las estimaciones se entregan de acuerdo a los impactos sobre la función de transición base, por lo que coeficientes menores que uno indican un impacto proporcional negativo sobre la función de transición, mientras que coeficientes mayores que uno indican impactos proporcionales positivos sobre la función de transición. En otras palabras, un coeficiente menor que uno indica un impacto negativo sobre la probabilidad de observarse un próximo nacimiento, mientras que un coeficiente mayor que uno indica un impacto positivo sobre esta probabilidad.

La Tabla $\mathrm{N}^{\circ} 5$ entrega las estimaciones para el caso de transiciones al primer nacimiento. Los resultados de esta tabla muestran que no existe diferencia significativa entre las estimaciones de los casos dentro y fuera del matrimonio y/o convivencia. De hecho en ambos casos la transición al primer hijo está negativamente influenciada por los precios relativos y positivamente influenciada por la tasa de mortalidad infantil, por lo tanto mayores tasas de mortalidad adelantan la transición al primer nacimiento, mientras que mayores precios relativos la retrasan.

La Tabla $N^{\circ} 6$ muestra similares estimaciones pero para las transiciones al segundo nacimiento. En este caso, hay claras diferencias. Si bien las tasas de mortalidad infantil siguen siendo relevantes, en este caso el costo de la educación es relevante sólo para las mujeres en convivencia formal, mientras que lo que determina la transición al segundo hijo en el caso de las mujeres fuera del matrimonio y/o convivencia son los ingresos. De hecho, mientras mayores son las fuentes de ingresos, más se adelanta la transición al segundo nacimiento. Similar conclusión aparece con años de escolaridad, que es una medida de ingreso permanente, y con jornada de trabajo. Finalmente la Tabla $\mathrm{N}^{\circ} 7$ presenta las estimaciones concernientes a las transiciones al tercer y cuarto nacimiento. Se presentan estimaciones sólo con mujeres en matrimonio y/o convivencia porque el conjunto de mujeres fuera de matrimonio y/o convivencia con tres o cuatro hijos es muy pequeño en esta muestra. En estos casos, los ingresos laborales hacen disminuir la probabilidad de transición al tercer o cuarto hijo posiblemente por el aumento en el costo de oportunidad del tiempo de estas mujeres; sin embargo otras fuentes de ingresos no relacionadas con el trabajo aumentan las probabilidades de tener un nuevo hijo, mostrando un efecto ingreso sobre tasa de natalidad.

\subsection{Discusión}

A continuación discutiremos las implicancias de nuestros resultados. Nótese que en nuestros resultados se pueden diferenciar las decisiones de natalidad al interior de los matrimonios o convivencias versus fuera 
del matrimonio o convivencia. Lamentablemente, en nuestros datos no podemos distinguir entre matrimonios y convivencias, que sería otra categoría interesante de analizar, por lo que nuestro análisis se centra en la categoría de matrimonio o convivencia.

En general, los resultados muestran que el matrimonio o convivencia parece tener algún impacto positivo sobre el número de hijos deseados —entre 0,6 y 1,1 hijos por mujer. Sin perjuicio de aquello parece importante diferenciar entre comportamientos de mujeres en matrimonios o convivencias versus mujeres sin matrimonio o convivencia. Esto resulta útil porque, como lo muestra la Tabla $\mathrm{N}^{\circ}$ 8, existen divergencias significativas en las decisiones de fecundidad de estos dos grupos de mujeres. Este cuadro muestra las decisiones de cuatro grupos etarios de mujeres. Como puede verse, las mujeres sin matrimonio o convivencia tienen fecundidad promedio bastante estable a través del tiempo —esto es, aproximadamente 0,5 hijos. Contrariamente, las mujeres con algún tipo de relación estable, sea matrimonio o convivencia, tienen tasas de fecundidad declinantes a través del tiempo. En el caso de mujeres con un matrimonio o convivencia, el promedio de hijos cae desde casi cuatro — mujeres de 55 años o más- a algo menos de dos hijos en promedio - mujeres de 26 a 35 años. En el caso de mujeres con dos o más matrimonios o convivencias, los resultados son similares. De esta forma, la disminución en la tasa de natalidad se explicaría mayormente por la disminución en la natalidad de mujeres en convivencia o matrimonio (hecho también descrito en la secciones 3.1 y 3.2 de este trabajo).

TABLA N ${ }^{\circ}$ 8: $\quad$ FERTILIDAD PROMEDIO, MUJERES DE DISTINTOS GRUPOS DE EDAD EN 2002, Y CON DISTINTOS PATRONES DE MATRIMONIOS O CONVIVENCIAS

\begin{tabular}{lcccc}
\hline Edad & $\begin{array}{c}\text { Sin matrimonio } \\
\text { convivencia }\end{array}$ & $\begin{array}{c}\text { Con } 1 \text { matrimonio } \\
\text { convivencia }\end{array}$ & $\begin{array}{c}\text { Con 2 o más } \\
\text { matrimonios } \\
\text { o } \\
\text { convivencias }\end{array}$ & $\begin{array}{c}\text { Fracción de mujeres } \\
\text { sin convivencia } \\
\text { o matrimonio }\end{array}$ \\
\hline 26 a 35 & 0,52 & 1,77 & 2,48 & $27,9 \%$ \\
36 a 45 & 0,81 & 2,43 & 3,02 & $15,99 \%$ \\
46 a 55 & 0,72 & 2,67 & 3,46 & $14,51 \%$ \\
56 o más & 0,55 & 3,87 & 4,22 & $15,39 \%$ \\
Todas las mujeres & 0,53 & 2,61 & 3,34 & $22,85 \%$ \\
\hline
\end{tabular}

Fuente: Cálculos propios a partir de EPS 2002. 
Nuestros resultados sirven para explicar los fundamentos de los cambios en natalidad de las mujeres casadas o en convivencia. Los resultados más importantes son los siguientes. En primer lugar, los cambios en tasas de mortalidad infantil parecen altamente relevantes para explicar el comportamiento en la tasa de natalidad. La tasa de mortalidad infantil se redujo desde 74 por mil nacidos vivos a cerca de 19 por mil en 1985. De acuerdo a nuestros resultados, este cambio en las tasas de mortalidad infantil explicaría una caída promedio de cerca de 0,81 hijos por mujer en matrimonio o convivencia. En segundo lugar, los costos de criar hijos, fundamentalmente el aumento en los costos educacionales, son el principal determinante de la disminución en las tasas de fecundidad al interior del matrimonio o convivencia. Los aumentos de costos educacionales experimentados entre 1983 y 2002 explican la disminución de algo más de un hijo por mujer en matrimonio o convivencia. Más aún, el análisis de intervalos entre nacimientos muestra que los aumentos en costos educacionales han pospuesto principalmente el nacimiento del primer hijo, lo que indicaría que para los padres el tema presupuestario es muy importante y se preparan (posiblemente posponiendo el momento de tener el primer hijo para en el intertanto mejorar las condiciones económicas familiares) para enfrentar los costos de criar a sus hijos. En tercer lugar, los aumentos en educación de las mujeres al interior del matrimonio y/o convivencia tienen alguna influencia en la disminución de fecundidad, pero estos efectos parecen ser bastantes menores para los efectos de los aumentos en costos de criar a los hijos. Finalmente, el resto de las variables no es muy relevante.

En relación con las mujeres fuera del matrimonio o convivencia, sus aumentos en ingresos (sean laborales o de otro tipo) les habrían permitido aumentar sus demandas por hijos, aunque los aumentos en precios de costos de formación de los hijos, tal como en el caso de las mujeres en matrimonio o convivencia, habrían actuado en la dirección inversa, lo que finalmente lleva al resultado de cambios menores en tasas de fecundidad de mujeres fuera del matrimonio y/o convivencia.

En síntesis, las primeras disminuciones en tasas de natalidad posiblemente estuvieron muy influidas por las caídas en tasas de mortalidad infantil. Con posterioridad, es decir desde mediados de los ochenta, variables como aumentos en niveles educacionales de las mujeres y principalmente el costo de criar a nuestros hijos parecen haber sido fuente importante de las disminuciones en fecundidad al interior del matrimonio y/ o convivencia.

Estos resultados son consistentes con evidencia reciente de encuestas. Al respecto, diríjase el lector al "Estudio de Calidad de Educación y 
Baja en Natalidad” elaborado por el Centro de Políticas Públicas de la Universidad del Desarrollo (2007). De hecho, esta última fuente de datos indica que el costo de la educación de calidad y la escasez de tiempo son los dos factores de la disminución en tasas de fecundidad.

Antes de terminar esta sección, debe indicarse al lector que en nuestras estimaciones no se ha incluido como control el uso de métodos anticonceptivos. La omisión de esta variable podría ser captada en parte por alguna de las otras variables que incluimos, lo que puede estar sobremagnificando el impacto de nuestras variables en cuestión.

\section{4. ¿Qué podemos esperar para el futuro?}

Una vez discutidas las posibles fuentes de la disminución de la tasa de natalidad de nuestro país, es conveniente discutir las posibles implicancias futuras para nuestro país. ¿Qué tipo de impactos económicos y sociales pueden producir estos cambios demográficos? Deberíamos esperar múltiples efectos. A continuación se abordarán algunos de los efectos más importantes.

\subsection{Antecedentes sobre la evolución futura de la demografía}

Los cambios demográficos se traducirán finalmente en una clara desaceleración de la tasa de crecimiento de la población. De hecho, mientras la población crecía en promedio entre 1950 y 1975 cerca del 2,2\% por año y 1,6\% entre 1975 y 2000, se espera una tasa de crecimiento anual promedio de $0,9 \%$ durante el período $2000-2025$ y de 0,2\% anual para el período 20252050. Esto se traduce en que la población de Chile se proyecta en cerca de 19 millones en el año 2025 y en aproximadamente 20 millones en el 2050, es decir, una población prácticamente estancada en el 2050.

Este tipo de cálculos se basa en una baja tasa de natalidad junto a bajas tasas de mortalidad, que finalmente redundan en un bajo crecimiento poblacional, como se discutía en la sección de fases de transición demográfica. Queda a esta altura la incógnita acerca de cómo se afectarían estos cálculos al considerar posibles migraciones de otros países hacia Chile. Este tipo de consideraciones parece válido. En el ambiente existe la idea de que la migración a Chile parece haber aumentado considerablemente en los últimos años, y algo de esto muestran los datos. De hecho, las visas otorgadas a ciudadanos extranjeros entre los años 1984 y 2002 aumentaron casi en $600 \%$. La cantidad de residentes extranjeros en Chile es aún bastante baja 
(cerca de 1,2\% de la población total de acuerdo al censo del 2002) y lejana del histórico 4\% alcanzada a principios del siglo 20, lo que sugeriría algún posible aumento adicional en la población por el lado de la migración. Sin embargo, incluso en el caso en que se volviera a los altos niveles de inmigración observados en el censo de 1907, esto significaría un ajuste en el stock de extranjeros totales que en un horizonte de 50 años, como el que consideramos en el análisis, no necesariamente afecta los crecimientos (flujos) anuales de población. Desde ese punto de vista, el fenómeno de migración no debería cambiar mayormente las predicciones de largo plazo.

En segundo lugar, y tal como ya se mencionó, existe un cambio importante en la pirámide de población y en el número de personas en ciertos grupos de edad (ver Tabla $N^{0} 1$ ). En el año 2000, el grupo de jóvenes entre 5 y 19 años de edad representaba cerca del 28\% de la población con 4,3 millones de individuos. Para los años 2025 y 2050 este grupo sumaría sólo 3,7 y 3,4 millones de individuos respectivamente, lo que representa casi el $20 \%$ y $17 \%$ de la población en cada uno de estos años. Esta disminución en el tamaño de la población joven contrasta con la evolución de la población de mayor edad. Los mayores de 60 años en el 2000 eran cerca de 1,5 millones (10\% de la población), pero se proyecta que este grupo pase a tener 3,8 millones en el 2025 (20\% de población) y 5,7 millones en el 2050 (28\% de población), es decir, cerca de 3,5 veces su tamaño en 2000.

\section{Crecimiento potencial}

A continuación analizaremos los posibles impactos. Por el momento, partiremos poniendo el énfasis en los impactos sobre crecimiento de la economía. Partimos por este punto porque determina las posibilidades generales de consumo y bienestar de las personas de nuestro país en el futuro. Existen bastantes estudios a nivel internacional sobre los impactos de los cambios demográficos sobre crecimiento económico y mercado laboral. En general, los estudios muestran que las variables demográficas —esto es, crecimiento poblacional, tasas de fecundidad, tasas de mortalidad- no tienen un impacto directo sobre el crecimiento potencial de la economía. Esto es lo que se conoce como la "visión neutral” el impacto demográfico sobre crecimiento económico (Ahlburg, 2002, y Kelley, 1988).

Sin embargo, una visión alternativa más reciente pone énfasis en efectos indirectos de la transición demográfica. Estos efectos indirectos se relacionan con el hecho de que al iniciarse una transición demográfica se produce un cambio en la pirámide de edad, y los cambios en esta pirámide sí pueden producir efectos sobre crecimiento futuro. 
La pirámide poblacional es importante en el crecimiento a través de dos mecanismos. En primer lugar, al ocurrir la transición demográfica cambia la importancia del grupo de jóvenes y adultos mayores con relación al grupo de adultos. Esto es importante porque el primer grupo se compone de personas que están fuera de la fuerza de trabajo, mientras que el segundo grupo, por el contrario, determina la fuerza de trabajo. De esta forma en la medida en que aumente la importancia del grupo de adultos en tercera edad y se reduzca la proporción de adultos de 15 a 65 años, se produce una reducción relativa en oferta de trabajo, lo que a su vez restringe las posibilidades de crecimiento del país en cuestión.

El segundo mecanismo es que el cambio en la pirámide de edades influye también sobre la capacidad de ahorro de la economía. Esto se debe a que típicamente los adultos mayores tienden a desacumular activos (desahorrar), mientras que las personas más jóvenes, participando en la fuerza de trabajo, son las que tienden a realizar más ahorro para enfrentar su posterior vejez. Al cambiar la pirámide poblacional, y tener una población con una mayor importancia de adultos en tercera edad, es por lo tanto bastante factible que se desacelere la capacidad de ahorro de la economía.

Por lo tanto, procesos demográficos que aumentan la importancia del grupo de adultos en tercera edad o de los jóvenes menores de 15 años, en desmedro de personas en edad de trabajar (15 a 65 años de edad), típicamente tienden a desacelerar las tasas de crecimiento de la economía, mientras que procesos inversos, es decir cuando tiende a aumentar la población en edad de trabajar (como puede haber sido en los años 60-70 en Estados

\section{GRÁFICO No 13: PROYECCIONES DE POBLACIÓN Y POBLACIÓN EN EDAD DE TRABAJAR}

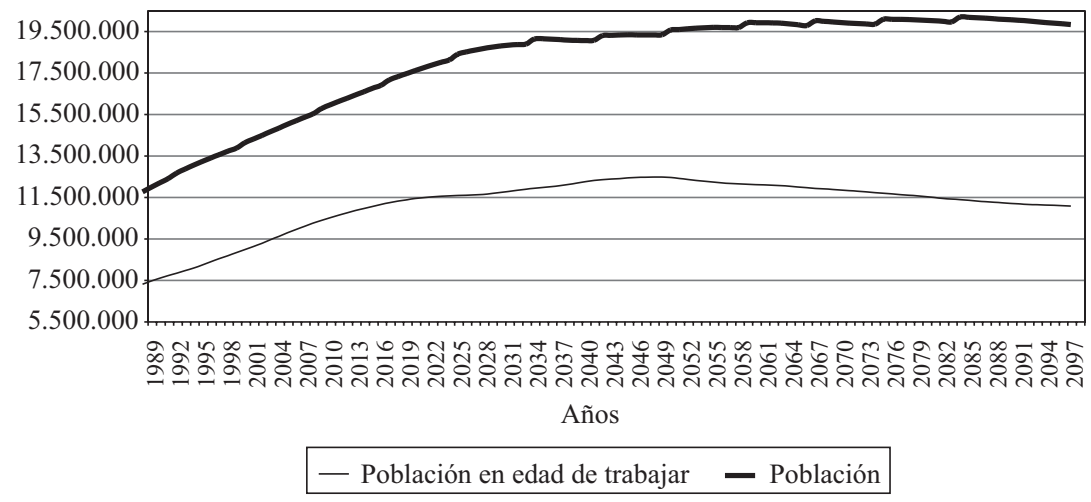

Fuente: Celade: Boletín Demográfico № 69. 
Unidos con la irrupción de los baby-boomers en la fuerza de trabajo), se tiende a acelerar la tasa de crecimiento de la economía.

¿Cuán importantes son estos efectos? Si bien existen ciertos estudios a nivel internacional que buscan responder estas preguntas (ver Kotlikoff, Smetters y Walliser, 2001, para el caso de Estados Unidos), no existen al respecto estudios referidos a Chile. Para tratar de responder, utilizaremos ejercicios de simulación para los impactos demográficos en el caso de Chile. En nuestras estimaciones se utiliza un modelo similar al desarrollado por Cerda (2007a). Éste es un modelo de simulación en el que interactúan personas, empresas y gobierno y que se resuelve siguiendo la metodología desarrollada por Auerbach y Kotlikoff (1987). Los parámetros de este modelo se ajustan a los datos de la economía chilena. El detalle del modelo se encuentra en el Apéndice 2. Dentro de los supuestos del modelo destaca una tasa de crecimiento exógena de la productividad de factores al 1\% anual, y crecimiento de niveles de capital humano (educación) de acuerdo a la tasa observada en la última década.

El modelo se alimenta con la evolución demográfica, que en este caso se puede observar en el Gráfico No 14 . A su vez, el Gráfico N ${ }^{\circ} 15$ complementa estos datos al mostrar que la participación de los jóvenes (menores de 15 años) disminuye hasta estabilizarse en $28 \%$ en aproximadamente el año 2050, mientras que los adultos mayores aumentan sustancialmente su importancia relativa hasta alcanzar casi el 25\% de la población. Vale la pena notar que entre 2000 y 2020 se produce un aumento en la población con edad para trabajar. Algo similar ocurre con posterioridad entre 2040 y 2050. Éstos son "bonos demográficos”, que consisten en que la transición demográfica produce inicialmente una disminución en la población joven, lo que lleva a aumentar la población en edad de trabajar. El primero de los bonos demográficos ocurre efectivamente debido a la disminución en tasas de natalidad de los 80 y 90, que llevan a “inflar” la fracción de la población con edad para trabajar. El segundo bono demográfico ocurre en la cercanía del año 2040. Este segundo aumento en población con edad para trabajar ocurre debido a la misma razón del anterior: las disminuciones en tasas de natalidad de los 80 y 90 producen una disminución en el crecimiento de adultos en tercera edad en la cercanía de 2040.

¿Cuáles son los impactos? El Gráfico Nº 15 muestra la evolución de la tasa de crecimiento del PIB y del PIB per cápita en los próximos 100 años. Las simulaciones muestran tasas de crecimiento relativamente altas en la cercanía del año 2000, para converger a una tasa de crecimiento del 4\% 
GRÁFICO No 14: PROYECCIONES DE POBLACIÓN JOVEN Y POBLACIÓN DE TERCERA EDAD, COMO PROPORCIÓN DE POBLACIÓN TOTAL

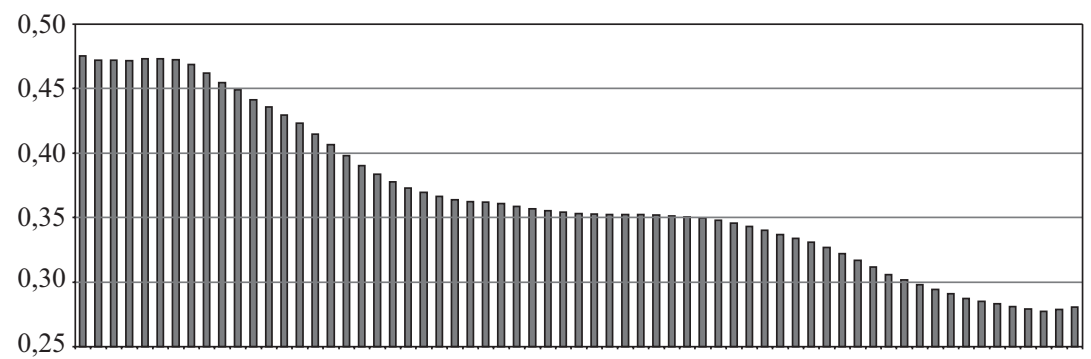

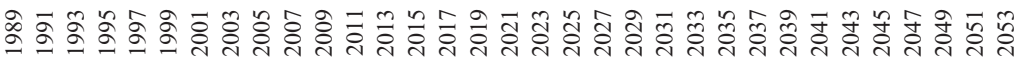
Años

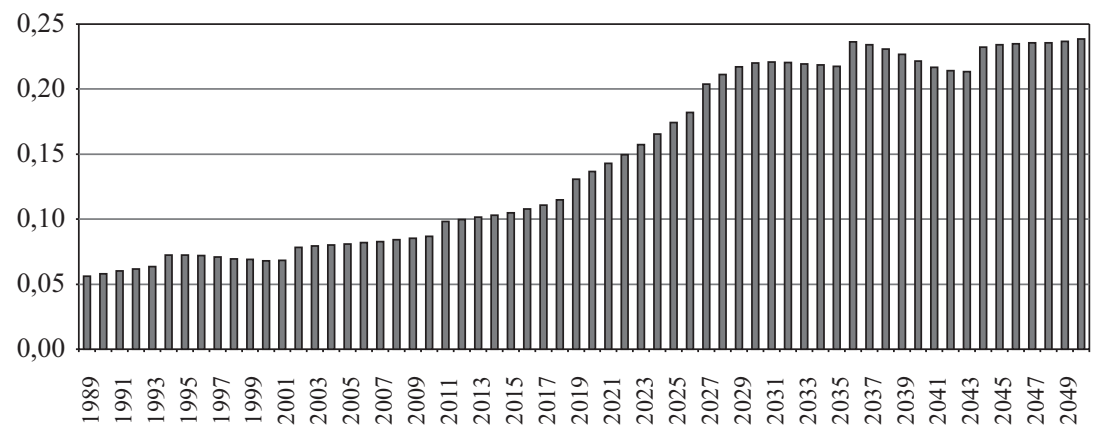

Años

Fuente: Celade: Boletín Demográfico № 69.

anual entre 2020 y 2040 y finalmente situarse en la proximidad del 3,5\% del 2050 en adelante. Esta última tasa corresponde al crecimiento de largo plazo de la economía cuyas fuentes son la productividad de factores y el crecimiento en capital humano, dado que la población permanece prácticamente constante en el largo plazo. Más interesante es la evolución del producto per cápita que muestra un aumento significativo entre 2020 y 2050. Este efecto ocurre debido al segundo bono demográfico que habíamos descrito con anterioridad, que impulsa las tasas de crecimiento sobre su nivel de largo plazo. En el largo plazo, la tasa de crecimiento del PIB per cápita es similar a la del PIB dado que la población tiende a permanecer constante.

De esta forma, estos resultados muestran que es bastante difícil volver a tasas de crecimiento de largo plazo cercanas al 6 o 7\% (incluso mayores que $5 \%$ ) porque la oferta laboral produce un cuello de botella importante 
GRÁFICO N N $^{\circ}$ 15: PROYECCIONES DE CRECIMIENTO DE PIB Y DE PIB PER CÁPITA

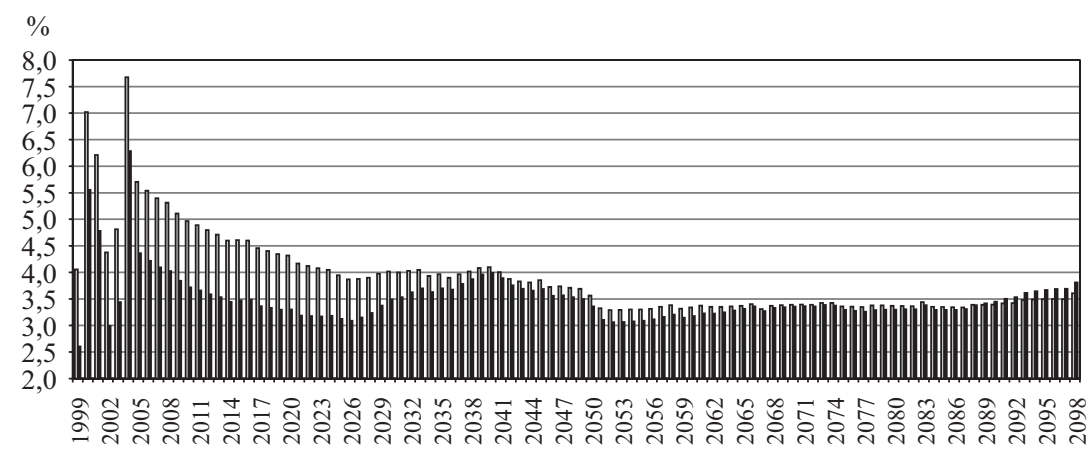

Años

$\square$ Crecimiento PIB $\square$ Crecimiento PIB per cápita

Fuente: Simulaciones propias.

en el crecimiento de largo plazo. Sin embargo, nótese que ese mismo escenario augura tasas de crecimiento para el PIB per cápita entre 3 y 4\%.

Los Gráficos Nos 16 y 17 muestran información adicional. Por un lado, los salarios crecen a tasas algo superiores al 1,5\%, lo que obedece a los aumentos en productividad de factores. La tasa de crecimiento de los salarios es algo mayor en la cercanía de 2040 debido nuevamente al advenimiento del segundo bono demográfico. La tasa de rentabilidad de la economía (que sigue la evolución del producto marginal del capital) disminuye debido a la acumulación de capital y converge en la cercanía del 5,5\% en el largo plazo. Tanto las disminuciones en la tasa de rentabilidad del capital como la disminución de la población con edad para trabajar producen una caída significativa en la tasa de ahorro, que era un resultado esperable de acuerdo a lo que habíamos indicado con anterioridad.

Finalmente el Gráfico Nº 18 muestra la evolución de la recaudación fiscal como fracción del PIB. Resulta interesante que la situación fiscal mejora en el horizonte de tiempo considerado. La razón principal es que aumenta la recaudación por el lado del consumo, es decir a través del IVA. Esto se debe a que como disminuye la tasa de ahorro, aumenta el gasto en consumo como fracción del PIB, y se aumenta la recaudación por medio de este concepto.

Para ahondar más en el análisis de las consecuencias económicas de la transición demográfica se procede a continuación a comparar tres escenarios que difieren en la tasa de natalidad de Chile. Los casos que se analizan 
GRÁFICO N ${ }^{\circ}$ 16: PROYECCIONES DE CRECIMIENTO DE SALARIOS Y TASA DE RENTABILIDAD DEL CAPITAL

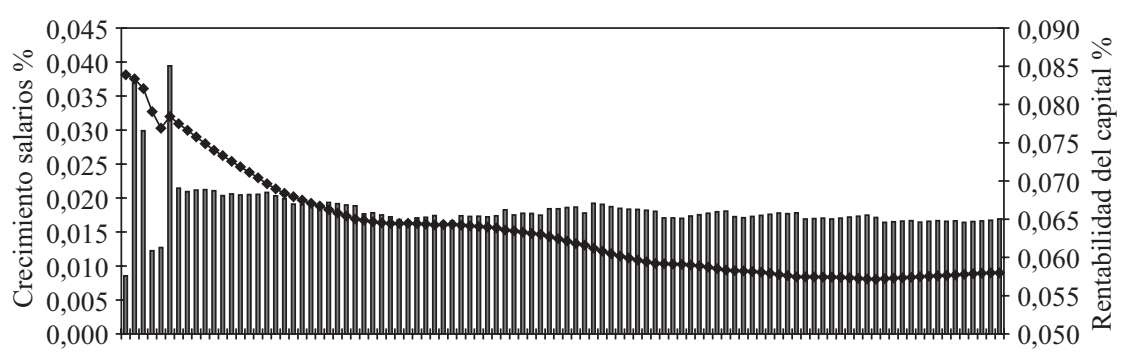

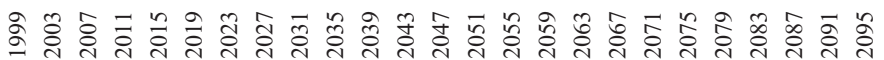

\section{$\square$ Crecimiento salarios $\rightarrow$ Rentabilidad}

Fuente: Simulaciones propias.

GRÁFICO No 17: PROYECCIÓN DE LA EVOLUCIÓN DE LA TASA DE AHORRO

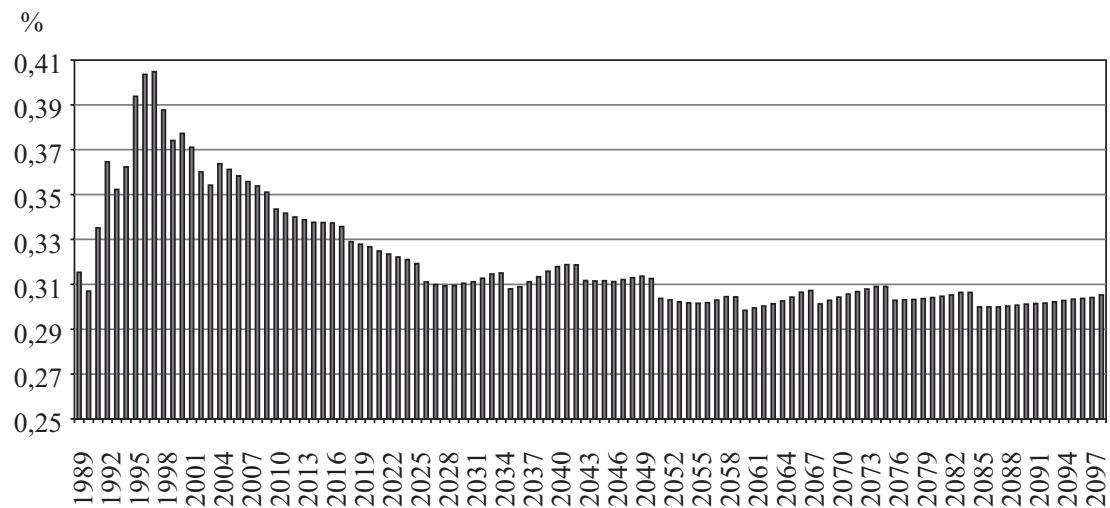

Años

Fuente: Simulaciones propias.

son los siguientes: (1) tasa de natalidad al 1,8\%, (2) tasa de natalidad al $1,0 \%$ y (3) tasa de natalidad al 2,5\%, todas cifras anuales. La tasa de natalidad de $1,8 \%$ es similar a las actuales tasas de natalidad, mientras que la tasa de $2,5 \%$ es similar a las tasas observadas en el quinquenio 1975-1980. El caso de tasa de natalidad de $1 \%$ es un escenario más restrictivo en términos de crecimiento poblacional, y corresponde a las proyecciones de natalidad de INE-Celade para el quinquenio 2045-2050, cuando el crecimiento pobla- 


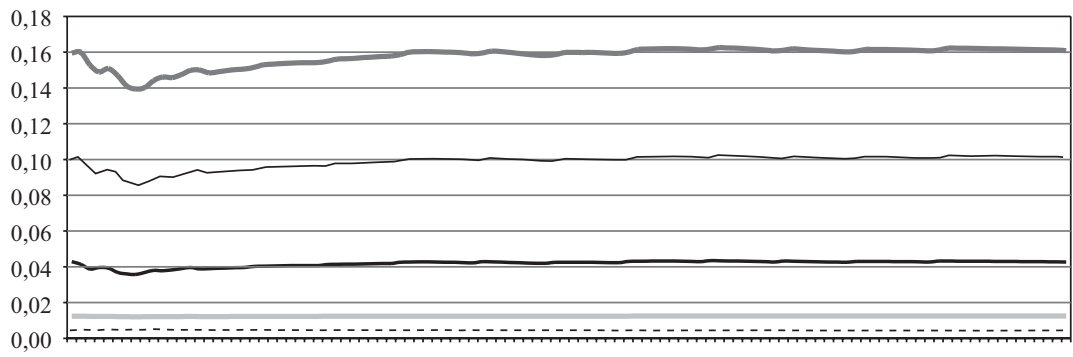

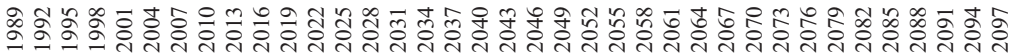

Años

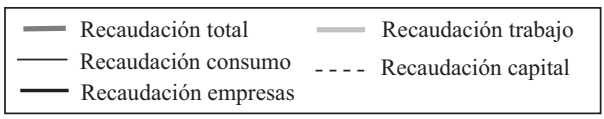

Fuente: Simulaciones propias.

cional tiende a estancarse. En nuestros ejercicios, la tasa de natalidad de 1,8\% se entenderá como caso 1, mientras que la tasa de 1,0\% será el caso 2 y la tasa de natalidad de 2,5\% será el caso 3.

Los Gráficos N N 19 y 20 muestran la evolución de las tasas de crecimiento del PIB y del PIB per cápita para los tres escenarios. En el caso de mayores tasas de natalidad, el PIB alcanza tasas de crecimiento considerablemente más altas que en los otros casos. En el caso de tasas de natalidad de sólo 1,0\%, el PIB muestra tasas de crecimiento considerablemente más bajas, pero nótese que nuevamente existe un aumento significativo en tasas de crecimiento en la cercanía de 2060. Esto se debe a que en este momento ocurre un nuevo bono demográfico debido a la disminución en las tasas de crecimiento poblacional, lo que lleva a una caída en la fracción de personas en tercera edad en esa fecha y a un aumento en la fracción de la población con edad para trabajar.

De estos ejercicios debe quedar claro que tasas de crecimiento poblacional menores producen menores tasas de crecimiento del PIB, sin embargo pueden provocar un efecto positivo de corto plazo debido a los bonos demográficos que, para el caso de Chile, pueden ser altamente relevantes en los próximos 45 años, si se cumplen las proyecciones de población.

Finalmente, el Gráfico No 21 muestra las diferencias en crecimiento de salarios. El escenario de menores tasas de natalidad muestra salarios mayores (casi 3\% en el largo plazo) que el caso de natalidad al 1,8\%, mientras que 
GRÁFICO N ${ }^{\circ}$ 19: TASAS DE CRECIMIENTO DEL PIB BAJO DISTINTOS ESCENARIOS DE TASAS DE NATALIDAD

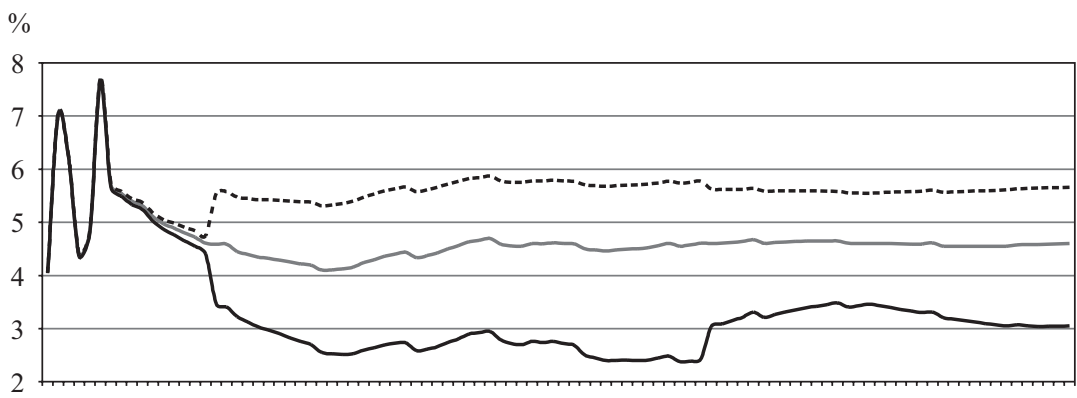

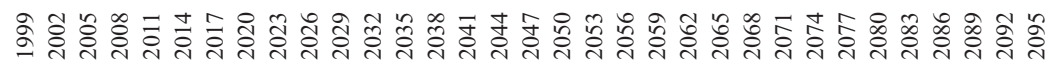

Años

$$
\text { - Caso } 1 \text { - Caso } 2 \text {-.. Caso } 3
$$

Fuente: Simulaciones propias.

GRÁFICO No 20: TASAS DE CRECIMIENTO DEL PIB PER CÁPITA BAJO DISTINTOS ESCENARIOS DE TASAS DE NATALIDAD

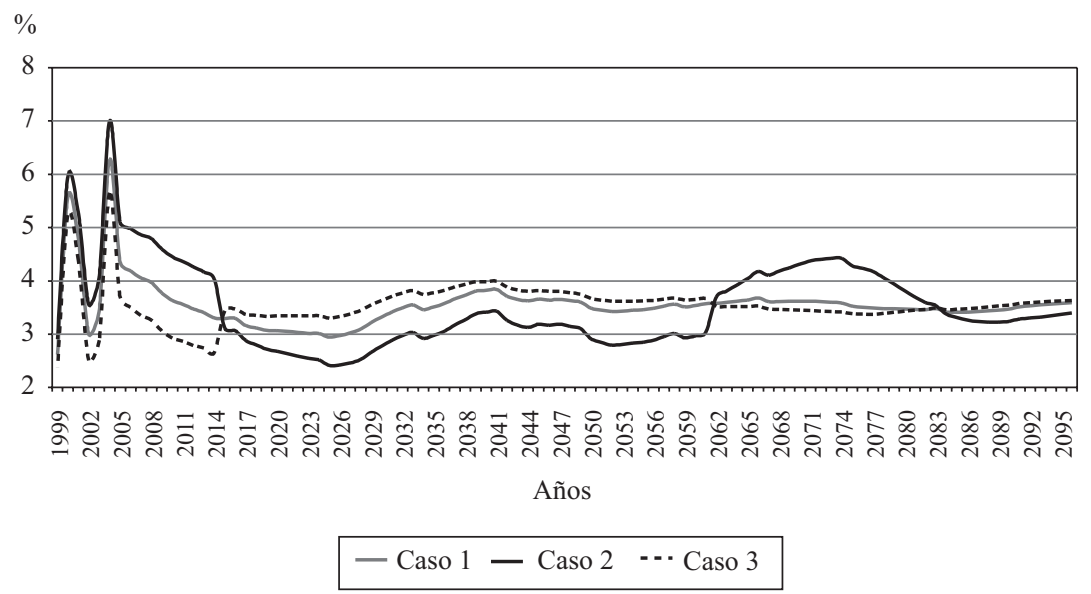

Fuente: Simulaciones propias. 
GRÁFICO N ${ }^{\circ}$ 21: COMPARACIÓN DE SALARIOS Y TASAS DE RENTABILIDAD BAJO DISTINTOS ESCENARIOS DE POBLACIÓN

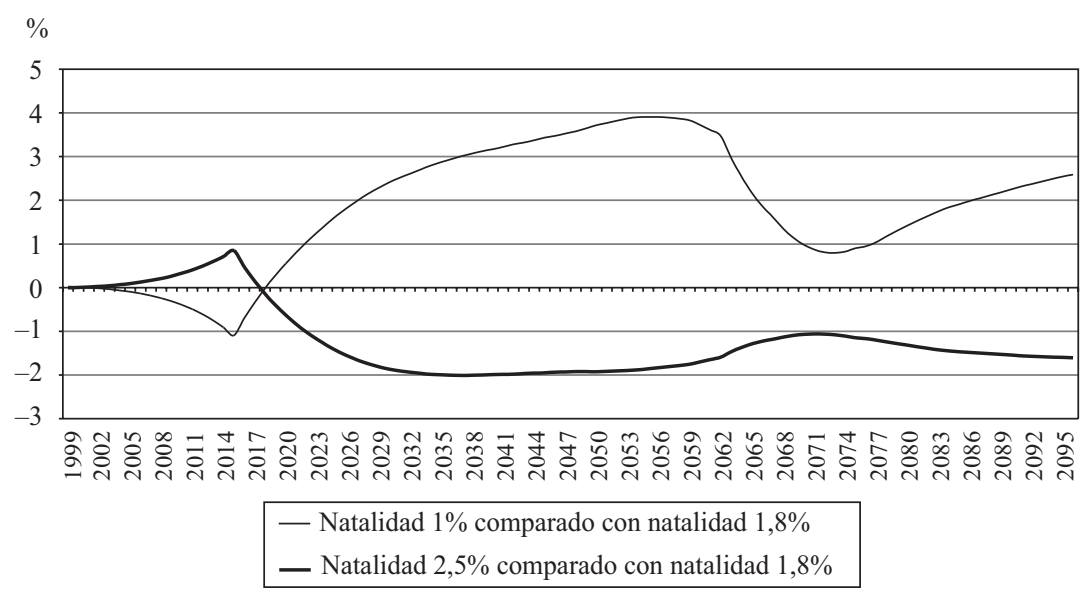

Fuente: Simulaciones propias.

el caso de mayores tasas de natalidad muestra salarios casi 2\% menores comparados con los del caso de natalidad al 1,8\%. De esta forma, mayores son los niveles de salarios mientras menores son las tasas de natalidad. Este resultado muestra que la escasez de oferta de trabajo aumenta los salarios.

En resumen, los impactos negativos de la transición demográfica sobre el PIB son considerables en el largo plazo. Esta conclusión se atenúa e incluso se revierte cuando se considera el PIB per cápita. La reversión ocurre porque aparecen bonos demográficos que aceleran el crecimiento del PIB per cápita en el corto plazo. Además la transición demográfica produce un cambio en el pago a los factores, aumentando los salarios en la medida en que disminuya el crecimiento poblacional.

Aumento del capital humano y sus impactos sobre desigualdad

Otro impacto esperable de esta transición demográfica es el aumento de capital humano. Existen dos razones para esperar este resultado. En primer lugar, los propios individuos deberían buscar aumentar su nivel de capital humano (educación). Lo que ocurre es que las personas nacerán con mayores expectativas de vida, y por lo tanto podrán participar en la fuerza 
de trabajo durante un período más largo. Como los mayores niveles de educación están generalmente relacionados con mayores salarios, la mayor expectativa de vida les permite obtener mayor rentabilidad de su inversión en educación, lo que incentiva a los individuos a aumentar sus niveles de educación. Al respecto ver Soares (2005).

Una segunda fuente por la que debería aumentar el capital humano de las personas es a través de una mayor inversión de los padres en la educación de sus hijos. La razón principal es que tendremos menos hijos y las familias mejorarán sus niveles de ingresos a través del tiempo. Esta última característica ocurre porque esperamos que el país continúe con tasas de crecimiento del PIB positivas, posiblemente no tan altas como en los finales de los 80 o en los 90, pero positivas y bastante significativas (de acuerdo a los ejercicios de simulación anteriores podríamos suponer tasas algo superiores al 4\%). Éste no es un dato menor, porque quiere decir que las familias, a partir de sus mayores ingresos laborales, tendrían mayores recursos disponibles que podrían ser gastados, entre otras cosas, en sus hijos. De esta forma, deberíamos esperar un aumento considerable en el gasto en educación de los hijos en el futuro.

Cierta evidencia de este tipo de argumento puede encontrarse a partir de la experiencia internacional. El Gráfico No 22 —obtenido de Vergara (2007) - muestra que países con mayor PIB per cápita asignan un mayor gasto en educación terciaria. De hecho, del gráfico se desprende que países con PIB per cápita en la cercanía de US\$ 10.000 (como Chile, Brasil y México) muestran niveles de gasto en educación terciaria de aproximadamente US\$ 3.000 a US\$ 5.000 anuales por alumno, mientras que otros países con

GRÁFICO No 22: GASTO EN EDUCACIÓN TERCIARIA VERSUS PIB PER CÁPITA, VARIOS PAÍSES

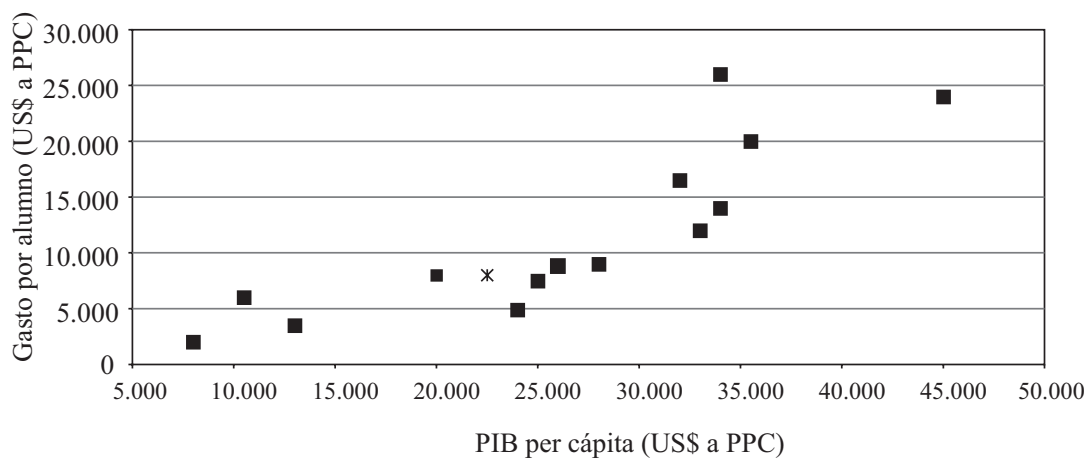

Fuente: Vergara (2007). 
PIB per cápita en el rango US\$ 25.000 a 30.000 — como España, Israel y Nueva Zelanda- muestran niveles de gasto en educación terciaria del orden de US\$ 7.000 a US\$ 8.000 anuales por alumno. Ahora, suponiendo que el PIB de Chile crezca en promedio durante los próximos 25 años al 4\%, es factible alcanzar niveles de PIB per cápita similares a los de España, Israel o Nueva Zelanda en la actualidad y, en ese sentido, es posible alcanzar gastos en educación terciaria por alumno cercanos a los US\$ 8.000 en ese horizonte de tiempo. Por lo tanto, en este contexto, es factible esperar aumentos importantes en el gasto de los hogares en cada uno de sus hijos y, específicamente, en la educación de cada uno de sus hijos.

No sólo debemos esperar aumentos en gasto en educación debido al crecimiento del PIB, sino que también debido a que las familias tendrán menos hijos. Para ilustrar la idea no solamente con educación terciaria, tomemos como ejemplo el caso de una familia cuyo ingreso representaba en el 2002 cerca de 325.000 pesos (caso típico para una familia de dos adultos de acuerdo a la Encuesta de Protección Social 2002, que se aplicó sólo a afiliados al sistema de pensiones). Esta familia está compuesta en promedio por 4,6 personas ( 2 adultos y 2,6 menores de edad). Además, de acuerdo con la misma encuesta, este hogar gasta en promedio aproximadamente 58.000 pesos mensuales de forma directa en la educación de sus hijos, lo que implica aproximadamente 22.000 por hijo. Ahora, nuevamente supongamos que además el PIB de Chile crece en promedio durante los próximos 20 años al 4\%, lo que aumenta los ingresos laborales a su vez en 4\% por año, y que la tasa de fecundidad converge dentro de los próximos 20 años a la cota inferior de tasa de fecundidad por mujer que asegure población constante, es decir a 2,1 hijos por mujer. Esto significa que si el hogar continúa gastando el mismo porcentaje de forma directa en sus hijos y si la tasa de fecundidad pasa a ser de 2,1, el gasto por hijo llegará a una cifra cercana a los 61.000.

Vale la pena recalcar dos puntos. En primer lugar, el gasto promedio por hijo casi se triplicaría, lo que redundaría en aumentos muy significativos en el gasto en educación y salud de estos niños y un mejoramiento sustancial en el capital humano del país. En segundo lugar, el aumento del gasto por hijo representa un aumento casi 25\% superior al aumento en los ingresos de la familia. ¿A qué se debe este último efecto? Básicamente a la transición demográfica: el hogar disminuye su número de hijos, lo que permite aumentar los recursos invertidos en cada hijo. De esta forma, debería haber menos niños, pero posiblemente con mejor educación. Esto es lo que típicamente se conoce como el trade-off entre calidad y cantidad de hijos (Barro y Becker, 1989). 
El capital humano y su relación con demografía podrían tener impactos directos sobre desigualdad social. Esto se debe a que las mujeres con menores niveles de educación tienen una menor participación laboral y un mayor número de hijos, por lo que en general sus hogares tienen menores ingresos. Esto finalmente redunda en que sus hijos tengan menores niveles de educación y posiblemente de menor calidad.

Cierta evidencia para esta idea — pero muy preliminar- puede encontrarse en las siguientes tablas. Siguiendo a Larrañaga (2006), la Tabla $\mathrm{N}^{\circ} 9$ muestra datos obtenidos de los censos de 1960 a 2002. Se reportan como aproximación de niveles socioeconómicos los cuartiles de educación. Además se trabaja con la cohorte de mujeres de 35 a 39 años de edad en cada uno de los años censales. Se trabaja con estas mujeres porque ellas típicamente han terminado su ciclo de vida reproductivo.

Como se puede apreciar en la tabla, en 1960 los sectores de menor nivel de educación tenían en promedio 4,73 hijos por mujer mientras que las mujeres con mayor educación tenían en promedio sólo la mitad de hijos comparado con el grupo anterior (2,55 hijos). La Tabla $\mathrm{N}^{\circ} 10$ muestra que en ese mismo año en el primer cuartil de educación casi el 60\% de las mujeres tenía 5 o más hijos, mientras que esto ocurría sólo en el 22,8\% de los casos si se consideraban mujeres en el $4^{\circ}$ cuartil de educación.

Esta combinación de factores, es decir (1) mujeres en el primer cuartil y (2) con muchos hijos, lamentablemente produce una desigualdad importante para los niños: las mujeres con menores niveles de educación (con menores ingresos) tienen más hijos y, por lo tanto, el nivel de inversión que se puede realizar por hijo es dramáticamente menor en estos casos de niveles sociales más bajos.

Un segundo enfoque para este argumento se obtiene cuando se observan los datos reportados en la Tabla $\mathrm{N}^{0} 11$, que muestra el porcentaje de mujeres que se declaran como dueñas de casa en cada uno de los años

TABLA N ${ }^{\circ}$ 9:

NÚMERO DE HIJOS, CHILE 1960-2002

\begin{tabular}{lllll}
\hline & \multicolumn{4}{c}{ Cuartil de educación } \\
\cline { 2 - 5 } Cohorte 35-39 en año & I & II & III & IV \\
\hline 1960 & 4,73 & 4,2 & 3,02 & 2,55 \\
1970 & 5,63 & 4,59 & 3,69 & 3,14 \\
1982 & 4,07 & 3,3 & 2,74 & 2,16 \\
1992 & 3,19 & 2,73 & 2,25 & 1,97 \\
2002 & 2,67 & 2,42 & 2,01 & 1,78 \\
\hline
\end{tabular}

Fuente: Cálculos propios a partir de extractos de los censos 1960, 1970, 1982, 1992, 2002, disponibles en el IPUMS, Minnesota Population Center. 
TABLA N No 10: PORCENTAJES MUJERES CON 5 Y MÁS HIJOS, CHILE 1960-2000

\begin{tabular}{llcrr}
\hline & \multicolumn{4}{c}{ Cuartil de educación } \\
\cline { 2 - 5 } Cohorte 35-39 en año & \multicolumn{1}{c}{ I } & II & III & IV \\
\hline 1960 & 56,3 & 45,1 & 30,8 & 22,8 \\
1965 & 57,2 & 45,9 & 39,1 & 23,8 \\
1970 & 57,6 & 42,6 & 30,8 & 20,5 \\
1975 & 51,6 & 41,7 & 26,2 & 15,3 \\
1980 & 43,7 & 34,1 & 17,4 & 9,7 \\
1985 & 34 & 22,6 & 10,3 & 4,9 \\
1990 & 27,2 & 18,4 & 8,2 & 3,7 \\
1995 & 20,6 & 10,9 & 5,1 \\
2000 & 13,1 & 7,5 & 3,3 & 1,8 \\
\hline
\end{tabular}

Fuente: Larrañaga (2006).

TABLA N ${ }^{\circ}$ 11: $\quad$ PORCENTAJE MUJERES DUEÑAS DE CASA, CHILE 1960-2002

\begin{tabular}{|c|c|c|c|c|}
\hline \multirow[b]{2}{*}{ Cohorte 35-39 en año } & \multicolumn{4}{|c|}{ Cuartil de educación } \\
\hline & I & II & III & IV \\
\hline 1960 & 84,1 & 80,9 & 80 & 65,2 \\
\hline 1970 & 82,2 & 78,5 & 73,9 & 57,1 \\
\hline 1982 & 76,2 & 75,2 & 68 & 40 \\
\hline 1992 & 73,5 & 69,8 & 55,8 & 22,6 \\
\hline 2002 & 65,1 & 59 & 42,2 & 23,1 \\
\hline
\end{tabular}

Fuente: Cálculos propios a partir de extractos de los censos 1960, 1970, 1982, 1992, 2002, disponibles en el IPUMS, Minnesota Population Center.

censales. Si seguimos analizando el año 1960, nos damos cuenta que las mujeres de menores niveles educacionales tienen tasas de participación laboral bastante menores que las mujeres con altos niveles educacionales. ¿Qué indica esto? Que las familias con menores niveles educacionales tienen menores ingresos por dos motivos: (1) menores salarios al tener menor capital humano y (2) menores tasas de participación laboral. Esto produce finalmente grandes diferencias de ingresos entre grupos educativos y aumenta la probabilidad de que los grupos de menor educación presenten situaciones de pobreza.

¿Qué ocurre si nada cambia en ese contexto? Como hemos dicho, los grupos de menor nivel educacional tendrán una enorme diferencia en sus capacidades de gasto e inversión en sus hijos, lo que produce grandes diferencias en niveles de capital humano y desigualdad social desde el nacimiento. La importancia de este efecto se ilustra en Tabla $\mathrm{N}^{\circ} 12$, que muestra las diferencias de años de escolaridad por cuartiles de educación. Como se 
TABLA No 12: $\quad$ AÑOS DE ESCOLARIDAD PROMEDIO

\begin{tabular}{lllcc}
\hline & \multicolumn{4}{c}{ Cuartil de educación } \\
\cline { 2 - 5 } Cohorte 35-39 en año & I & II & III & IV \\
\hline 1960 & 0,6 & 3,79 & 6,2 & 9,99 \\
1970 & 1,58 & 5,23 & 7,6 & 11,1 \\
1982 & 2,35 & 5,73 & 8,57 & 12,88 \\
1992 & 4,16 & 8,06 & 11,25 & 15,7 \\
2002 & 5,67 & 9,8 & 12,3 & 15,7
\end{tabular}

Fuente: Cálculos propios a partir de extractos de los censos 1960, 1970, 1982, 1992, 2002, disponibles en el IPUMS, Minnesota Population Center.

observa nuevamente para el año 1960, las diferencias son dramáticas: los individuos del primer cuartil sólo tienen en promedio 0,6 años de educación, mientras que los individuos del cuarto cuartil muestran en promedio casi 10 años de educación.

En resumen, todo este análisis nos indica una combinación de factores muy explosiva desde el punto de vista de la desigualdad social: a mayores niveles de educación, se trabaja más y se obtienen mayores ingresos; pero al mismo tiempo estos grupos más educados tienen menos hijos. Esto finalmente les permite invertir más en términos per cápita en cada uno de sus hijos y es un elemento que lleva a perpetuar las diferencias en desigualdad educacional. Contrariamente, sectores socioeconómicos postergados son menos educados y trabajan menos, por lo que obtienen menores ingresos; pero además estos grupos en general tienen más hijos, lo que finalmente implica que pueden invertir menos en cada uno de sus hijos. Éste es un elemento que lleva a perpetuar la desigualdad social a través de generaciones ${ }^{5}$.

La transición demográfica debería atenuar esta desigualdad social que ocurre a partir del nacimiento. La principal razón es que, como hemos discutido, la transición demográfica viene de la mano con menos hijos, pero al mismo tiempo con mayor gasto en educación por cada hijo, y consecuentemente con mayores niveles de educación. Nótese que, como los sectores de bajo nivel socioeconómico son los que tienen mayor número de hijos, estos efectos deberían observarse con mayor intensidad en estos sectores, lo que redunda en disminuir la diferencia entre sectores socioeconómicos a través del tiempo. Evidencia en este último sentido puede observarse en la

${ }^{5}$ Obviamente pueden existir otros elementos que produzcan desigualdad social que no son analizados en este estudio. Al respecto, ver Contreras (1996), Larrañaga (1999), Nuñez y Riesco (2004), Sapelli (2005), y Solimano y Torche (2007). 
Tabla $\mathrm{N}^{\circ}$ 9. El primer cuartil de educación disminuye su tasa de fecundidad entre 1960 y 2002 desde 4,73 hijos hasta 2,67 hijos, mientras que el cuarto cuartil disminuye en el mismo período sólo desde 2,55 hasta 1,78 hijos. Por otro lado, casi todos los grupos han aumentado sus años de escolaridad en aproximadamente 5 años.

Sin perjuicio de que los grupos han aumentado sus años de escolaridad en aproximadamente lo mismo, la caída en desigualdad debe esperarse porque la escolaridad promedio parece haber llegado a niveles máximos en el cuarto cuartil, mientras que tiene amplio espacio para seguir creciendo en el resto de los grupos. Siendo más explícitos aún, el cuarto cuartil de educación muestra niveles de educación en la cercanía de 15 años (lo que representa educación media completa y algo de educación superior), mientras que el primero y segundo cuartil muestran niveles de educación de 5,6 y 9,8 años en promedio. Estos últimos grupos son los que tienen más espacio para hacer crecer sus niveles de educación, por lo que es aquí donde esperaríamos mayores impactos.

Además, si bien ha aumentado la participación de las mujeres de niveles socioeconómicos bajos en el mercado laboral, tal como se observa en la Tabla $N^{\circ} 11$, aún queda bastante espacio para que se integren más de estas mujeres al mercado laboral, lo que nuevamente no ocurre en demasía en los sectores con niveles de educación altos.

De esta forma, la transición demográfica debe impactar mayoritariamente a los sectores socioeconómicos más bajos y tiene espacio para aumentar considerablemente los niveles de educación de estos grupos, lo que irá de la mano con aumento en sus ingresos laborales, y por lo tanto con reducción de desigualdad y pobreza. Esto ocurrirá debido a (1) los mayores salarios que encontrarán los grupos más atrasados al tener más capital humano, pero también debido a (2) las mayores tasas de participación laboral de las mujeres de estos grupos.

¿Cuán importante será este efecto? ¿Cuán rápida será la velocidad de la disminución en desigualdad? Por el momento no existen estudios al respecto que respondan este tipo de preguntas. Por lo tanto, para tener alguna idea de las magnitudes y la velocidad del ajuste utilizaremos nuevamente un modelo de simulación simple, similar al utilizado en las secciones anteriores para determinar los efectos económicos de la transición demográfica, pero con algunas modificaciones importantes. La principal modificación es que los padres determinen endógenamente los años de educación de sus hijos. Además supondremos que distintos grupos socioeconómicos tienen distintas tasas de natalidad, siguiendo la evidencia en la Tabla $N^{0}$ 9. Para realizar la simulación se ocuparán los salarios y tasas de rentabilidad obtenidos del 
modelo de la sección anterior. La descripción del modelo de simulación puede observar en el Apéndice 3.

En nuestros ejercicios se suponen 10 grupos socioeconómicos en los que la fecundidad promedio disminuye a través del tiempo, así como la varianza de tasas de fecundidad entre grupos. De esta forma, se supone que grupos con mayores tasas de fecundidad tienden a converger con los grupos de menores tasas de fecundidad. Los resultados pueden observarse en los Gráficos Nos 23 a 25, que muestran la evolución de las variables principales de este modelo. Resulta interesante notar que el grupo con mayor tasa de fecundidad es también el grupo con menos años de educación, lo que es un resultado similar a los datos que hemos discutido con anterioridad. A medida que este grupo enfrenta menores tasas de fecundidad (pasando de casi un promedio de 4,5 hijos en 1990 a 3 hijos en el 2050), aumenta sus niveles de educación, pasando desde casi 7 años de educación en promedio a cerca de 11 años de educación en el 2050. Por otro lado, grupos que en 1990 tienen bajas tasas de fecundidad parten en esa fecha con niveles de educación altos. El resultado de la transición demográfica es que para el 2050 prácticamente todos los grupos tienen en promedio 3 hijos o menos, lo que les permite aumentar considerablemente los años de educación por hijo, con un piso de años de educación de aproximadamente 11 años en 2050. La transición demográfica permite aumentar los niveles de educación en la población, siendo los efectos más importantes en los sectores socioeconómicos más atrasados, que acortan significativamente su brecha educativa.

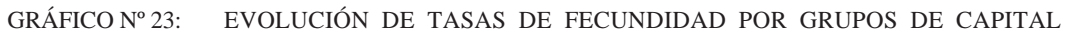
HUMANO, MODELO DE SIMULACIÓN

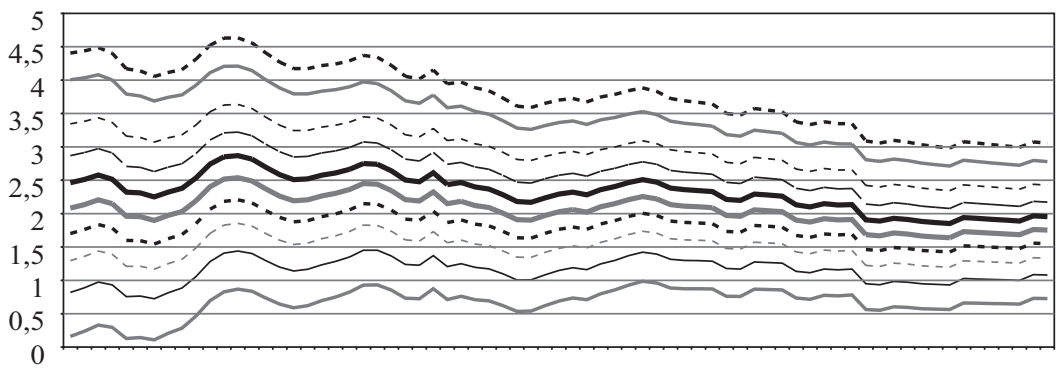

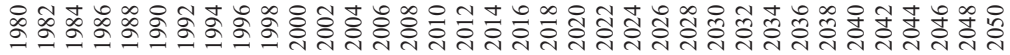

Años

Fuente: Simulaciones propias. 
GRÁFICO N ${ }^{\circ}$ 24: EVOLUCIÓN DE AÑOS DE EDUCACIÓN POR GRUPOS DE CAPITAL HUMANO, SIMULACIONES

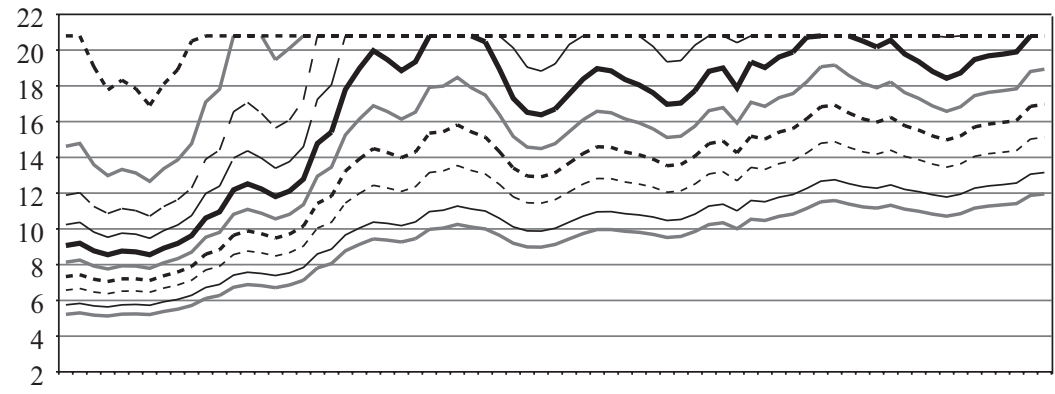

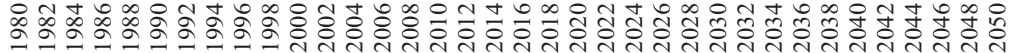

Años

Fuente: Simulaciones propias.

GRÁFICO Nº 25: $\quad$ EVOLUCIÓN DE ÍNDICE GINI. SIMULACIÓN

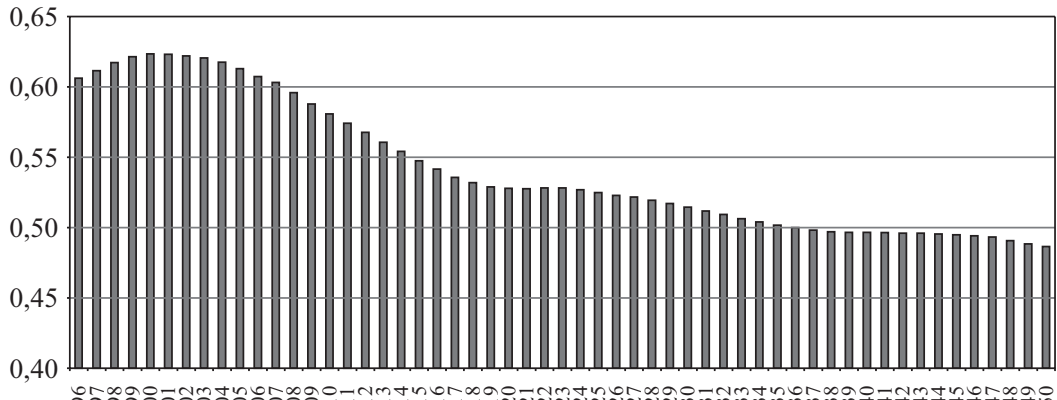

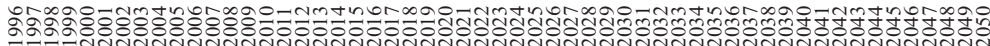

Años

Nota: El índice Gini se calcula a partir de los ingresos laborales.

Fuente: Simulaciones propias.

Lo más interesante de todo este proceso es que como los ingresos laborales de las personas dependen directamente de los niveles de educación ${ }^{6}$, la brecha de ingresos entre grupos socioeconómicos tiende a dismi-

${ }^{6}$ En nuestras simulaciones, las personas más educadas obtienen mayores retornos del mercado laboral para la misma jornada laboral, lo que parece un supuesto razonable de acuerdo a la amplia evidencia disponible de la literatura de retornos de la educación. 
nuir a través del tiempo, tal como lo ilustra el Gráfico $\mathrm{N}^{\circ} 25$ por medio de la evolución del índice Gini de desigualdad. Nuestro índice, que resulta de un simple modelo de simulación que se basa en diferencias en tasas de fecundidad entre grupos socioeconómicos, con su posterior impacto en diferencias educacionales, muestra un alto grado de desigualdad a finales de los 90 y comienzos del siglo XXI, tal como se observa en la actualidad. Sin embargo, este índice tiende a disminuir considerablemente en casi 10 puntos para finales de 2050. La velocidad del ajuste es bastante alta y muestra que para 2015-2020 deberíamos tener avances significativos en el tema de desigualdad de ingresos.

En relación con estos ejercicios, es importante notar que la evolución de la desigualdad está determinada por cambios demográficos e impactos en educación. Sin perjuicio de aquello, es posible que existan otros factores que también influyan en la evolución futura de la desigualdad social, por lo que este ejercicio debe considerarse como una aproximación al tema suponiendo que otros factores están dados.

\section{Impactos sobre la estructura del mercado laboral}

El análisis realizado en las secciones anteriores no considera posibles cambios que pueden afectar el mercado laboral. A continuación esbozamos algunos de esos impactos. Nuestro análisis, en este caso, es sólo descriptivo.

\section{- Trabajadores calificados y no calificados}

¿Cuáles pueden ser las implicancias de este aumento en capital humano en el mercado laboral? En primer lugar, el aumento del nivel educacional de los chilenos en las próximas décadas traerá una consecuencia obvia, pero con repercusiones importantes: aumentarán los trabajadores calificados en desmedro de los no calificados. Esto ocasionará un cambio en la oferta relativa de trabajadores que posiblemente producirá un exceso de oferta en el mercado de trabajadores calificados versus un exceso de demanda de trabajadores no calificados.

Los equilibrios pueden restablecerse por dos vías: (1) cambios en los salarios relativos de trabajadores no calificados versus calificados, o alternativamente (2) a través de flujos de trabajadores. Este último caso está directamente relacionado por un lado con inmigración de trabajadores no calificados — posiblemente desde nuestros países vecinos_ y con la emi- 
gración de trabajadores chilenos calificados hacia países que necesiten de ellos.

En el primer tipo de ajuste, es decir vía ajuste de salarios relativos, deberíamos observar un aumento de los salarios relativos de los trabajadores menos calificados versus el de los más calificados, lo que nuevamente se traduce en una fuente de reducción de desigualdad social. Ahora bien, este ajuste seguramente debe ser hecho de todas formas con flujos de trabajadores: posiblemente trabajadores no calificados de otras economías tendrán altos incentivos para inmigrar hacia Chile, mientras que trabajadores calificados chilenos querrán emigrar para obtener mayor rentabilidad para su calificación laboral. Por lo tanto, el flujo de trabajadores hacia y desde Chile es un tema que debe abordarse. Más aún, es importante implementar políticas que permitan realizar un rápido ajuste en los mercados de trabajadores calificados y no calificados para evitar problemas sociales como el de posibles nuevos “cesantes ilustrados”, es decir, personas con altos niveles de educación pero que no encuentran trabajo.

Para facilitar este proceso de flujo de personas hacia y desde Chile es necesario implementar como futura política pública tratados de libre comercio de “segunda generación”. Este tipo de tratados debe buscar que se regule no sólo el comercio de bienes y servicios entre países, sino que también el movimiento de trabajadores entre países, facilitando su inserción en el país que reciba al trabajador.

\section{- Participación femenina en el mercado laboral}

Un segundo tipo de impacto está relacionado con la participación laboral femenina. Como hemos indicado antes, los mayores niveles de educación femenina entregarán incentivos para que un mayor número de mujeres participen del mercado del trabajo, al obtener mayores retornos del mercado laboral. ¿De qué magnitud será este efecto? Si bien existen varios estudios sobre participación laboral femenina en Chile (por ejemplo Bravo, Contreras y Puentes, 2005), no existen estudios que aborden directamente la relación cambio demográfico-oferta laboral femenina en los próximos 50 años. Para tener una primera aproximación recuérdese que en la actualidad casi el 70\% de las mujeres fuera de unión consensual o matrimonio participa del mercado laboral, mientras que en el grupo de mujeres casadas o en uniones consensuales la cifra es sólo de 35 a 40\%. Las mujeres fuera del matrimonio y/o convivencia tienen niveles educacionales relativamente altos, por lo que si bien puede haber aumentos en años de escolaridad, estos 
aumentos no deberían ser demasiado significativos. En este sentido, una posición razonable es suponer que estas mujeres no cambiarían significativamente su participación en el mercado del trabajo.

Por otro lado, en el caso de las mujeres casadas o en unión consensual, la situación es diferente. Un aumento en sus niveles educacionales promedio podría acercarlas a niveles similares a los de mujeres fuera del matrimonio y/o convivencia, lo que debería provocar el aumento de la oferta de trabajo de este grupo. Como este último grupo tiene una participación importante (representa casi el 70\% de las mujeres entre 30 y 45 años), y además tiene en promedio una tasa de participación laboral aún muy baja, es posible esperar aumentos que pueden tener un efecto importante en la oferta de trabajo de las mujeres en general.

De esta forma, los posibles cuellos de botella para el crecimiento que vienen del lado de la fuerza de trabajo pueden ser al menos parcialmente subsanados por medio de la incorporación de la mujer al mercado laboral, en particular de las mujeres en matrimonio y/o convivencia.

Sin embargo, no debe perderse de vista que la incorporación de la mujer a la fuerza de trabajo puede acentuar aún más la dicotomía entre trabajar y criar hijos. Por lo tanto, el impulsar políticas de mayor participación laboral de mujeres podría eventualmente acelerar aún más la transición demográfica y el cambio en la pirámide de edades. Desde ese punto de vista, para poder implementar este tipo de políticas debe tratarse de subsanar esta dicotomía por medio de eliminar barreras para que las mujeres logren llevar a cabo ambas actividades (criar hijos y trabajar) de forma simultánea. Obviamente la barrera principal es el tiempo que debe dedicarse a cuidar a los hijos y en ese sentido la implementación de políticas como salas cuna y guarderías de niños de bajo costo y cerca de los hogares o lugares de trabajo va en el sentido correcto. Si esto se conjuga con un mercado laboral que permita contratos por horas o jornadas más flexibles, es posible disminuir el impacto negativo de la participación en el mercado laboral sobre la decisión de tener hijos.

\section{Aumento del grupo de adultos mayores}

Una implicancia adicional de la transición demográfica es el considerable aumento de los adultos mayores. Este grupo de individuos llegará a ser de más de 4 millones de personas en el 2050. Los individuos de este grupo entran a una nueva etapa de su vida, con necesidades distintas de las de otros grupos etarios. Estas necesidades dependen de factores tales 
como la edad de la persona, su estado de salud o el tipo de familia en que viva. Dentro de las necesidades de la tercera edad destaca la cobertura de salud, tanto de procedimientos médicos como de remedios. Éstos son gastos de costo bastante significativo.

Para poder cubrir sus requerimientos, las personas de tercera edad necesitan ingresos que, en su caso, provienen de (i) pensiones, (ii) ahorros, (iii) trabajo y (iv) la ayuda económica de terceros, en especial de familiares. La Tabla $\mathrm{N}^{\circ} 13$ desglosa las tres primeras fuentes de ingresos para adultos mayores de acuerdo a la Casen 2000. La tabla muestra que la fracción de individuos que reciben ingresos por rentas en la tercera edad es menos del $35 \%$, debido posiblemente a que la capacidad de ahorro es baja durante la vida laboral de las personas. Además, la fracción de personas que trabajan, y por lo tanto reciben ingresos laborales, decrece significativamente desde los 60 años en adelante. Esta observación no es preocupante en la medida en que los ingresos laborales se reemplacen por ingresos provenientes de otras fuentes, típicamente pensiones. Sin embargo, y tal como se observa de la tabla, en el 2000 una fracción significativa de personas en edad de recibir pensiones no lo hacía, posiblemente porque no cumplían con el requisito del número mínimo de cotizaciones para recibir pensión.

Parte de la baja cobertura de pensiones debe resolverse a partir de la próxima reforma previsional. Sin perjuicio de aquello, sigue pareciendo claro que en este escenario la ayuda proveniente de terceros, tanto económica como en la vida cotidiana, pasa a ser muy relevante. Ahora, este tipo de ayuda típicamente proviene de redes sociales o de familiares, por lo que resulta importante saber el estado de estas redes sociales o familiares. Como una primera aproximación a este tema, buscaremos examinar el tipo de hogar en que viven estas personas, es decir, buscaremos saber si esas personas en tercera edad viven con familiares, con amigos, solas, etc.

TABLA N ${ }^{\circ}$ 13: $\quad$ FUENTES DE INGRESOS EN LA TERCERA EDAD (\%)

\begin{tabular}{lccc}
\hline & 60 años a 64 años & 65 años a 69 años & 70 años y más \\
\hline Fracción de personas trabajando & 38,1 & 26,9 & 10,3 \\
Fracción de personas sin ingreso por rentas & 70,3 & 66,9 & 65,3 \\
Fracción de personas sin ingreso por jubilación & 74,6 & 55,27 & 49,1
\end{tabular}

Los ingresos por rentas se definen como ingreso autónomo menos ingresos por jubilaciones e ingresos laborales.

Fuente: Cálculos propios a partir de Casen 2000. 
$\mathrm{Al}$ parecer existe una tendencia a que las personas en tercera edad vivan cada vez más solas o de forma independiente. De acuerdo a los datos del censo, casi el 8\% de los individuos mayores de 70 años vivían solos en 1970. Esta fracción ha estado subiendo continuamente y alcanzó a ser casi el 10\% en 1982, 12\% en 1992 y 15\% en 2002. Más aún, casi el 20\% de estos individuos vivía en hogares conformados prácticamente por personas de tercera edad en 1970. Este número subió a casi 35\% en 2002. Éste es un escenario donde cada vez hay más adultos mayores, pero también cada vez más solitarios y posiblemente más desatendidos. De hecho, si mantenemos la fracción de mayores de 70 años viviendo solos en el $15 \%$ y hacemos proyecciones para 2025 y 2050, encontramos la no despreciable cifra de 150.000 y 278.000 adultos viviendo solos en esos años respectivamente.

Éste es un desafío mayor, en el sentido que se debe buscar algún diseño que permita cumplir con el objetivo de independencia y autosuficiencia en que los individuos de tercera edad tengan los suficientes recursos económicos para satisfacer sus necesidades. Seguramente parte de estos individuos podría satisfacer estas necesidades por medio de sus ahorros o con la ayuda de familiares (terceros), pero en la medida en que las personas tengan menos hijos, la ayuda de familiares parece cada vez menos probable y por lo tanto más individuos pueden quedar desprotegidos.

Se deben diseñar políticas públicas que enfrenten los problemas de este grupo. A continuación esbozamos algunas ideas de las posibles políticas por implementar. En el ámbito de ingresos, tal como indicamos antes, se ha dado un paso con el proyecto de reforma previsional. Sin perjuicio de aquello, sería importante generar condiciones para que personas en tercera edad puedan tener oportunidades laborales, si así lo desean. En ese sentido debe buscarse eliminar posibles discriminaciones por edad que puedan darse en el mercado laboral a la contratación de personas mayores. De hecho, dado el aumento de expectativa de vida, es bastante factible que cada vez más adultos mayores deseen seguir participando en la fuerza de trabajo después de su edad legal de retiro y debe velarse por eliminar cualquier tipo de discriminación laboral en contra de ellos. En el mismo sentido, y para poder permitir que las personas de tercera edad sigan ligadas al mercado laboral si así lo deciden, es necesario potenciar sistemas de educación continua y/o capacitación para adultos mayores.

Respecto de los beneficios otorgados por el Estado, debe considerarse que la demanda por algunos de ellos debería cambiar a medida que existan más adultos mayores. Ejemplos son las políticas de salud y vivien- 
da. En el caso de la política de vivienda, debe incentivarse la construcción de viviendas con más de un dormitorio para el caso de adultos mayores solos, de forma de permitir la estadía de acompañantes o cuidadores, o alternativamente los medios de transporte deben adecuarse para las personas de la tercera edad. Los cambios en el sector salud los abordamos un poco más adelante.

Cambios sectoriales: el sector educacional y la salud

- Perspectivas en el sector educacional

Finalmente, una implicancia adicional para que disminuya la tasa de natalidad es que en el futuro habrá menos niños, lo que debería impactar directamente en el sector educacional. En efecto, se necesitarían menos colegios o colegios de menor capacidad. De hecho, nótese que el número de individuos entre 5 y 14 años en la actualidad es aproximadamente 2,7 millones, mientras que el grupo de jóvenes cuya edad fluctúa entre 15 y 19 años es aproximadamente de 1,2 millones. En el horizonte de los próximos 10 años se espera una disminución de casi $10 \%$ en el número de individuos del grupo de 5 a 14 años (alumnos de educación básica) y de 13\% en el grupo de 15 a 18 años (educación media). Esta disminución en estos grupos etarios necesariamente iría de la mano de una disminución en las matrículas totales del sector educacional. De esta forma, el sector educacional podría tener significativos cambios debido a nuestra transición demográfica: (1) deberíamos tener menos alumnos matriculados, (2) pero con una inyección importante de recursos privados por alumno al sistema educacional.

Uno esperaría que, en general, estos mayores recursos debieran mejorar significativamente la calidad educacional y aumentar los años de escolaridad de los chilenos. Sin embargo, no debe perderse de vista que los resultados finales dependerán de cómo reaccione la industria a este shock exógeno que enfrentará a partir de los cambios en variables demográficas. Frente a la disminución de matriculados, la industria puede reaccionar disminuyendo el número de colegios, disminuyendo el tamaño de los cursos o disminuyendo el número de cursos por nivel. La primera reacción sería que se cierren colegios, y posiblemente sea deseable en la medida en que se cierren colegios de baja calidad educacional. El segundo tipo de reacción de la industria sería permitir que sigan existiendo colegios de baja calidad, pero al mismo tiempo que se reduzca el número de alumnos por clase. 
¿Cuál es la política óptima? ¿Cerrar colegios? ¿Disminuir el tamaño de cursos? Ésas son preguntas cuyas respuestas van más allá del objetivo de este trabajo, pero queda claro que deberán ser contestadas en el futuro próximo por las autoridades. ¿Cuál será finalmente el resultado? Depende del diseño que se adopte para afrontar el shock demográfico que se acerca. En la medida en que no se actúe, es posible que los colegios de baja calidad deseen seguir en el mercado educacional, aunque enfrenten menores matrículas, porque seguramente podrán cobrar montos algo mayores a sus alumnos en el futuro.

\section{- Perspectivas en el sector salud}

Otro de los sectores que deberían enfrentar considerables cambios es el de la salud. Esto se debe a que en los próximos años los requerimientos de salud de la población chilena cambiarán drásticamente. Estos cambios ocurren debido a que múltiples enfermedades tienen mayor prevalencia en la tercera edad, lo que lleva a que un país que envejece, como es el caso de Chile, muestre significativos cambios en cuanto a las enfermedades que afecten a su población. Ejemplos de este tipo de cambios en prevalencia de enfermedades pueden observarse a partir de las Tablas $\mathrm{N}^{\text {os }} 14$ y 15 . La Tabla $\mathrm{N}^{\circ} 14$ muestra, entre otros datos, la prevalencia de distintas enfermedades para distintos grupos de edad en el año 2004. Los datos se obtuvieron de la Encuesta de Protección Social 2004, que contiene un exhaustivo conjunto de preguntas sobre salud de la población. Como se puede observar de esta tabla, casi todas las enfermedades muestran tasas de prevalencia mayores en la tercera edad, y en algunas enfermedades los aumentos de prevalencia son muy importantes. Destacan los problemas cardíacos, la hipertensión, diabetes e invalidez.

¿Cuán importantes pueden llegar a ser estos efectos? Para tener alguna idea de su magnitud trataremos de entregar el número esperado de diagnósticos en el futuro en cada tipo de enfermedad si se mantuvieran las tasas de prevalencia actuales. La Tabla $\mathrm{N}^{\circ} 15$ entrega información en este sentido. Esta tabla utiliza los datos de prevalencia de la Tabla $\mathrm{N}^{\circ} 14$ junto a proyecciones de población por grupos de edad de INE-Celade. Se observa que la población menor de 65 años de edad se mantiene relativamente constante en un horizonte de 50 años, mientras que la población mayor de 65 años crece y prácticamente se cuadruplica en ese horizonte de tiempo. Las consecuencias de este aumento en población mayor de 65 años, bajo el supuesto de que las tasas de prevalencia se mantengan relativamente simi- 
TABLA N ${ }^{\circ}$ 14: PREVALENCIA DE ENFERMEDADES DIAGNOSTICADAS POR GRUPOS DE EDAD

\begin{tabular}{|c|c|c|c|c|c|c|c|}
\hline & & $\begin{array}{l}64 \text { años } \\
\text { o menos }\end{array}$ & $\begin{array}{c}65 \text { años } \\
\text { o más }\end{array}$ & $\begin{array}{c}65 \text { a } \\
69 \text { años }\end{array}$ & $\begin{array}{c}70 \mathrm{a} \\
74 \text { años }\end{array}$ & $\begin{array}{c}75 \text { a } \\
79 \text { años }\end{array}$ & $\begin{array}{l}80 \text { años } \\
\text { y más }\end{array}$ \\
\hline \multicolumn{2}{|l|}{ Invalidez } & 5,8 & 21,9 & 17 & 19,2 & 25,3 & 30,9 \\
\hline \multicolumn{2}{|l|}{ Asma } & 3 & 7,9 & 6,7 & 6,7 & 9,8 & 9,5 \\
\hline \multicolumn{2}{|l|}{ Depresión } & 7,3 & 7,9 & 8 & 8,1 & 7,9 & 6,1 \\
\hline \multicolumn{2}{|l|}{ Diabetes } & 4,3 & 14,1 & 14,3 & 12,9 & 17,6 & 12 \\
\hline \multicolumn{2}{|l|}{ Hipertensión } & 13,6 & 45,4 & 40,1 & 48,9 & 46,9 & 46,3 \\
\hline \multicolumn{2}{|l|}{ Cardíacos } & 3,7 & 14,4 & 11,1 & 14,2 & 18 & 16,6 \\
\hline \multicolumn{2}{|l|}{ Cáncer } & 1,2 & 3 & 2,8 & 3,7 & 2 & 3,5 \\
\hline \multicolumn{2}{|l|}{ Artritis } & 4 & 20 & 17,4 & 18,8 & 22,2 & 24,1 \\
\hline \multicolumn{2}{|l|}{ Enfermedad renal } & 2,1 & 4,1 & 3,5 & 4,3 & 4 & 4,9 \\
\hline \multicolumn{2}{|l|}{ Derrame cerebral } & 0,2 & 1,4 & 1,2 & 0,9 & 1,5 & 2,8 \\
\hline \multicolumn{2}{|c|}{ Enfermedad mental } & 0,6 & 1,01 & 0,4 & 0,6 & 0,6 & 3,2 \\
\hline \multicolumn{8}{|c|}{ Población } \\
\hline 2007 & \multicolumn{2}{|c|}{15.219 .761} & 1.384 .065 & 471.661 & 362.083 & 272.779 & 277.542 \\
\hline 2010 & \multirow{2}{*}{\multicolumn{2}{|c|}{$\begin{array}{l}15.552 .511 \\
16.346 .536\end{array}$}} & 1.541 .759 & 539.279 & 389.319 & 295.148 & 318.013 \\
\hline 2020 & & & 2.202 .559 & 754.047 & 572.158 & 419.566 & 456.788 \\
\hline 2030 & \multicolumn{2}{|c|}{16.348 .998} & 3.238 .123 & 1.091 .929 & 867.942 & 599.087 & 679.165 \\
\hline 2040 & \multicolumn{2}{|c|}{16.134 .829} & 3.975 .493 & 1.074 .577 & 988.108 & 882.501 & 1.030 .307 \\
\hline 2050 & \multicolumn{2}{|c|}{15.843 .643} & 4.361 .136 & 1.150 .215 & 942.596 & 880.189 & 1.388 .136 \\
\hline
\end{tabular}

Fuente: Encuesta de Protección Social (EPS) 2004.

lares a las de la Tabla $\mathrm{N}^{0}$ 14, son un aumento de más de $50 \%$ de los casos diagnosticados en la mayoría de las enfermedades. Nótese incluso que en el caso de depresión, en el que las tasas de prevalencia son similares entre grupos etarios, se observa un aumento significativo en el número de personas diagnosticadas. Esto se debe a que el grupo en tercera edad aumenta considerablemente en este período.

Estas cifras revelan un incremento de demanda considerable en el sector salud, impulsado por el crecimiento del grupo de tercera edad. Esto conlleva un desafío por satisfacer esta demanda futura, en el que la provisión de servicios a la población deberá adecuarse a las necesidades de este grupo de adultos mayores ${ }^{7}$. De esta forma, resulta esperable un impulso importante a especialidades como geriatría, psicología geriátrica y medicina preventiva en general.

\footnotetext{
${ }^{7}$ En cuanto a lineamientos de política de salud para adultos mayores, ver Marín (2006).
} 
TABLA N ${ }^{\circ}$ 15: PROYECCIONES DE NÚMERO DE PERSONAS DIAGNOSTICADAS CON DISTINTAS ENFERMEDADES, POR GRUPO DE EDAD

\begin{tabular}{|c|c|c|c|c|c|c|}
\hline & $\begin{array}{l}64 \text { años } \\
\text { o menos }\end{array}$ & $\begin{array}{l}65 \text { años } \\
\text { o más }\end{array}$ & $\begin{array}{c}65 \text { a } \\
69 \text { años }\end{array}$ & $\begin{array}{c}70 \text { a } \\
74 \text { años }\end{array}$ & $\begin{array}{c}75 \text { a } \\
79 \text { años }\end{array}$ & $\begin{array}{c}80 \text { años } \\
\text { y más }\end{array}$ \\
\hline \multicolumn{7}{|c|}{ Invalidez } \\
\hline 2007 & 882.746 & 303.110 & 80.182 & 69.520 & 69.013 & 85.761 \\
\hline 2010 & 902.046 & 337.645 & 91.677 & 74.749 & 74.672 & 98.266 \\
\hline 2020 & 948.099 & 482.360 & 128.188 & 109.854 & 106.150 & 141.147 \\
\hline 2030 & 948.242 & 709.149 & 185.628 & 166.645 & 151.569 & 209.862 \\
\hline 2040 & 935.820 & 870.633 & 182.678 & 189.717 & 223.273 & 318.365 \\
\hline 2050 & 918.931 & 955.089 & 195.537 & 180.978 & 222.688 & 428.934 \\
\hline \multicolumn{7}{|c|}{ Asma } \\
\hline 2007 & 456.593 & 109.341 & 31.601 & 24.260 & 26.732 & 26.366 \\
\hline 2010 & 466.575 & 121.799 & 36.132 & 26.084 & 28.925 & 30.211 \\
\hline 2020 & 490.396 & 174.002 & 50.521 & 38.335 & 41.117 & 43.395 \\
\hline 2030 & 490.470 & 255.812 & 73.159 & 58.152 & 58.711 & 64.521 \\
\hline 2040 & 484.045 & 314.064 & 71.997 & 66.203 & 86.485 & 97.879 \\
\hline 2050 & 475.309 & 344.530 & 77.064 & 63.154 & 86.259 & 131.873 \\
\hline \multicolumn{7}{|c|}{ Depresión } \\
\hline 2007 & 1.111 .043 & 109.341 & 37.733 & 29.329 & 21.550 & 16.930 \\
\hline 2010 & 1.135 .333 & 121.799 & 43.142 & 31.535 & 23.317 & 19.399 \\
\hline 2020 & 1.193 .297 & 174.002 & 60.324 & 46.345 & 33.146 & 27.864 \\
\hline 2030 & 1.193 .477 & 255.812 & 87.354 & 70.303 & 47.328 & 41.429 \\
\hline 2040 & 1.177 .843 & 314.064 & 85.966 & 80.037 & 69.718 & 62.849 \\
\hline 2050 & 1.156 .586 & 344.530 & 92.017 & 76.350 & 69.535 & 84.676 \\
\hline \multicolumn{7}{|c|}{ Diabetes } \\
\hline 2007 & 654.450 & 195.153 & 67.447 & 46.709 & 48.009 & 33.305 \\
\hline 2010 & 668.758 & 217.388 & 77.117 & 50.222 & 51.946 & 38.162 \\
\hline 2020 & 702.901 & 310.561 & 107.829 & 73.808 & 73.844 & 54.815 \\
\hline 2030 & 703.007 & 456.575 & 156.146 & 111.965 & 105.439 & 81.500 \\
\hline 2040 & 693.798 & 560.545 & 153.665 & 127.466 & 155.320 & 123.637 \\
\hline 2050 & 681.277 & 614.920 & 164.481 & 121.595 & 154.913 & 166.576 \\
\hline \multicolumn{7}{|c|}{ Hipertensión } \\
\hline 2007 & 2.069 .888 & 628.366 & 189.136 & 177.059 & 127.933 & 128.502 \\
\hline 2010 & 2.115 .141 & 699.959 & 216.251 & 190.377 & 138.424 & 147.240 \\
\hline 2020 & 2.223 .129 & 999.962 & 302.373 & 279.785 & 196.776 & 211.493 \\
\hline 2030 & 2.223 .464 & 1.470 .108 & 437.864 & 424.424 & 280.972 & 314.453 \\
\hline 2040 & 2.194 .337 & 1.804 .874 & 430.905 & 483.185 & 413.893 & 477.032 \\
\hline 2050 & 2.154 .735 & 1.979.956 & 461.236 & 460.929 & 412.809 & 642.707 \\
\hline
\end{tabular}




\begin{tabular}{|c|c|c|c|c|c|c|}
\hline \multicolumn{7}{|c|}{ Cardíacos } \\
\hline 2007 & 563.131 & 199.305 & 52.354 & 51.416 & 49.100 & 46.072 \\
\hline 2010 & 575.443 & 222.013 & 59.860 & 55.283 & 53.127 & 52.790 \\
\hline 2020 & 604.822 & 317.168 & 83.699 & 81.246 & 75.522 & 75.827 \\
\hline 2030 & 604.913 & 466.290 & 121.204 & 123.248 & 107.836 & 112.741 \\
\hline 2040 & 596.989 & 572.471 & 119.278 & 140.311 & 158.850 & 171.031 \\
\hline 2050 & 586.215 & 628.004 & 127.674 & 133.849 & 158.434 & 230.431 \\
\hline \multicolumn{7}{|c|}{ Cáncer } \\
\hline 2007 & 182.637 & 41.522 & 13.206 & 13.397 & 5.456 & 9.714 \\
\hline 2010 & 186.630 & 46.253 & 15.100 & 14.405 & 5.903 & 11.130 \\
\hline 2020 & 196.158 & 66.077 & 21.113 & 21.170 & 8.391 & 15.988 \\
\hline 2030 & 196.188 & 97.144 & 30.574 & 32.114 & 11.982 & 23.771 \\
\hline 2040 & 193.618 & 119.265 & 30.088 & 36.560 & 17.650 & 36.061 \\
\hline 2050 & 190.124 & 130.834 & 32.206 & 34.876 & 17.604 & 48.585 \\
\hline \multicolumn{7}{|c|}{ Artritis } \\
\hline 2007 & 608.790 & 276.813 & 82.069 & 68.072 & 60.557 & 66.888 \\
\hline 2010 & 622.100 & 308.352 & 93.835 & 73.192 & 65.523 & 76.641 \\
\hline 2020 & 653.861 & 440.512 & 131.204 & 107.566 & 93.144 & 110.086 \\
\hline 2030 & 653.960 & 647.625 & 189.996 & 163.173 & 132.997 & 163.679 \\
\hline 2040 & 645.393 & 795.099 & 186.976 & 185.764 & 195.915 & 248.304 \\
\hline 2050 & 633.746 & 872.227 & 200.137 & 177.208 & 195.402 & 334.541 \\
\hline \multicolumn{7}{|c|}{ Enfermedades renales } \\
\hline 2007 & 319.615 & 56.747 & 16.508 & 15.570 & 10.911 & 13.600 \\
\hline 2010 & 326.603 & 63.212 & 18.875 & 16.741 & 11.806 & 15.583 \\
\hline 2020 & 343.277 & 90.305 & 26.392 & 24.603 & 16.783 & 22.383 \\
\hline 2030 & 343.329 & 132.763 & 38.218 & 37.322 & 23.963 & 33.279 \\
\hline 2040 & 338.831 & 162.995 & 37.610 & 42.489 & 35.300 & 50.485 \\
\hline 2050 & 332.717 & 178.807 & 40.258 & 40.532 & 35.208 & 68.019 \\
\hline
\end{tabular}

Fuente: Cálculos propios a partir de EPS 2004.

\subsection{Discusión y conclusiones}

En este trabajo hemos discutidos los fuertes cambios demográficos que ha tenido Chile en los últimos cuarenta años. Estos cambios demográficos aún se encuentran en desarrollo y de hecho se esperan considerables cambios tanto en tamaño poblacional como en la estructura de la población entre grupos etarios.

Nuestra discusión plantea buenas y malas noticias. En primer lugar, se debe esperar un aumento considerable en capital humano: por una parte las mujeres elevarán su nivel de educación y su participación laboral y, por otra, el gasto en educación por hijos aumentará, lo que debería redundar en 
una mejor calidad educacional. Asimismo, el menor número de niños permitiría una mayor inversión pública y privada por niño en educación. Sin embargo, esto plantea un desafío: incorporar a estos individuos de mayor capital humano al mercado laboral. El desafío ocurre porque los cambios educacionales producen un cambio en la oferta relativa de trabajadores calificados versus no calificados. Los primeros deberían ser algo más abundantes mientras que los segundos pueden pasar a ser algo más escasos. Obviamente esto se puede ajustar vía cambios en salarios relativos, pero también planteamos que puede resultar interesante explorar caminos alternativos, como tratados de movilidad de trabajadores entre países. Esto requiere por supuesto de un debate sobre política de inmigración-emigración, que aún no se encuentra presente en las discusiones nacionales.

Una de las consecuencias que también resaltan es que el cambio demográfico puede ser una fuente de fuerte disminución de desigualdad social. Esto ocurre porque los grupos socioeconómicos que presentarán mayor disminución en tasas de fecundidad son los grupos socioeconómicos bajos. De esta forma, son estos grupos los que deberían ver incrementado más su gasto en educación por hijo y, al mismo tiempo, son estos mismos grupos los que pueden aumentar más la participación laboral de las mujeres. Ambos factores (mayor capital humano y mayor participación laboral de las mujeres) van en la dirección de aumentar los ingresos laborales de estos grupos de menores ingresos, lo que debería repercutir en disminuciones de pobreza y de disminuciones en desigualdad social.

Las malas noticias parecen venir por el lado del crecimiento de largo plazo de la economía que puede verse afectado negativamente al disminuir el tamaño relativo del grupo de individuos en edad de trabajar. Esto genera un cuello de botella por el lado de la oferta de trabajo, pero al mismo tiempo un impacto negativo en la tasa de ahorro, al tener menos individuos ahorrando y más consumiendo. De acuerdo a nuestras simulaciones en este escenario, de oferta laboral restringida, resulta muy poco plausible volver a observar tasas de crecimiento de largo plazo superiores al 5\%, y de hecho las tasas de crecimiento deberían converger en el horizonte de 50-10 años en la cercanía del $4 \%$. Debe notarse, sin embargo, que estos impactos en el PIB en el largo plazo tienden a desaparecer cuando se considera la evolución del PIB per cápita. En ese caso, la transición demográfica generará incluso bonos demográficos que aceleren el crecimiento per cápita en el corto plazo.

Finalmente, se plantea que el grupo de adultos mayores es de muy alto crecimiento y que debe recibir mayor atención en el futuro de parte de las políticas sociales, debido a la creciente tendencia a vivir solos. Esta 
tendencia no es casualidad, sino que seguramente obedece al hecho de que cada vez los hogares tienen menos hijos $y$, por lo tanto, los adultos mayores tienen menos redes familiares a las que acudir cuando lo necesiten durante su vejez. El diseño y la implementación de políticas públicas en esta dimensión revisten la mayor urgencia si se considera que el grupo de individuos mayores de 60 años crecerá desde 1,5 millones en el 2000 hasta casi 3,0 millones en el 2020, mientras que el grupo de mayores de 70 años pasará de cerca de 700.000 en el 2000 a cerca de 1,5 millones en el 2020. Tal como se ilustra en la discusión anterior, el sector salud tiene un importante desafío.

Y por último, de nuestra discusión emerge que una de las fuentes más importantes de la disminución en tasas de fecundidad al interior del matrimonio y/o convivencia es el aumento en los "costos" de criar hijos. Desde este punto de vista, las políticas que busquen implementarse para incentivar la fecundidad deben estar dirigidas a este concepto.

\section{APÉNDICE 1: DESCRIPCIÓN DE DATOS}

La sección empírica de este trabajo, relacionada con los determinantes de la disminucion en tasas de fecundidad, utiliza datos de la Encuesta de Protección Social 2002 (EPS 2002), encargada por la Subsecretaría de Previsión Social y elaborada por el Centro de Microdatos de la Universidad de Chile. Esta encuesta es la primera ola de un panel de individuos de la economía chilena. Tal como en las encuestas Casen, se obtienen datos a nivel de individuos por medio de entrevistas en hogares y se obtienen datos relacionados con actividades e ingresos laborales, así como información de otros ingresos y actividades e informaciones demográficas, entre otras. Sin embargo, para nuestros efectos existen secciones adicionales que son de particular interés. Estas secciones están relacionadas con (1) historias individuales que entregan información sobre matrimonios y convivencias de los entrevistados, (2) historias laborales de los entrevistados y (3) antecedentes familiares, donde se incluye — entre otros tipos de información — datos sobre los matrimonios y convivencias, así como educación de los padres del entrevistado. A continuación se explica el tipo de datos que se utilizan en el análisis economeétrico.

Fecundidad por mujer. Por un lado, a partir de la seccion de historia individual que entrega información sobre matrimonios y convivencias de los entrevistados - incluyendo datos respecto a cada uno de los hijos- es posible distinguir entre hijos dentro o fuera de matrimonios o convivencias. Además, se entrega información acerca del número de hijos totales que ha 
tenido el entrevistado, así como el número de hijos que planea tener en el futuro. Esto último nos permite obtener el número de hijos planeados por mujer, es decir incluyendo a los que desea tener en el futuro. El análisis se realiza con datos de fecundidad planeada.

Participación laboral de mujeres. Otra sección de la EPS 2002 que resulta interesante para nosotros es la sección de historias laborales. Esta sección entrega datos de auto-reporte relacionados con la historia laboral de cada uno de los entrevistados desde 1980 hasta el momento de la encuesta. Cada entrevistado auto-reporta cada actividad desarrollada desde 1980 en adelante (o desde los 16 años en adelante, si el individuo era menor a esa edad en 1980). En cada actividad, el entrevistado se puede autocalificar como (1) buscando trabajo por primera vez, (2) cesante, (3) trabajando o (4) inactivo. Si el entrevistado está trabajando, se le solicita además que reporte la jornada laboral en número de horas trabajadas por semana, entre otras preguntas. Utilizando esta información, se procedió a calcular una variable llamada "fracción de tiempo trabajando" que corresponde a la fracción del tiempo disponible que cada mujer trabajó cuando tenía entre 16 y 35 años de edad — correspondiente típicamente al rango de edad fertil de las mujeres en la segunda parte del siglo 20-, fijando como tope máximo 112 horas por semana, que corresponde al número máximo de horas reportadas. En las estimaciones, se utilizará como medida de participación laboral de las mujeres la cantidad de horas trabajadas en la actividad anterior al nacimiento del primer hijo.

Ingresos laboral y no laboral. Estos ingresos se reportan para el año 2002 y la información incluye subsidios del gobierno.

Educación. Los datos de educación están disponibles en la EPS 2002. Se utilizan datos de escolaridad por mujer.

Mortalidad infantil. Se obtuvieron datos de mortalidad infantil por regiones de los anuarios de demografía del INE (Instituto Nacional de Estadísticas). Los datos se recolectaron para los años 1920-1924 y 1954-2002. Utilizando la información de la EPS 2002, a cada mujer se le imputó la tasa de mortalidad infantil prevaleciente en la región y año de nacimiento de su primer hijo.

Costos de criar hijos. Se procedió a obtener los datos desagregados del índice de precios al consumidor reportados por el INE. Pudimos obtener 
estos datos desde 1983. La disponibilidad de estos datos desagregados nos permitió calcular índices de precios para los ítems (1) productos lácteos y huevos, (2) vestuario de guagua (menores a un año) y (3) educación. Estos índices de precios se miden como fracción del índice IPC, lo que nos permite obtener índices de precios relativos del costo de criar hijos.

\section{APÉNDICE 2: MODELO DE SIMULACIÓN}

El modelo de simulación busca determinar la evolución de variables económicas como el PIB los salarios, la tasa de rentabilidad, el stock de capital, etc. El modelo tiene la siguiente estructura: todos los años nace una nueva cohorte de individuos con cierto horizonte de vida; el tamaño y la extensión de vida de cada cohorte reproducen la historia de Chile. Por ejemplo, la cohorte nacida en 1980 tiene tamaño cercano a 235.000 individuos — que se ajusta por tasa de mortalidad infantil—, y su horizonte de vida es 75 años —expectativa de vida de esta cohorte al nacer. Para el horizonte 2005 -2100, se supone que la expectativa de vida aumenta paulatinamente hasta converger a 85 años de vida en 2025.

Cada cohorte se descompone en diez grupos que difieren de acuerdo a niveles de capital humano. Dado su capital humano, cada grupo resuelve el problema de determinar cuánto consumir cada año y cuánto ahorrar para el futuro. Una vez que estos individuos alcanzan cierta edad se retiran de la fuerza de trabajo.

De esta forma estos individuos, durante su ciclo de vida, ofrecen servicios laborales y ahorran activos que se ofrecen en el mercado de capitales. La suma de los servicios laborales de las cohortes y la suma de los activos ofrecidos por todas las cohortes corresponden a la oferta de trabajo y la oferta de activos en el mercado de capitales. Estas cantidades ofrecidas son demandadas y ocupadas por las empresas de la economía. Los precios de equilibrio del mercado del trabajo y del mercado de activos se calculan al equilibrar las cantidades ofrecidas y demandadas en cada uno de estos mercados.

\section{Problema de los hogares}

Supondremos que año a año nacen nuevas cohortes de individuos. Cada cohorte de individuos debe decidir cuánto trabajar y cuánto ahorrar para generar ingresos que les permitan consumir. Una vez que se retiran de la fuerza laboral, reciben flujos de ingresos de sus ahorros, que les permiten consumir durante su jubilación. 
El ingreso laboral de los individuos depende de su nivel de capital humano. Supondremos que dentro de cada cohorte nacen individuos con distinto capital humano. Específicamente, supondremos que cada cohorte se descompone en diez grupos de personas de acuerdo a distintos niveles de capital humano. El capital humano de cada uno de los grupos del cohorte "s" se denotara como $e_{s}^{i}, i=1, \ldots, 10$, donde supondremos que $e_{1}^{s}<e_{2}^{s}<\ldots<$ $e_{10 .}^{s}$.

Para poder determinar cómo los individuos eligen sus niveles de consumo, partiremos describiendo las funciones de utilidad de las personas. La ecuación siguiente indica el nivel de utilidad para individuos nacidos el año "s". Estos individuos al nacer tienen una expectativa de vida que llamaremos $T$ s, y se jubilan a la edad $R$, donde $R<T s$.

El nivel de utilidad de estas personas depende de los patrones de consumo $\left(c_{t}\right)$ que el individuo elige entre esos años. El individuo tiene disponible $\bar{H}$ unidades de tiempo, que ofrece inelásticamente en el mercado del trabajo. Entre el año $s+R$ y $s+T s$, el individuo se jubila y deja de ofrecer trabajo. Por lo tanto, la función de utilidad de los hogares es:

$$
U=\sum_{t=s}^{T s} \beta^{t}\left(\gamma \ln c_{t}\right)
$$

donde $\beta<1$ es el factor de descuento. Las decisiones de consumo y de ocio se encuentran restringidas por las restricciones presupuestarias que enfrentan los individuos, que están descritas por las ecuaciones:

$$
\begin{aligned}
& \mathrm{A}_{t+1}=\left(1+\left(1-\bar{\tau}_{t}^{A}\right) r_{t}\right) A_{t}+w_{t} e_{t}^{i}\left(1-\bar{\tau}^{w}\right) \bar{H}-\left(1+\tau_{t}^{c}\right) c_{t} \quad \forall t \leq R \\
& \mathrm{~A}_{t+1}=\left(1+\left(1-\bar{\tau}_{t}^{A}\right) r_{t}\right) A_{t}-\left(1+\tau_{t}^{c}\right) c_{t} \quad \forall t>R
\end{aligned}
$$

donde $\mathrm{A}_{t+1}$ indica los activos financieros en el año $t+1$, mientras que (1 $\left.\bar{\tau}_{t}^{A}\right) r_{t} A_{t}$ es el retorno de activos financieros en el período $t$ después de impuestos al capital. El consumidor debe elegir cuánto consumir $c_{t}$ y cuánto ahorrar $\mathrm{A}_{t+1}-A_{t}$. Una de las condiciones de primer orden de este problema es:

$$
\frac{c_{t+1}}{c_{t}}=\beta\left(1+\left(1-\bar{\tau}_{t+1}^{A}\right) r_{t+1}\right)\left(\frac{1-\tau_{t}^{c}}{1+\tau_{t+1}^{c}}\right) \forall t
$$

donde $\tau_{t}{ }^{w} \mathrm{y} \tau_{t}^{A}$ representan las tasas marginales de impuestos sobre trabajo y capital. La condición (3) es la tradicional ecuación de Euler. Además hay una condición de transversalidad asociada: 


$$
A_{T+1}=0
$$

El comportamiento de un individuo nacido en el año $s$ con capital humano $e_{s}^{i}$ se caracteriza por las ecuaciones (3) a (4). En la solución a este problema, el individuo supone como dados la secuencia de precios $\left(w_{t}, r_{t}\right)$, las variables demográficas $T_{s}$ y el capital humano $e_{s}^{i}$.

\section{Comportamiento de las empresas}

En esta economía existe una empresa representativa con tecnología de retornos constantes a escala en trabajo $N_{t}$ capital $K_{t}$. Además la función de producción tiene un nivel de productividad $Z t$. La productividad se ve afectada por shocks exógenos, por lo que se indexa por $t$. La función de producción de la empresa representativa es

$$
Y_{t}=Z_{t} K_{t}^{\alpha} L_{t}^{1-\alpha}
$$

La empresa maximiza el valor presente de los dividendos de los accionistas, esto es:

$$
\underset{K t, N t}{\operatorname{máx}} \sum_{t=0}^{\infty} \prod_{k=0}^{\mathrm{t}} \frac{1}{1+r_{k}}\left\{\left(\left(1-\tau_{t}^{\pi}\right) Y_{t}-w_{t} N_{t}\right)-\left(1-(b+z) \tau_{t}^{\pi}\right) I_{t}\right\}
$$

sujeto a la ley de movimiento del stock de capital.

$$
K_{t+1}=(1-\delta) K_{t}+I_{t}
$$

donde $\tau_{t}^{\pi}$ es la tasa de impuestos corporativos; $b$ es la fracción de inversión financiada con deuda; $z$ es el valor presente de los créditos por depreciación y $\delta$ es la tasa de depreciación. Las condiciones de primer orden son las siguientes:

$$
\begin{aligned}
& w_{t}=(1-\alpha) Z_{t}\left(\frac{Y_{t}}{N_{t}}\right) \\
& r_{t}=\frac{1-\tau_{t}^{\pi}}{1-(b+z) \tau_{t}^{\pi}} \alpha Z_{t}\left(\frac{Y_{t}}{K_{t}}\right)-\delta
\end{aligned}
$$




\section{Gobierno}

Supondremos que el gobierno mantiene un presupuesto equilibrado entre su gasto $g_{t} \mathrm{y}$ sus ingresos por impuestos, es decir, el gobierno satisface:

$$
\sum_{s, i} \tau_{t}^{c} c_{t}^{i}+\sum_{s, i} \bar{\tau}_{t}^{A} r_{t} A_{s}^{i}+\sum_{s, i} w_{t} e_{s}^{i} \bar{\tau}^{w} \bar{H}+\tau{ }_{t}^{\pi} \pi_{t}=g_{t}
$$

donde $\pi_{t}$ son las utilidades de la empresa representativa.

\section{Equilibrios de mercado}

En equilibrio, los mercados se deben vaciar cada período. Las condiciones de vacío de mercado son las siguientes:

$$
\begin{aligned}
& \sum_{s, i} \bar{H}=N_{t} \\
& \sum_{s, i} A_{t}^{i, s}=K_{t} \\
& \sum_{s, i} c_{t}^{i, s}+\left(A_{t+1}^{i, s}-A_{t}^{i, s}\right)+g_{t}=Y_{t}
\end{aligned}
$$

Las ecuaciones (9) y (10) son las condiciones de vacío de mercado en el mercado del trabajo en el mercado de capitales, respectivamente. La condición (11) es el vacío del mercado de bienes. El lado izquierdo de (9) y (10) representa la oferta de factores de los hogares mientras que el lado derecho es la demanda de factores por parte de la empresa. Similarmente, en la ecuación (11) el lado izquierdo es la demanda de bienes de los hogares y el lado derecho es la oferta de bienes de las empresas. En cada ecuación, se suma través de cohortes $s$ y a través de grupos de capital humano $i$.

\section{Equilibrio}

A continuación se define el equilibrio de esta economía, que se resuelve en los ejercicios de simulación.

En esta economía un equilibrio competitivo está constituido por una secuencia de precios $\left(w_{t}, r_{t}\right)$ y una secuencia de asignaciones $\left(c_{t}^{i, s}, A_{t}^{i, s}, h_{t}^{i, s}\right.$, $\left.Y_{t}, K_{t}, N_{t}\right)$ si y sólo si: 
1. Dados $\left(w_{t}, r_{t}\right)$, las asignaciones $\left(c_{t}^{i, s}, A_{t}^{i, s}, h_{t}^{i, s}\right)$ resuelven (1)-(4) $\forall i, s, t$.

2. Dados $\left(w_{t}, r_{t}\right)$, las asignaciones $\left(Y_{t}, K_{t}, N_{t}\right)$ resuelven (5)-(7) $\forall t$.

3. El gobierno satisface su restricción presupuestaria (8) $\forall t$.

4. Los mercados se vacían, esto significa que las asignaciones $\left(c_{t}^{i, s}\right.$, $\left.A_{t}^{i, s}, h_{t}^{i, s}, Y_{t}, K_{t}, N_{t}\right)$ satisfacen las condiciones de vacío de mercado (9)-(11) $\forall t$.

Finalmente, los parámetros del modelo se calibran tal como se indica en Cerda (2007a).

\section{APÉNDICE 3: SIMULACIÓN DE EVOLUCIÓN DE DESIGUALDAD}

En este caso procederemos a modificar de la siguiente forma el problema de los hogares expuesto en el apéndice anterior. Primero introduciremos de forma exógena el número de hijos de cada grupo de capital humano en cada cohorte. En segundo lugar, cada grupo decidirá la inversión en capital humano de cada hijo. En tercer lugar, el tiempo que los padres le dedican la educación de los hijos no puede utilizarse para trabajar.

Tal como en el modelo del apéndice anterior, supondremos que año a año nacen nuevas cohortes de individuos que deciden cuánto ahorrar y trabajar, y que, una vez que se retiran de la fuerza laboral, reciben flujos de ingresos de sus ahorros que les permiten consumir durante su jubilación.

El ingreso laboral de los individuos depende de su nivel de capital humano. Tal como antes, habrá diez grupos de personas de acuerdo a distintos niveles de capital humano. El capital humano de cada uno de los grupos del cohorte " $s$ " se denotará como $e_{s}^{i}, i=1, \ldots, 10$, donde supondremos que $e_{1}^{s}<e_{2}^{s}<\ldots<e_{10}^{s}$. Este capital humano está en este caso determinado endógenamente por las decisiones de los padres.

La función de utilidad de los hogares es:

$$
U=\sum_{t=s}^{s+25} \beta^{t}\left(\gamma \ln c_{t}+\psi n_{t} \frac{e s c_{t}^{1+\sigma}}{1+\sigma}\right)+\sum_{t=s+26}^{T} \beta^{t}\left(\gamma \ln c_{t}\right)
$$

donde $\beta<1$ es el factor de descuento, $n_{t}$ es el número de hijos y $h_{t}$ es la fracción del tiempo en el año $t$ que los padres dedican a la educación de sus hijos. El parámetro $\psi$ mide la importancia que le dan los padres a la eduación de los hijos. Nótese que en esta función de utilidad los padres pueden realizar inversión en el capital humano de sus hijos sólo durante 25 años. Las decisiones de consumo de ocio se encuentran restringidas por las restricciones presupuestarias que enfrentan los individuos, y que están descritas por las ecuaciones: 


$$
\begin{aligned}
& A_{t+1}=\left(1+\left(1-\bar{\tau}_{t}^{A}\right) r_{t}\right) A_{t}+w_{t} e_{t}^{i}\left(1-\bar{\tau}^{w}\right) \bar{H}-n_{t} e s C_{t}-\left(1+\tau_{t}^{c}\right) c_{t} \forall t \leq s+25 \\
& A_{t+1}=\left(1+\left(1-\bar{\tau}_{t}^{A}\right) r_{t}\right) A_{t}+w_{t} e_{t}^{i}\left(1-\bar{\tau}^{w}\right)(\bar{H})-\left(1+\tau_{t}^{c}\right) c_{t} \forall s+25 \leq t \leq R \\
& A_{t+1}=\left(1+\left(1-\bar{\tau}_{t}^{A}\right) r_{t}\right) A_{t}-\left(1+\tau_{t}^{c}\right) c_{t} \quad \forall s R
\end{aligned}
$$

Las condiciones de optimalidad en este problema son:

$$
\begin{aligned}
& \frac{c_{t+1}}{c_{t}}=\beta\left(1+\left(1-\bar{\tau}_{t}^{A}\right) r_{t}\right)\left(\frac{1-\tau_{t}^{c}}{1+\tau_{t+1}^{c}}\right) \forall t \\
& \frac{\psi e s c_{t}^{\sigma}}{\gamma / c_{t}}=\frac{w_{t} e_{t}^{i}\left(1-\bar{\tau}^{w}\right)}{1+\tau_{t}^{c}} \forall t
\end{aligned}
$$

donde la primera condición es la ecuación de Euler y la segunda es la tasa marginal de sustitución entre inversión en hijos consumo. Además está la condición de transversalidad:

$$
A_{T+1}=0
$$

Finalmente, el capital humano que tienen los hijos de este grupo es:

$$
e_{t+25}^{i}=\sum_{t} e s c_{t}
$$

\section{REFERENCIAS}

Adsera, A. (2004): “Marital Fertility and Religion in Spain”. En Population Studies, 60, 2, 205-221.

(2005): "Vanishing Children. From High Unemployment to Low Fertility in Europe”. En American Economic Review, Papers and Proceedings, 95, 2, 189193.

Ahlburg, D. A. (2002): “Does Population Matter?”. En Population and Development Review, 28 (2).

Auerbach y Kolikoff (1987): Dynamic Fiscal Policy. Cambridge: Cambridge University Press.

Barro, R. y G. S. Becker (1989): “Fertility Choice in a Model of Economic Growth”. En Econometrica, 57 (2): 481-501. 
Becker, G. (1981): A Treatise on the Family. Harvard University Press, Cambridge, MA.

Becker, G. y H. G. Lewis (1973): "On the Interactions Between Quantity and Quality of Children”. En Journal of Political Economy, 81, S279-S288.

Bloom, D. y D. Canning (2004): "Global Demographic Change: Dimensions and Economic Significance”. NBER working paper, 10817, Cambridge, MA.

- (2001): "Demographic Change and Economic Growth: The Role of Cumulative Causality”. En N. Birdsall, A. C. Kelley y S. W. Sinding (eds.), Population Does Matter: Demography, Growth, and Poverty in the Developing World. New York: Oxford University Press, pp. 165-197.

Bloom, D., D. Canning y P. Malaney (2000): "Demographic Change and Economic Growth in Asia”. En Population and Development Review, 26: 257-290.

Bloom, D., y J. G. Williamson (1998): "Demographic Transitions and Economic Miracles in Emerging Asia”. En World Bank Economic Review, 12: 419-456.

Bravo, D., D. Contreras y E. Puentes (2005): "Female Labour Force Participation in Greater Santiago, Chile: 1957-1997. A Synthetic Cohort Analysis”. En Journal of International Development, 17, 2, 169-186.

Celade (Centro Latinoamericano y Caribeño de Demografía) (2002): Boletín Demográfico. América Latina y Caribe: Estimaciones y Proyecciones de Población 1950-2050. Santiago, Cepal.

Centro de Políticas Públicas (2007): "Estudio de Calidad de Educación y Baja en Natalidad”. Universidad del Desarrollo, 2007.

Centro Latinoamericano y Caribeño de Demografía (CELADE, 2002): "Boletín Demográfico No. 69. América Latina y Caribe: Estimaciones y Proyecciones de Población. 1950-2050”. Cepal, Santiago de Chile.

CEPAL (2007): “Una Región Donde Nacen Menos Niños”. En Notas de la CEPAL, 53, julio.

Cerda, R. (2005): “On Social Security Financial Crisis”. En Journal of Population Economics, Vol. 18, № 3, 509-518.

(2006): “¿Dónde Están los Niños? Determinantes Socioeconómicos de la Tasa de Natalidad en Chile”. Investigaciones para que Nuestros Pueblos Tengan Vida, Celam, académicos UC, Santiago, Pontificia Universidad Católica de Chile.

(2007a): “The Chilean Pension Reform: A Model to Follow?”. Por aparecer en Journal of Policy Modeling.

(2007b): "Cambios Demográficos: Desafíos y Oportunidades de un Nuevo Escenario”. En Temas de la Agenda Pública, año 2, 17, septiembre, Dirección de Asuntos Públicos, Pontificia Universidad Católica de Chile.

Cerda, R. y A. Torche (2006): "El Valor Económico de Reducir Tasas de Mortalidad: El Caso de Chile". En El Trimestre Económico, Vol. LXXIII (4), Nº 292, octubre diciembre, pp. 719-748.

Cigno, A. y F. C. Rosati (1996): “Jointly Determined Saving and Fertility Behavior: Theory, and Estimates for Germany, Italy, UK and USA". En European Economic Review, 40, 1561-1589.

Contreras, D. (1996): "Pobreza y Desigualdad en Chile: 1987-1992. Discurso, Metodología y Evidencia Empírica”. En Estudios Públicos Nº 64, primavera.

De Gregorio, J. y J-W. Lee (1999): "Education and Income Distribution: New Evidence from Cross-country Data”. Documentos de Trabajo, $N^{\circ}$ 55, 1999, Centro Economía Aplicada de la U. de Chile. 
Díaz, J., R. Lüders y G. Wagner (2008): “La República en Cifras”. Mimeo, Departamento de Economía, Pontificia Universidad Católica de Chile.

Greene, W. (1993): Econometric Analysis. McMillan Press.

Greenwood, J. y A. Seshadri (2002): “The US Demographic Transition”. En American Economic Review (Papers and Proceedings), May, V. 92, N. 2: 153-159.

Holtz, V. J., J. A. Klerman y R. J. Willis (1997): “The Economics of Fertility in Developed Countries". En Handbook of Population and Family Economics, Volumen 1A, North-Holland.

Instituto Nacional de Estadísticas (INE): “Indicadores Mensuales - Índices de Precios”. En Boletín Informativo. Varios números.

(2006): “Fecundidad en Chile. Situación Reciente”. Santiago, Chile.

Kelley, A. C. (1988): "Economic Consequences of Population Change in the Third World”. En Journal of Economic Literature, 27: 1685-1728.

Kotlikoff, L., K. Smetters y J. Walliser (2001): "Finding a Way Out of America's Demographic Dilemma”. NBER working paper, 8258, Cambridge, MA.

Larrañaga, O. (1999): "Distribución de Ingreso y Crecimiento Económico en Chile”. Serie Reformas Económicas, Cepal.

- (2006): “Comportamientos Reproductivos y Fecundidad, 1960-2003”. En J. Samuel Valenzuela, Eugenio Tironi y Timothy Scully (eds.), El Eslabón Perdido. Familia, Modernización y Bienestar en Chile. Santiago: Taurus.

Lee, R. D. (2003): “The Demographic Transition: Three Centuries of Fundamental Change”. En Journal of Economic Perspectives, 17: 167-190.

Marín, P. P. (2006): "Lineamientos para la Reformulación de la Política Pública de Salud para Personas Mayores”. En Temas de la Agenda Pública, año 1, 5, diciembre, Dirección de Asuntos Públicos, Pontificia Universidad Católica de Chile.

Mideplán (2004): "Pobreza, Distribución del Ingreso e Impacto Distributivo del Gasto Social”. Santiago, Chile.

Minnesota Population Center (2007): “Integrated Public Use Microdata Series International: Version 3.0”. Minneapolis: University of Minnesota.

Newman, J. y Ch. McCulloch (1984): "A Hazard Rate Approach to the Timing of Births". En Econometrica, 52, 4, 939-961.

Nuñez, J. y C. Riesco (2004): "Movilidad Intergeneracional del Ingreso en un País en Desarrollo: El Caso de Chile”. Documento de Trabajo 210, Departamento de Economía, Universidad de Chile.

OECD: “OECD Factbook 2007. Economic, Environment and Social Statistics”.

Sapelli, C. (2005): "Returns to Schooling and Income Distribution by Cohort in Chile: An Analysis Based in Synthetic Panel Data”. Documento de Trabajo N 290 Instituto de Economía, U. C. Santiago Chile.

Schultz, T. P. (1997): "Demand for Children in Low Income Countries”. En Handbook of Population and Family Economics, Volumen 1A, North-Holland.

Soares, R. (2005): "Mortality Reductions, Educational Attainment, and Fertility Choice”. En American Economic Review, 95 (3), June, 580-601.

Solimano, A. y A. Torche (2007): "La Distribución del Ingreso en Chile 1987-2003: Análisis y Consideraciones de Política”. Mimeo, Pontificia Universidad Católica de Chile.

Subsecretaría de Previsión Social, Gobierno de Chile (2002): "Primera Encuesta de Protección Social”. www.proteccionsocial.cl. 
(2004): "Segunda Encuesta de Protección Social”. www.proteccionsocial.cl.

Vergara, R. (2007): “Tendencias Demográficas y Económicas en Chile y sus Implicancias para la Educación Superior”. En Estudios Públicos, No 106, otoño, 129-152.

Willis, R. (1973): “A New Approach to the Economic Theory of Fertility Behavior”. En Journal of Political Economy, 81, S14-S64. 